\title{
Towards a Dual Process Conception of the Selective Influence of Financial Literacy on Economic Behavior
}

\author{
Thesis submitted in fulfillment \\ of the requirements for the degree of \\ “DOCTOR OF PHILOSOPHY"
}

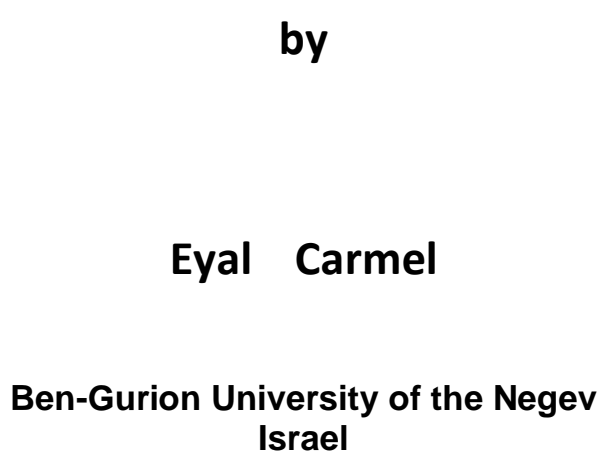

Israel

Approved by the advisors: David Leiser, Avia Spivak

Approved by the Dean of the Kreitman School of Advanced Graduate Studies

November 15, 2018 


\section{Summary}

The recent decade has witnessed a growing interest in people's ability to manage their financial affairs. Leading organizations such as the OECD and the World Bank are promoting educational programs intended to help consumers to acquire better financial abilities and to protect citizens from taking the wrong financial turn. Those efforts are accompanied by extensive academic research that presents conflicting results about the effectiveness of financial education as a means to improve financial decisions (Fernandes, Lynch Jr, \& Netemeyer, 2014). But despite the global interest in financial literacy, most research in this field focuses on the "what" rather than the "why". While many studies examined the relationship between financial literacy and economic behavior, no fundamental theory that explains the mechanism by which financial knowledge influences behavior has yet emerged.

This dissertation addresses this research gap by presenting a new theoretical model for financial literacy - the Cognitive Modulation of Economic Behavior [CMEB] that relates availability of cognitive and mental resources with factors that influence individuals' ability to rely on their knowledge. The CMEB model stems from Dual Process Models such as Kahneman's two systems model (Kahneman, 2011) and Thaler and Shefrin's model of self-control (Thaler \& Shefrin, 1981). Such models distinguish between intuitive behaviors that rely on rapid, effortless thinking, and calculated decisions that require deliberate thinking and demand cognitive and mental effort. The CMEB model translates this perception into the field of financial literacy and suggests that financial literacy-based behavior requires mental effort and cognitive resources. Therefore, in

order to understand the conditions by which financial literacy would influence economic behavior, we must first consider the amount of cognitive and mental resources available to, and required from, the decision maker.

The model focuses on two factors: (i) the personal characteristics of the decision-maker, and (ii) the characteristics of the task that he wishes to perform. The first factor draws on the perception that cognitive and mental abilities are limited-recourses. Hence, situations or personal features that hamper the availability of such resources reduce the decision-makers' likelihood to conduct deliberate thinking and prevent them from relying on financial knowledge. The second factor in 
the model focuses on features of the economic engagement that is being conducted. Based on the conjecture that complex financial tasks, or tasks that do not provide an immediate financial reward, demand a larger amount of mental resources than other economic engagements, the model produces several predictions regarding the influence of financial literacy. For example, planning future expenses requires many cognitive resources due to its complexity and deferred gratification, and is therefore unlikely to be affected by financial literacy. On the other hand, price comparison is a relatively easy task that provides immediate feedback, leaving people with enough resources to rely on their knowledge and resulting in greater influence for financial literacy.

The study examines the role of a number of factors that influence the ability to carry out deliberate thinking: economic pressure, self-control, and financial avoidance. To distinguish between different types of economic behaviors, I adopted the categorization presented by Atkinson, McKay, Collard, and Kempson (2007), who stated that financial capability could be conceived as encompassing four different domains: (a) managing money - people's ability to make ends meet and their ability to keep track of their finances; (b) planning ahead - financial precautions taken for the future; (c) choosing products - choice and purchase of financial products; (d) staying informed - engagement with current economic developments. Since I perceived "money management" and "planning ahead" as tasks that require many mental resources, I expect that people who suffer economic pressure, lack of self-control, or financial avoidance would show inadequate behavior in these categories. Yet, I do not expect to find such influences at the simple and immediately rewarded "choosing products" category.

The influence of cognitive and mental resources on the ability to apply financial knowledge when needed was investigated in four different studies. The first uses data from a financial literacy survey delivered by the Israel Central Bureau of Statistics to examine the relations between financial knowledge and economic behavior. The findings indicate that financial literacy is an inaccurate and insufficient measure of economic abilities. The study raises the need to distinguish between different types of economic behaviors when analyzing the impact of financial literacy, as it relates financial constraints with inferior financial management but not with investment. The second study examines the relations between several psychological and demographic 
variables and financial literacy and capabilities through an online survey. The findings indicate that financial literacy predicts wise consumer behavior, but other economic activities are mainly influenced by personality traits and socio-economic status. The study delivers several theoretical insights to the research of financial literacy literature. It again highlights the need to distinguish between different types of economic behaviors and presents a statistical model that indicates that financial avoidance mediates the influence of income on financial management.

The third study presents an analysis of an intervention program aiming to help people who experience financial hardship. The study tests the influence of the intervention according to the predictions of the CMEB model for financial literacy. Due to its large scope, the analysis is presented in two separate parts. The first part focuses on the short-term influence of the program while highlighting the role of income. It reveals that the financial situation at the beginning of the intervention predicts the intervention's outcome and presents two different paths to recovery - increase in income for low-wage participants and decrease in expenses for high-income participants.

The second part focuses on the long-term outcome of the program, and it too allows to test the CMEB model. Results indicate that all participants adopted principles of the program that were related to consumption, but the likelihood to conduct management practices several years after the intervention was related to the participants' financial situation. So too, a longitudinal analysis shows that participants' financial situation at the end of the intervention predicts their management scores several years later, but not their consumption. The results confirm that the influence of financial knowledge is mediated by financial situation, and by features of the financial task that is being performed. Similarly, emotions or personality traits that lead to the depletion of cognitive resources decreased the tendency to engage in complicated management activities but did not impact the simple consumption engagements.

The last study looks at the dependency between knowledge and behavior in the context of pension decisions and suggests several ways to increase the influence of financial knowledge while deciding whether to cash-out severance payments from a retirement savings account. A customer survey that was delivered to savers of a leading pension fund reveals that early withdrawals of money from a retirement savings account are better explained by the need for 
money rather than by knowledge. Two behavioral experiments complemented the survey and indicate that early withdrawal could be reduced by associating money cash-out with retirement savings at the time of the decision. The first study shows that information displayed to subjects at the time of the decision to cash-out compensation from their pension savings account reduced the tendency to withdraw. In addition, framings of the compensation as long-term savings rather than windfall also reduced the desire to conduct early withdrawals. The two experiments demonstrate the contribution of two well-accepted tools to enhance behavioral change - timely intervention and mental accounting (Thaler \& Sunstein, 2008).

While the first two studies in this work are mostly theoretical, the last two studies support the development of educational programs and regulatory intervention that enhance adequate financial behavior. However, the contribution of this work goes far beyond the specific aspects of financial literacy described in these studies. The results presented above integrate ideas from research of human rationality with research of financial literacy. By presenting a dual-process model that focuses on the role of deliberate thinking on financial literacy-based behavior, this work expands our understating of the mechanism by which financial literacy operates. The CMEB model explains the wide-ranging influence of financial literacy on economic behavior and can serve as a basis for many theoretical advancements that are still needed in th is field of research.

Keywords: financial literacy, financial capability, dual process models, scarcity, self-control, financial avoidance 


\section{Acknowledgments}

First and foremost, I am deeply grateful for my advisers, Professor David Leiser and Professor Avia Spivak for their guidance and support. Their supervision and insights made the past four years an enriching experience, and their open mind and encouragement made it a pleasant and enjoyable journey. I would also like to thank my dissertation committee of Rami Yosef, Tehila Kogut and Ilana Ritov for their helpful feedback and direction.

A major part of this work consists of collaboration with Paamonim - a non-profit organization in the field of financial literacy in Israel. I would like to thank the organization for their faith in this research, and their willingness to collaborate and to share information. Special thanks to Efrat Plotnik, the organization's head of academic relations, for her commitment to the study and for countless hours working on this project.

I can't thank enough to my family for their love and support. To my parents for their continued love and guidance, and to my wife Dana, for being a pinnacle of understanding during the late nights and early mornings, and for keeping me sane over the past few months. Finally, a special thank you to my two children, Adam and Abigail, who put things in perspective and reminded me what is truly important in life. 


\section{Table of Contents}

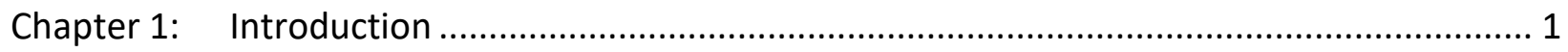

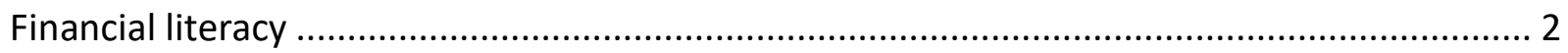

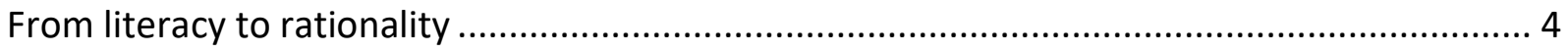

The Cognitive Modulation for Economic Behavior ..................................................... 6

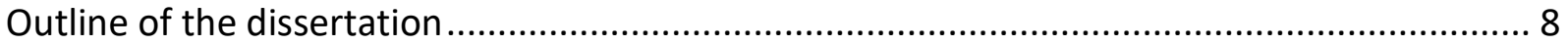

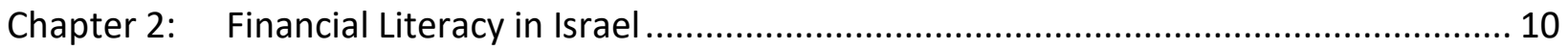

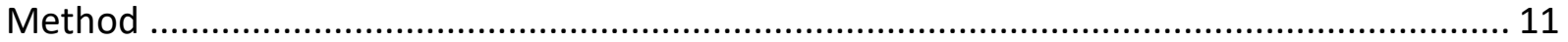

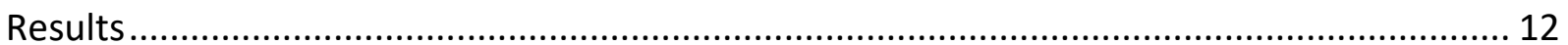

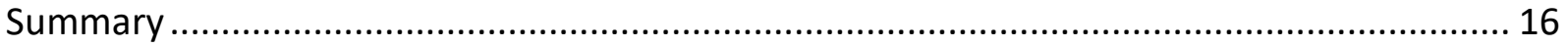

Chapter 3: From Financial Literacy to Financial Capability................................................ 19

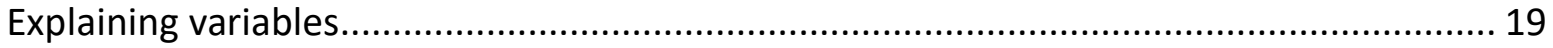

Complexity and timing gratification of financial engagements .................................... 21

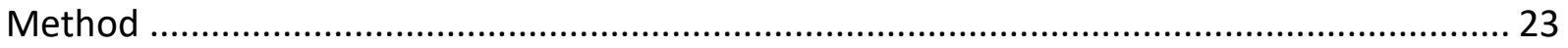

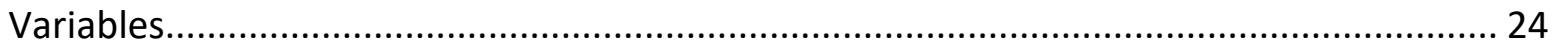

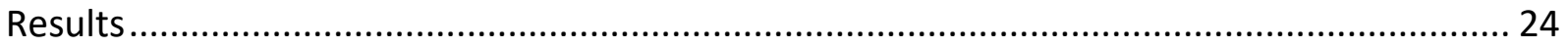

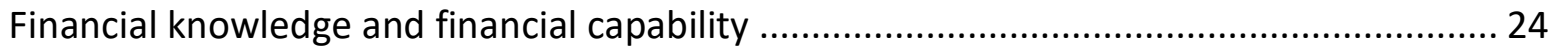

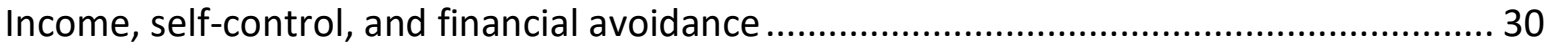

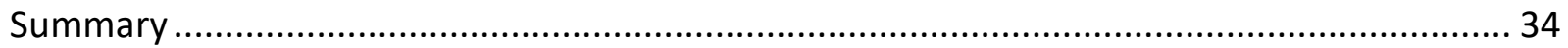

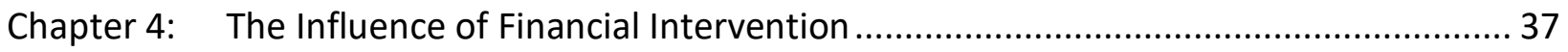

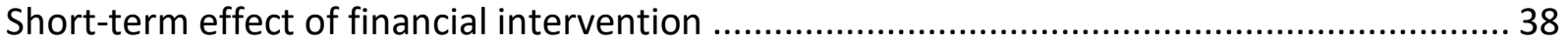

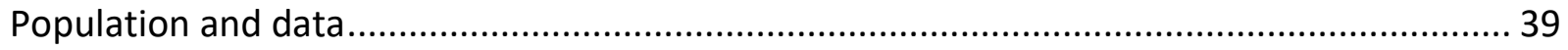




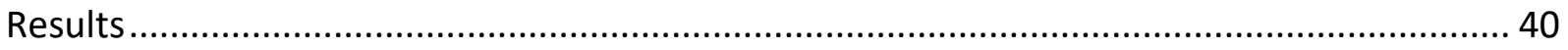

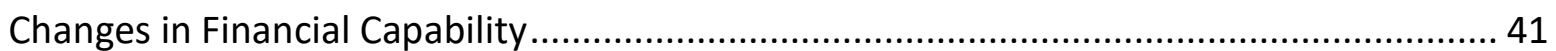

Comparison of financial indicators before and after the program ..................................... 43

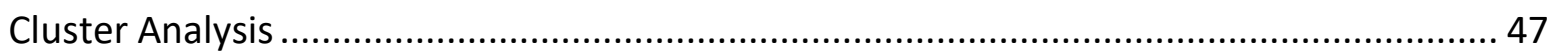

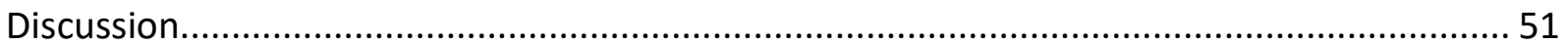

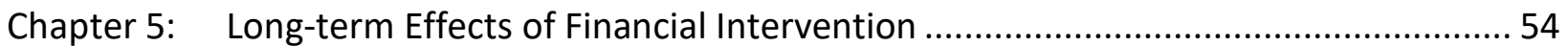

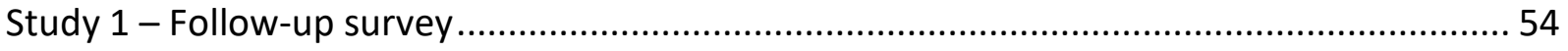

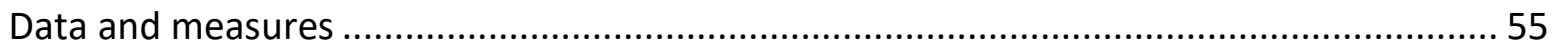

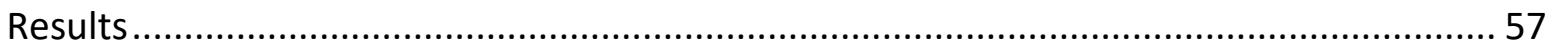

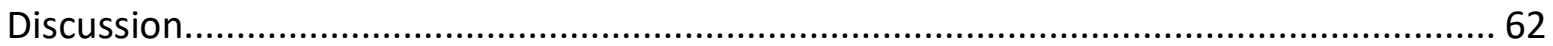

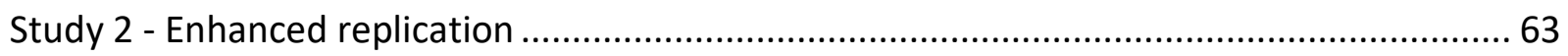

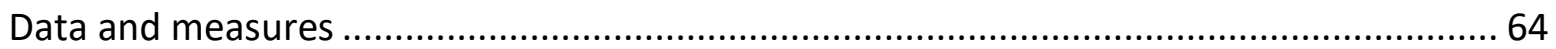

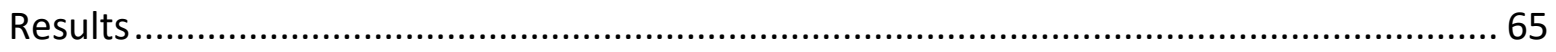

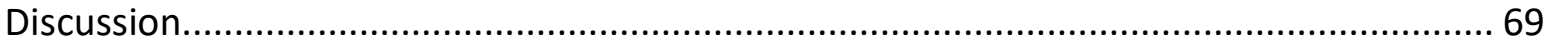

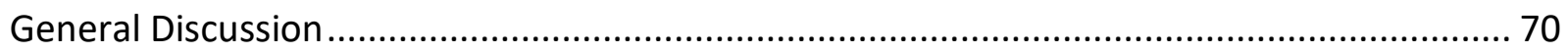

Chapter 6: Money Cash-out During Job Replacement - an experimental approach................ 73

Study 1: Motives behind money cash-out ........................................................................ 73

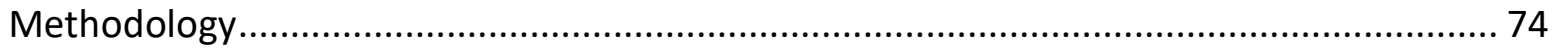

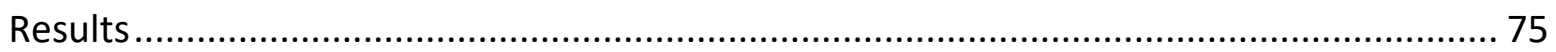

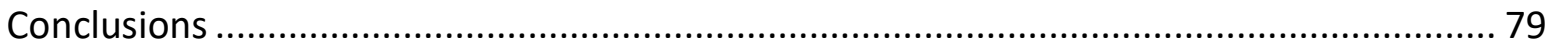

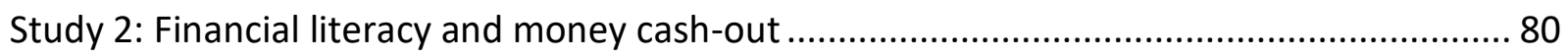

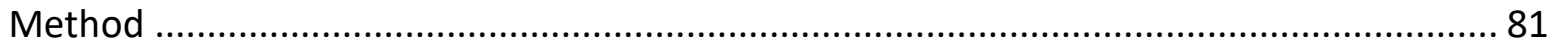

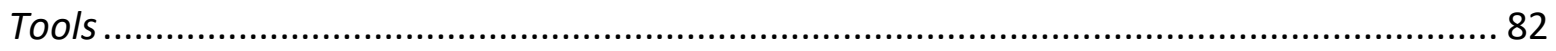


Results

Conclusions 86

Study 3: The effect of framing on money cash-out ........................................................ 86

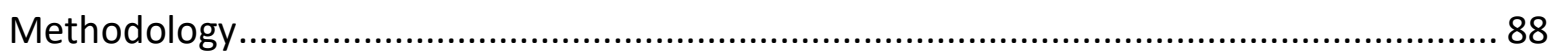

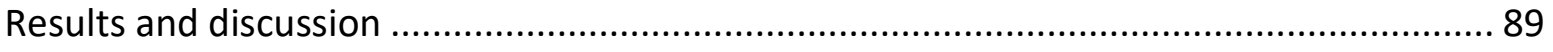

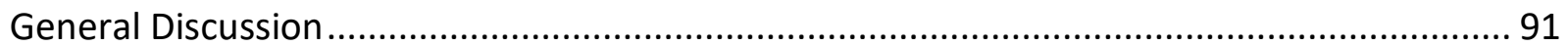

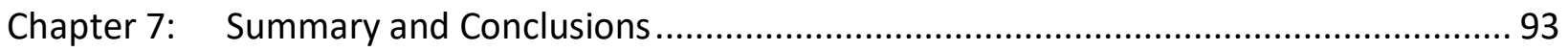

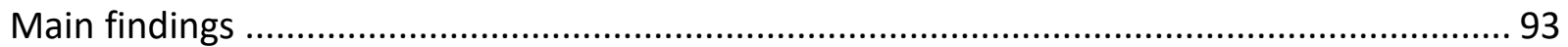

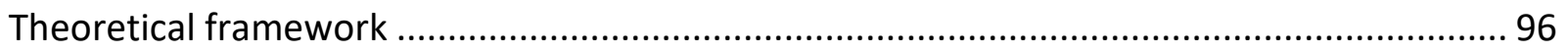

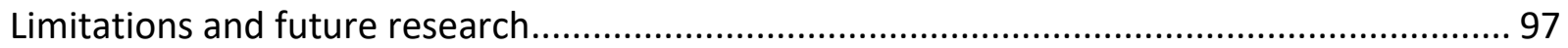

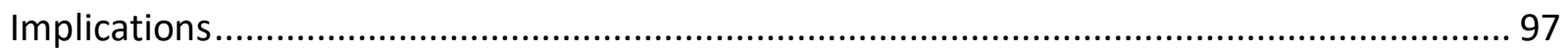

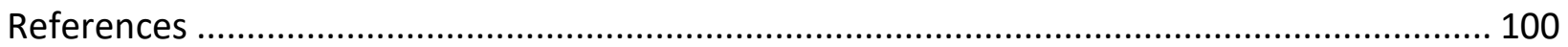

Appendix 2A - Financial Literacy Survey: Knowledge, Behavior and Perceptions ................... 109

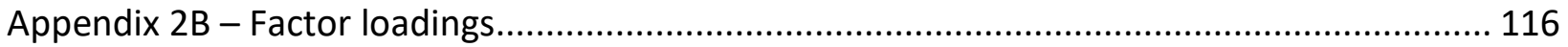

Appendix 3A - Financial Capability and Literacy Survey ................................................. 117

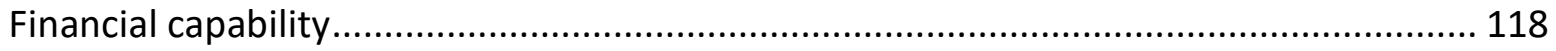

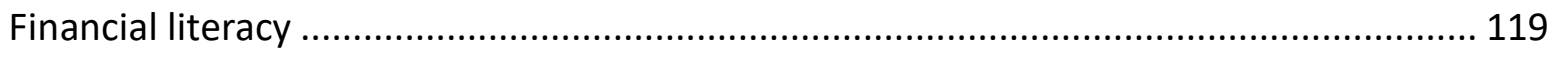

Appendix 3B - Cluster Analysis of Financial Capability Survey .......................................... 121

Appendix 4A - Paamonim Intervention. Program Description .......................................... 122

Appendix 4B - Financial Capability Survey and Factor analysis ..................................... 123

Appendix 4C - Income and Demographic Distributions ................................................ 124

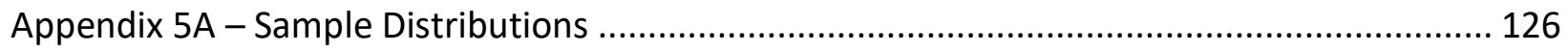

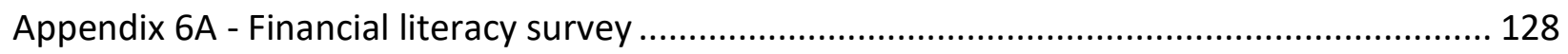




\section{List of Figures}

Figure 2.1. Financial literacy in Israel by gender, education, and ethnicity. ............................ 13

Figure 2.2. A two-way ANOVA for income and financial literacy ......................................... 16

Figure 3.1. Effect of income on choosing product and management ..................................... 33

Figure 3.2. Interaction between financial literacy and avoidance ..................................... 34

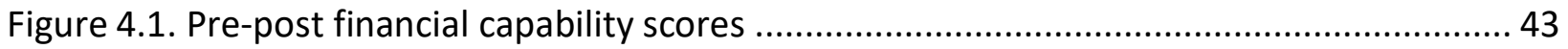

Figure 4.2. Pre-post ratio of financial indicators ........................................................ 46

Figure 4.3. The gap between perceived and actual financial situation ................................. 47

Figure 4.4. Graphic illustration of four clusters. .............................................................. 49

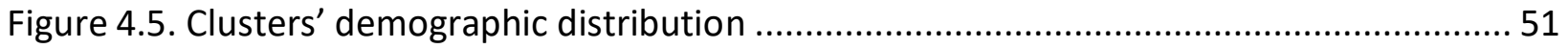

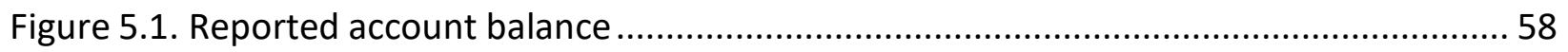

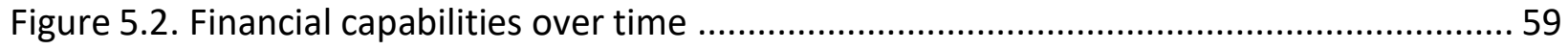

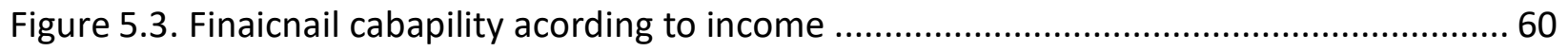

Figure 5.4. Long-term trends in financial capabilities .................................................... 61

Figure 5.5. Capabilty differences between the groups according to shortfall .......................... 66

Figure 5.6. Long-term trends in financial capabilitie according to shortfall............................ 67

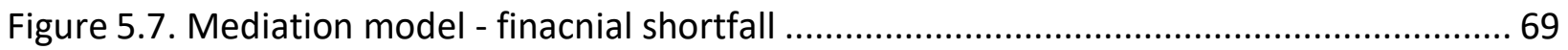

Figure 6.1. Compensation use in case of early withdrawals ............................................ 79

Figure 6.2. "Tendency to withdraw" as a function of income and time preference .................. 79

Figure 6.3. Compensation withdrawls as a function of literacy and information display........... 86

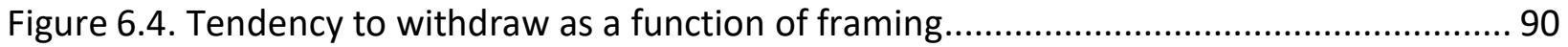




\section{List of Tables}

Table 2.1. Financial literacy in the general population......................................................... 12

Table 2.2. Results of the general linear model.................................................................... 14

Table 2.3. Correlations of savings and investments with financial literacy and income............. 15

Table 3.1. Financial capabilities based on complexity and delayed gratification....................... 22

Table 3.2. Percentage of correct responses for financial knowledge questions...................... 25

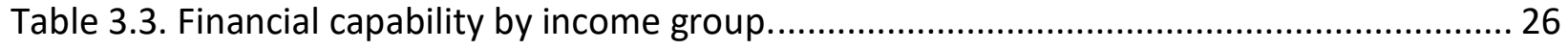

Table 3.4. Financial literacy and capability as predictors of financial state........................... 27

Table 3.5. Financial capability statements by level of financial literacy................................... 28

Table 3.6. Correlations between financial capabilities, literacy, and personal features. ........... 30

Table 3.7. Multiple regression of financial capabilities ................................................... 31

Table 4.1. Financial capability scores at the beginning and at the end of the program. ........... 41

Table 4.2. Regression analysis of three dependent variables: PGB, PGE1, PGE2 ..................... 44

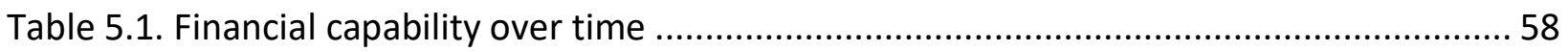

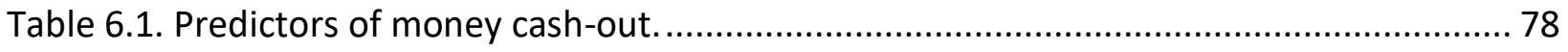

Table 6.2. Respondents' success rate in the financial literacy survey................................... 83

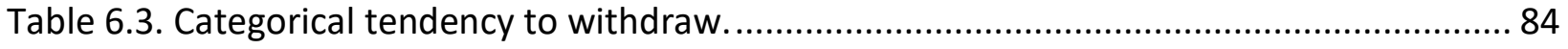

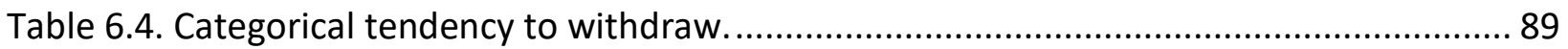




\section{Chapter 1: Introduction}

In the midst of the 2008 global financial crisis, U.S. President George W. Bush launched a new president's advisory council on financial literacy aiming to "improve financial literacy among all Americans." The establishment of the council reflects a common perception among decision makers who see the enhancement of financial literacy as a tool to protect citizens from making financial mistakes. But while supporters of the financial literacy approach point to correlations between financial knowledge and behavior (Lusardi \& Mitchelli, 2007; Van Rooij, Lusardi, \& Alessie, 2011), others argue for a non-causal relationship between the two and claim that financial education has minimal impact that decays rapidly (Fernandes, Lynch Jr, \& Netemeyer, 2014). Other critics of financial education state that governments focus on education as a poor replacement for stiff and effective regulation (Willis, 2008). While the dispute around the contribution of financial literacy is unlikely to be settled soon, the aim of this work is to change the discussion from a results-driven debate to a theory-based dialog. Based on recent advancements in psychology, I propose a model to explains financial knowledge's meager influence on behavior and points to circumstances in which financial literacy does contribute to adequate financial behavior.

The model, named the Cognitive Modulation for Economic Behavior [CMEB], stems from the ongoing discussion in behavioral economics about human rationality. In the previous century, scholars such as Herbert Simon, Amos Tversky, and Daniel Kahneman challenged the realism of the assumption of human rationality and highlighted the role of heuristics and cognitive biases (Kahneman, 2011; Simon, 1972; Tversky \& Kahneman, 1974; Tversky \& Kahneman, 1981). In recent years, this approach has found its way into public policy and was embraced by policymakers who used cognitive mistakes and biases such as status quo bias, social comparison, and framing, to direct people for adequate behavior. The term "nudge" was coined to describe this type of subtle intervention, based on Richard Thaler and Cass Sunstein's best-selling book (R. Thaler \& Sunstein, 2008). The idea that people are irrational agents with limited knowledge, limited cognitive capacity, and poor self-control, had spread quickly and made regulators acknowledge the often ineffectiveness of direct incentives and legislation to promote public 
policy. Nevertheless, the rapid emergence of new financial education initiatives suggests that many researchers and practitioners still think that customers do not maximize their utilities due to limited financial knowledge (Willis, 2011). Supporters of the financial literacy approach assume that by simply adding knowledge, clients would achieve wise consumption behavior and better decision making. This assumption fits a rational model in which people operate according to their skills and abilities.

Incorporation of the concept of financial literacy into the discussion about human rationality offers fresh thinking about the reasons for the minimal impact of financial knowledge. While research on financial literacy is relatively new, the investigation of irrationality has a long tradition. Thanks to countless studies we can now understand the circumstances in which people are more or less likely to present rational behavior. Ample evidence has shown that irrationality is often a result of limited cognitive capacity and depletion of emotional resources (Kahneman, 2011). Similarly, based on the parallelism between knowledge-based behavior and rational behavior, we can assume that lack of cognitive and mental resources would explain why certain individuals are unable to apply their financial knowledge when needed.

By framing financial literacy as part of the discussion about human rationality, this dissertation investigates the influence of financial literacy and recognizes its strengths and weaknesses. The literature review below provides the necessary background for this enterprise. First, I present major findings from the research of financial literacy, discuss its limitations, and describe the difference between financial literacy and financial capability. Next, I stress the connection between cognitive resource and decision making and frame financial literacy in the context of irrationality and dual system theories. Based on dual system theories, I introduce the CMEB model and propose that the interplay between financial literacy and limited resources determines the efficacy of financial knowledge. Finally, I outline the remaining six chapters of this work.

\section{Financial literacy}

The times are changing and bring new challenges to people throughout the world. A combination of an aging population, the transfer of risk from governments to citizens, and a gloomy economic 
climate increase people's responsibility for their financial well-being during their working lives and at retirement. Unfortunately, evidence suggests that people are poorly informed about basic issues in personal finance and make decisions that are difficult to interpret as rational (De Meza, Irlenbusch, \& Reyniers, 2008; Lusardi \& Mitchell, 2007; Sherraden, 2013).

A common approach to improve people's financial decisions is to increase their "financial literacy," defined by Huston (2010) as "the knowledge, ability, skills and confidence to make good financial decisions." According to The Organization for Economic Co-Operation and Development (OECD), individuals with higher financial literacy are better at handling their money, participating in the stock market, choosing mutual funds with lower fees, and having better retirement plans (Atkinson and Messy, 2012). This claim is supported by many studies. For example, workers chose better pension plans after participating in a pension seminar (Clark, Morrill, \& Allen, 2012); Hilgert, Hogarth, \& Beverly (2003) linked financial literacy to better financial behavior in several practices, and Van Rooij, Lusardi, and Alessie (2011) showed that financial literacy correlates with successful investments in equities.

But even with the attention given to financial literacy, it is still unclear how financial literacy affects financial behavior and what is the causal direction between the two (Van Rooij et al., 2011). A meta-analysis performed by Fernandes et al. (2014) revealed that, despite the strong correlations found between measured financial literacy and financial behavior, attempts at imparting financial literacy were ineffective, and interventions to improve financial literacy explained only a minuscule $(0.1 \%)$ proportion of the variance of the financial behaviors. Similarly, Cole \& Shastry (2009) showed that financial literacy educational programs at school had no effect on participation in the financial market, while cognitive differences and level of education were found to be significant. Willis's review of the cost of effective financial education reveals that even semester-long high school courses and eighteen months of adult credit counseling were insufficient to make financial education more effective (Willis, 2011). In fact, as Cole and Shastry (2009) stated, the most effective way to increase participation in the $401(\mathrm{k})$ plans is not through education, but simply by changing the default enrollment status. Therefore, it is understandable why some argue that it is better to focus on people's actual financial habits rather than on their 
knowledge, an approach usually referred to as financial capability (Johnson \& Sherraden, 2007; Sherraden, 2013).

\section{From literacy to rationality}

The gap between financial literacy and capability could be interpreted in terms of rational vs. actual behavior. Rational agents are expected to show instrumental behavior, to be consistent, and to use all the information available to them. Likewise, financially literate people are expected to use their skills, to include short- and long-term considerations and apply their knowledge in order to achieve their financial goals. Alas, in both cases we have strong evidence that individuals fail to meet these expectations (Fernandes et al., 2014; Kahneman, 2011). The parallelism between the two concepts provides a useful framework to investigate financial literacy. Kahneman (2011) explains deviations from rationality with a dual system theory that separates reasoning from intuition. According to Kahneman, reasoning requires mental effort. It includes deliberate thinking that involves a slow process of reasoning and demands attention and cognitive resources. Kahneman labeled these types of cognitive processes as "system 2". Since deliberate thinking demands high energy, people mostly rely on their intuition, which often makes "good enough" decisions based on heuristics and rules of thumb that were developed through experience. Kahneman named this type of thinking "system 1". Now let us go back to the gap between financial literacy and capability. Literacy represents knowledge and sophisticated skills, but financial capability is often a result of habits, experiences, and perceptions. In order to use their knowledge, lay people need to perform deliberate thinking, but as mentioned above this type of thinking is an exhausting process that people often like to avoid. Hence, financial capability is more likely to be based on the easily approached system 1, and not on the skilled and literate system 2.

Several researchers used dual process theories to explain why perfectly capable people present inconsistent and irrational behavior (e.g., Chaiken \& Trope, 1999; Stanovich \& West, 2000). Economists Richard Thaler and Hersh Shefrin proposed a dual system that includes two 
(imaginary ${ }^{1}$ ) selves - the planner and the doer (Shefrin \& Thaler, 1988; Thaler \& Shefrin, 1981) to explain intertemporal choice and saving behavior. Using the distinction between the two personalities, Thaler and Shefrin developed a behavioral life cycle model that opposed the, then popular, hypotheses that individuals plan their consumption to secure a stable lifestyle throughout their entire lifetime (Ando \& Modigliani, 1963; Modigliani \& Brumberg, 1954). According to the new model, a trade-off exists between clients' satisfaction from consumption, and their understanding that it is better to save money for the future. Therefore, in order to save for the future, the planner should impose self-control over the doer, but people are impatient and fail to do so. For that reason, people intentionally choose to restrict themselves using commitment devices, rules of thumb, and mental calculations that reduce the need for selfcontrol. By adopting the psychological concept of self-control, the authors were able to minimize the gap between expected and actual behavior in their economic model. The planner and the doer represent an inherent tension between short- and long-term perspectives. While people would rather use their money in the present to maximize current satisfaction, this type of behavior would surely have a heavy cost in the future. As I show later, this tension can explain why knowledge predicts decisions that provide immediate, but not deferred gratification.

The application of the dual system, or two selves, theories on the field of financial literacy is straightforward. Supporters of financial literacy argue that the development of knowledge and skills would advance better financial decisions. In other words, they offer to strengthen customers' system 2 to improve their financial behavior and to support their planner-self to increase savings. On the other hand, critics argue that financial decisions are mostly influenced by personal and situational features rather than knowledge (De Meza et al., 2008; Willis, 2008). According to this perception, knowledge has little influence on financial behavior since people mostly rely on system 1 , or the myopic doer-self. Our goal being to help people improve their financial habits, the main questions are: which circumstances will encourage people to use deliberate thinking during their financial activities? when do people rely on their system 2, rather

\footnotetext{
${ }^{1}$ Interestingly, while the two selves are strictly hypothetical, MRI studies indicated two different processes in the brain: the limbic system that is activated by decisions involving immediate gratification, and regions of the lateral prefrontal cortex and posterior parietal cortex that are activated in response to intertemporal choices that involve delay gratification (McClure, Laibson, Loewenstein, \& Cohen, 2004).
} 
than their impulses and intuition? and how can they avoid the negative influences of cognitive overload and limited mental resources? By answering these questions, we could identify the situations in which people use their financial knowledge, or otherwise rely on heuristics, habits, and intuition.

Kahneman's dual system theory provides the answers. Research shows that lack of cognitive resources disrupts the operation of system 2 . When time is short people are more likely to present instinctive and impatient behavior, such as heuristics judgments (Finucane, Alhakami, Slovic, \& Johnson, 2000), poor reasoning (Evans, Handley, \& Bacon, 2009; Stanovich \& West, 2000), and even dishonesty (Shalvi, Eldar, \& Bereby-Meyer, 2012). Furthermore, ego depletion and cognitive load influence self-regulation, presumably due to the weakening of deliberate control that is done by system 2 (Kahneman, 2011; Schmeichel, Vohs, \& Baumeister, 2003).

To avoid the negative effects of reduced cognitive and mental resources, people often use coping mechanisms that obviate deliberate thinking. Thaler suggests that by segregating their funds into separate mental accounts (e.g., liquid money, savings, investments), people avoid the need to resist temptation, as they consider a meaningful part of their financial resources unavailable for current consumption (Thaler, 1985). Similarly, several studies confirmed that techniques that reduce the need for self-regulation, such as pre-commitment, rules of thumb, and avoiding risky environment, enables peoples to save more money compared to those who do not use such tools (Rabinovich \& Webley, 2007; Rha, Montalto, \& Hanna, 2006). Gollwitzer proposed that strategic pre-planning, done in the form of implementation intention, linked intentions with actions and leads to automatic behavior that does not require mental effort (Gollwitzer, 1999).

\section{The Cognitive Modulation for Economic Behavior}

In this work, I present the Cognitive Modulation for Economic Behavior [CMEB]. According to the model, the ability to operate according to level of financial literacy depends on the ability to use cognitive and mental resources, an ability that might be affected by two different types of factors: (i) the personal and demographic characteristics of the decision-maker, and (ii) the characteristics of the task that she wishes to perform. The first category draws on the perception that cognitive and mental abilities are limited-recourses. Hence, situations or personal characteristics that 
hamper the availability of such resources (e.g., financial constraints, emotions, self-control) reduce the decision-makers' likelihood to conduct deliberate thinking and prevent them from relying on their financial knowledge. The second type of factors focuses on features of the economic engagement that is being conducted. I conjecture that complex financial tasks, or tasks that provide deferred gratification, demand a larger amount of mental resources than other economic engagements. For instance, buying a cheap product rather than a highly regarded brand provides immediate positive feedback since the consumer knows exactly how much money she saves. On the other hand, while keeping track of bills and planning future expenses could save a consumer a great deal of money, it is hard to recognize the amount saved thanks to these activities. Unfortunately, the contribution of those tasks could only be recognized in the long term. These different features lead to different cognitive demands and create variations in the influence of financial literacy on economic behavior. The model, therefore, predicts the influence of financial literacy as a function of one's ability to conduct deliberate thinking due to the availability of cognitive resources.

By comparing the influence of knowledge with other determinants of financial behavior I aim to determine the upper bound of knowledge for different populations and personalities. The study is presented in five chapters. Some focus on the general influence of knowledge on behavior, others on financial education, and one on pension decisions. Each chapter provides the specific background needed at the time, but they all have a common ground - they all test the influence of knowledge under the assumption that knowledge-based behavior demands deliberate thinking. Based on this assumption I argue that the influence of financial literacy on economic behavior interacts with situational and personal features that create mental effort. In addition, I argue that financial literacy has a stronger influence on simple tasks that provide immediate gratification since they demand less cognitive resources than complicated tasks. This argument is explained in detail in Chapter 3. Finally, the study presented in Chapter 6 offers a way to increase the influence of financial knowledge, by displaying strategic information just before a decision is being made. 


\section{Outline of the dissertation}

This work is composed of four major studies that complement each other and present a broad picture of the influence of financial literacy, and the mechanisms that stand behind it. Chapters 2 and 3 set the foundations for this work. Chapter 2 presents results of a financial literacy survey delivered to a representative sample of Israeli respondents by the Israel Central Bureau of Statistics. Chapter 3 shifts the discussion from financial literacy to financial capability by adding a bundle of psychological and behavioral elements into the research. In this chapter, I link financial literacy with a model of limited-resources, by comparing the influence of financial knowledge with personal and situational factors.

Chapters 4 and 5 present an analysis of an intervention program aiming to help people who experience financial hardship. The two chapters test the influence of the intervention according to the predictions of the new model for financial literacy that is introduced in Chapter 3. Chapter 4 focuses on the short-term influence of the program while highlighting the role of knowledge. Chapter 5 has a longer-term orientation and is focused on the psychological aspects of financial difficulties and their interaction with knowledge.

Chapter 6 demonstrates the role of financial knowledge on pension behavior. Since decisions about pension pertain in the far future, it is a unique arena to investigate the importance of knowledge. By comparing administrative data with responses to a customer survey that was delivered to clients of a leading insurance company, I demonstrate the poor influence of knowledge on savers' decision to conduct early withdraw from their retirement savings account. Results of two online experiments propose a simple and effective way to reduce this tendency by presenting wisely formed information to savers who wish to cash-out their funds.

The final chapter summarizes the findings of this work, brings them into the context of the newly proposed model of financial literacy, and discusses limitations of the work and possible avenues for future research. 
Finally, I would like to clarify that the model is based on theoretical assumptions at this point. Most of the studies in this work are based on data analysis and collection of survey responses and does not contain direct manipulation to test the prediction of the CMEB model. Therefore, the purpose of this work is to confirm the appropriateness of the model as an explanation for the inconsistent influence of financial literacy, in order to directly validate it in future research. 


\section{Chapter 2: Financial Literacy in Israel}

"I am almost 18 and have no idea about taxes, rent, or insurance. But, I can analyze a poem. In 4 languages." (Naina. Tweeter)

In January 2015, a tweet by a 17-year-old high-school student named Naina triggered a nationwide debate in Germany regarding the relevancy of high school syllabus to everyday life. The tweet was retweeted tens of thousands of times, and provoked reactions from many public figures and politicians, including Johanna Wanka, the German Minister of Education, who responded: "I think it's very positive Naina has initiated this debate."

This public discussion is a demonstration of the global interest in peoples' ability to manage their financial affairs. The need to support citizens in developing a sound economic understanding is recognized by both professionals and the general public. But how effective is financial education, and how strong are the relations between financial knowledge and actual behavior? A growing body of literature suggests that the answers are less intuitive than we would like to believe. Attempts to impart financial literacy are often ineffective, raising claims regarding a non-causal relationship between financial knowledge and behavior (Braunstein \& Welch, 2002; Fernandes, Lynch Jr, \& Netemeyer, 2014). Opponents of financial literacy also mention that it is hard to separate financial literacy from omitted variables that impact financial behavior. For example, Fernandez discussed the influence of psychological variables. Moreover, financial literacy is heavily correlated with income and education, which might influence financial literacy, as well as economic behavior.

On the other hand, the importance of financial literacy cannot be belittled. Correlations between financial literacy and economic behavior are too strong to be ignored, and Van Rooij and Lusardi argue for a causal relationship between financial literacy and financial behavior (Van Rooij et al., 2011). Also, evidence shows that financial education is effective for some specific domains of economic behavior. For example, programs were less effective for loan default behavior compared to keeping records and saving behaviors (Miller, Reichelstein, Salas, \& Zia, 2015). The authors explain those differences by the ability to control the situation. In this work, I challenge the financial literacy approach by asking whether financial knowledge is an appropriate proxy for 
sufficient financial behavior. The current chapter uses data collected by the Israel Central Bureau of Statistics (CBS) who delivered a financial literacy survey to more than 1200 respondents during the first half of 2012. Preliminary results were published as a media release by the bureau itself (CBS, 2012), and researchers were invited to use the data for further analysis. Since the survey was developed for specific purposes, it does not directly address this study's research questions, but it is a good place to start and to look at factors that are associated with financial literacy using high-quality data. Specifically, I try to identify the relationship between personal features and financial literacy and ask whether knowledge modulates the influence of demographic variables such as income and education on respondents' financial state.

\section{Method}

The survey used in this study is part of the yearly "Social Survey" administered by the Israel Central Bureau of Statistics (CBS). The Social Survey provides information regarding the living conditions and welfare of the population in Israel, including perceptions and public opinion on various matters. Each year, a sample of the respondents is asked to take an expansion of the survey and fill in a short questionnaire that focuses on a particular topic that interests the public and the policymakers. The 2012 expansion focused on financial literacy.

A representative national sample of 1,214 respondents aged 20 or older completed pen-andpaper questionnaires at home under the supervision of a CBS staff member. They were asked to answer 40 questions about their financial habits, knowledge, and considerations made during specific financial decisions (e.g., mortgage). A measure of financial literacy is based on 6 questions, 5 that were used at the OECD comparative international study (Atkinson and Messy, 2012), and a single question about Israel's prime lending rate. The behavioral statements overlap with the financial capability statements used by Atkinson et al. (2007) but cover only a few aspects of economic behavior, mainly money management and investment. For the survey see Appendix 2A 


\section{Results}

The majority of the population is able to live within its means. Eighty-two percent report that they are paying their bills on time and 65 percent do not agree with the statement "I struggle to make ends meet." More explicit indicators of respondents' financial situation show that only 8 percent of the respondents had their credit card blocked, and 12 percent had their checking account blocked due to financial difficulties during the 12 months prior to the survey. Together, these measures suggest that the financial capability of most consumers is sufficient for paying bills on time and making ends meet.

On the other hand, results indicate that financial literacy in Israel is relatively low. The average number of correct answers is 2.4 out of six questions $(S D=1.88)$, with a majority of respondents (55\%) who answered correctly only 2 questions or fewer. Less than one-third of the respondents present sufficient knowledge in fundamental issues such as compound interest and understanding the concept of prime rate. A comparison to other OECD countries shows that success rates are relatively low on other questions as well. Table 2.1. shows the percentage of correct responses per question, and a comparison to a survey taken in the OECD countries (Atkinson and Messy, 2012).

Table 2.1. Financial literacy in the general population.

\begin{tabular}{lcccc} 
Question type & Correct (\%) & Incorrect (\%) & Do Not Know & $* *$ OECD \\
& & & $(\%)$ & Average \\
Prime Rate & 28.7 & 19.1 & 52.1 & N/A \\
Definition of inflation & 65.0 & 7.3 & 27.7 & 80 \\
Diversification & 35.5 & 10.5 & 54.0 & 53 \\
Risk and Return & 48.8 & 9.9 & 41.3 & 71 \\
Compound Interest & 28.1 & 27.5 & 44.4 & 30 \\
*Interest Paid on a Loan & $79.7(41.7)$ & 17.2 & 3.1 & 82 \\
\hline
\end{tabular}


* The number in parentheses reports the percentage of correct responses when missing responses were taken into account, due to an unusual portion of missing reports -578 cases (48\%). Missing reports were excluded from the rest of the analysis, to conform with previous studies (average rate of responses among other questions was $94 \%)$.

** Based on a pilot study among 14 OECD countries conducted at the same time. Wording may vary between countries (Atkinson and Messy, 2012).

Further analysis reveals more details about financial literacy in Israel. Financial literacy is affected by ethnicity, gender, and education $\left(p<0.0001 ; \eta_{p}^{2}=.03, .04\right.$, and .09 for ethnicity, gender, and education, respectively. See Figure 2.1.). A general linear model aiming to predict financial literacy based on demographic variables indicates that gender, income, and education are all significant predictors of financial literacy (Table 2.2.).
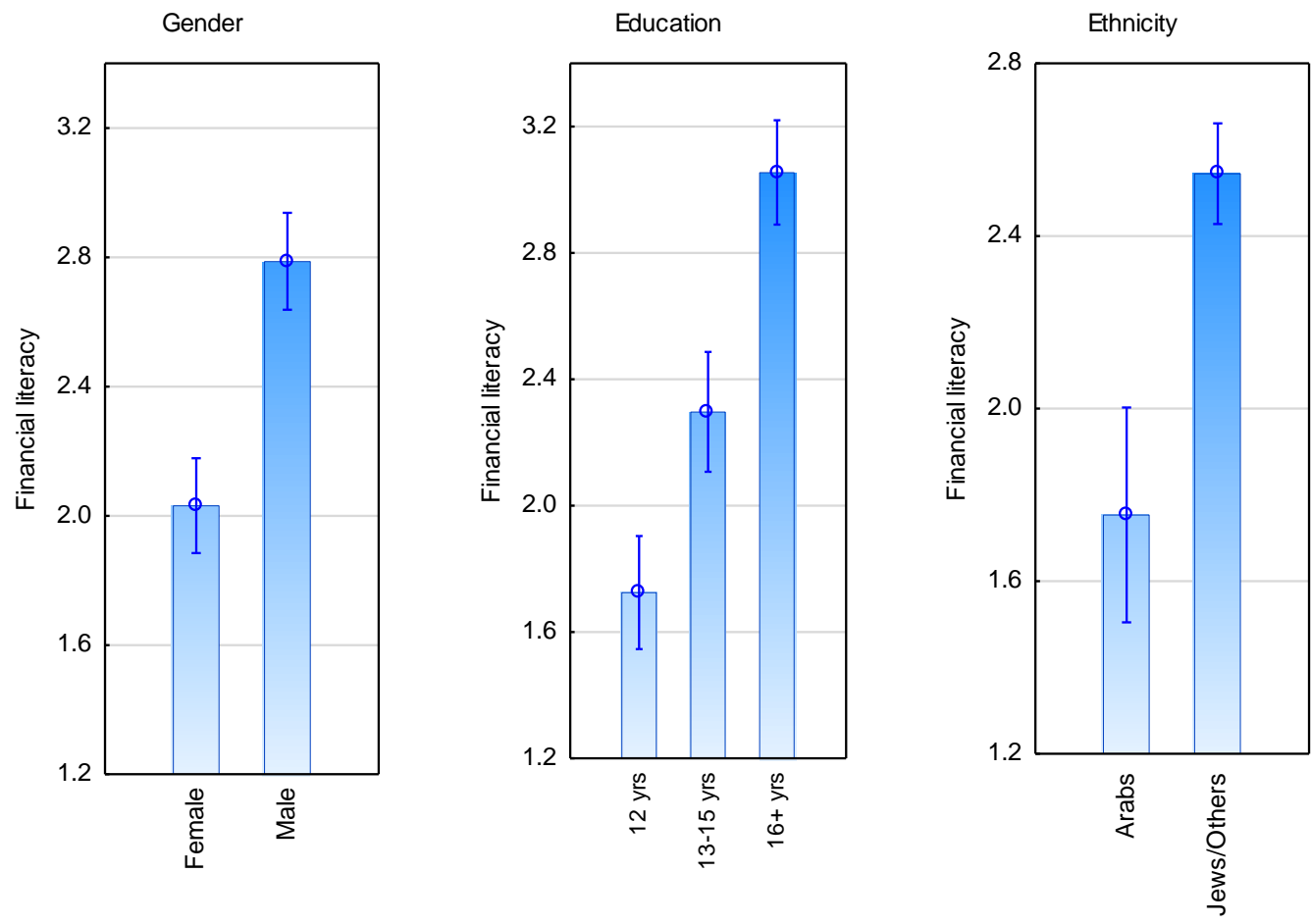

Figure 3.2 1. Financial literacy in Israel by gender, education, and ethnicity. 
Table 2.2. Results of the general linear model.

\section{Financial literacy}

\begin{tabular}{lcc}
\hline & Beta $(ß)$ & $\mathrm{P}$ \\
\hline Intercept & & $.000^{*}$ \\
\hline Equivalent Income & .264 & $.000^{*}$ \\
\hline Gender & & \\
\hline \multicolumn{1}{c}{ Male } & .198 & $.000^{*}$ \\
\hline
\end{tabular}

\section{Education}

Up to 12 Yrs.

$-.213$

$.000^{*}$

13-15 Yrs.

$-.013$

0.69

\section{Ethnicity}

Jews/Others

.04

0.14

\begin{tabular}{ll}
\hline Multiple R & .206 \\
\hline Adjusted $\mathbf{R}^{2}$ & .202 \\
\hline F & 53.6 \\
\hline Observations & 1036 \\
\hline
\end{tabular}

$* \boldsymbol{p}<.0001$

Independent variables: income, gender, education, and ethnicity; DV - financial literacy

The analysis confirms that financial literacy is strongly related to demographic variables, which might explain other types of financial behaviors. Support for this claim comes from strong correlations between financial literacy and education $(r=.29)$, personal income $(r=.37)$, and household's equivalent income $(r=.35)$.

Indicators of financial behavior show weak relations with financial literacy. People who are responsible for managing their household's finance received better financial literacy score comparing to people who reported their partner to be in charge ( 2.3 vs. 2.7 ; $s d=1.9$ for both 
groups), but the explained variance is very small $\left(p<.05 ; \eta_{\mathrm{p}}{ }^{2}=.008\right)$. Attempt to predict the tendency for seeking financial advice from a trained consultant produced only slightly better results $\left(\beta=.20,95 \% \mathrm{Cl}[.15, .26], p=0.001 * *\right.$, adjusted $\left.\mathrm{R}^{2}=0.04\right)$. A simple linear regression shows a very weak predictive power for occurrences of adverse events such as having a negative balance in checking account $\left(p<.001 ; \eta_{p}{ }^{2}=0.01\right)$ and having checking account blocked over the past twelve months. Analysis of demographic variables produced similar findings (income and education: $p<.001, \eta_{p}^{2}=0.01$; ethnicity: $\left.p<.001, \eta_{p}^{2}<0.003\right)$.

Another comparison between financial literacy and income is shown in Table 2.3, which presents correlations between financial literacy and income and a bundle of behavioral statements. The analysis reveals that financial literacy is closely related to investments decisions, but the ability to keep track, to compare prices, and to pay bills on time is only weakly correlated with financial literacy. Income, naturally, provides a good explanation for making ends meet; yet, it cannot explain other types of behaviors, including price comparison and investments.

2Table 2.3. Correlations matrix of statements regarding savings and investments with financial literacy, income, and 'making ends meet.'

Financial literacy

\begin{tabular}{lll}
\hline Follow monetary expenses & $0.17^{*}$ & 0.03 \\
\hline Struggle to pay for basic expenses & $-0.10^{*}$ & $-0.37^{*}$ \\
\hline Pay bills on time & $0.18^{*}$ & $0.25^{*}$ \\
\hline I buy things even if I have no money & 0.03 & 0.02 \\
\hline I Compare prices before purchase & $0.18^{*}$ & 0.01 \\
\hline Thrifty & $0.08^{*}$ & $-0.07^{*}$ \\
\hline Improvident & 0.00 & 0.01 \\
\hline Sufficient knowledge to invest & $0.36^{*}$ & $0.15^{*}$ \\
\hline Take risks in investments & $0.26^{*}$ & $0.15^{*}$ \\
\hline Compare investment tracks & $0.38^{*}$ & $0.22^{*}$ \\
\hline
\end{tabular}

Using factor analysis, I created two categories from the statements presented above: "management" - managing money, including expense tracking, price comparison, budgeting, and 
paying bills, and "investments" - investment decisions and risk-taking (for factor loadings see Appendix 2B). Figure 2.2 shows a two-way ANOVA between financial literacy and income using "management" or "investments" as dependent variables. The analysis included only subjects with low (0-1 correct answers) or high (4-6 correct answers) financial literacy scores and indicates that financial literacy improves investment behavior $\left(p<.0001 ; \eta_{p}{ }^{2}=.14\right)$, while income has no significant effect $\left(p>.05 ; \eta_{p}{ }^{2}=.02\right)$. Regarding the ability to manage money, the analysis reveals an interaction between income and financial literacy $\left(F(3,681)=2.744, p<.05 ; \eta_{p}{ }^{2}=.01\right)$, and a significant main effect for both income $\left(p<.05 ; \eta_{p}{ }^{2}=.01\right)$ and financial literacy $\left(p<.05 ; \eta_{p}^{2}=.03\right)$. Post hoc analysis confirms that people with low-income do not benefit from high financialliteracy (post-hoc: $p<.05)$.

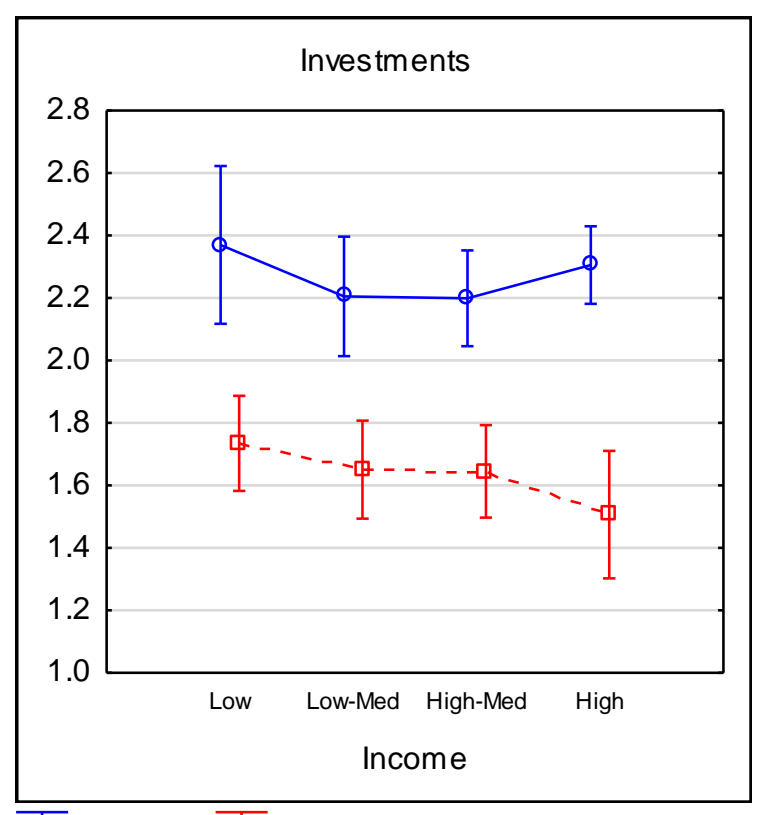

흐 High FL 五- Low FL

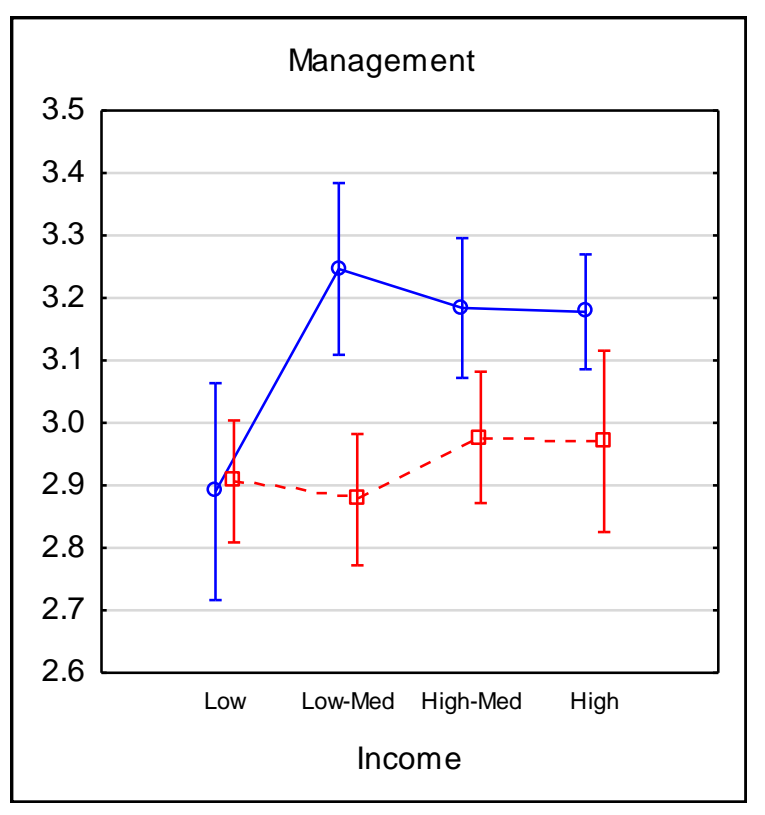

Figure 3.2 2. A two-way ANOVA for income and financial literacy (FL), DV - investments, and management.

\section{Summary}

The analysis provides a first-order demonstration of the limited ability to use financial literacy as a proxy for adequate financial behavior. Financial literacy in Israel is relatively low, but the vast majority of the public is able to live within its means. The relationship between financial literacy 
and the occurrences of an adverse financial event is very weak and could be explained by demographic variables as well. It appears that financial literacy score is affected by individual attributes such as cultural background, or socioeconomic status, and might not solely represent financial skills.

As for the question that lies at the heart of this work - the effect of financial difficulties and psychological features on economic behavior - this work has limited contribution. The CBS's database does not directly address those issues. Yet, we can make an observation that will be further investigated in the next studies. Looking at the interaction between income and financial literacy, we can see that when it comes to managing money, knowledge is irrelevant for people with low income but does play a meaningful role for other respondents. Investment scores, on the other hand, are closely linked to knowledge, but unrelated to the level of income. Those different patterns suggest that while researchers tend to generalize the term financial literacy when they discuss the effect of knowledge on behavior, financial literacy may play a dissimilar role on different economic encounters.

As we saw, supporters of financial literacy show evidence about the strong relations between financial literacy, investment management, portfolio management, and stock market participation. The analysis supports these claims, but also challenges the common conclusion that advocates financial literacy as a remedy for inadequate financial behavior. While financial literacy goes together with investment abilities, it is poorly related to other types of economic skills such as managing money, paying bills on time, and being a wise consumer. Although financial literacy is defined as a combination of skills and knowledge needed for adequate financial behavior (Huston, 2010), its measures often rely on topics that are related to investments and numeracy. Therefore, the relationship between financial literacy and investment found in this study is understandable. However, when it comes to other types of financial engagement, this type of knowledge is not necessarily useful. One possible explanation is that keeping track of income, expenses, and future expenditures does not require knowledge about the stock market, inflation, or compound interest; it demands time and mental resources. Other possible explanations include reverse causality between financial state and economic behavior, and an intervening variable that influence the relationship between economic behavior 
and financial knowledge. While reverse causality is less plausible in this case -- our measure of financial state was income, which is unlikely to be affected by financial knowledge -- we cannot rule out the possibility of an intervening variable. In this spirit, the next study looks at factors that consume mental resources and analyzes the way they influence economic behavior. 


\section{Chapter 3: From Financial Literacy to Financial Capability}

The analysis presented in Chapter 2 confirmed that financial literacy is not a good indicator of economic behavior and suggested that the effect of financial literacy could be explained by other variables such as education and income. In the current chapter, I direct the discussion from financial literacy to financial capability. As noted in the literature review, despite the fact that the two terms are often used interchangeably, research of literacy mainly focuses on knowledge, while capability research tends to focus on daily practices and financial engagements. Using methodology adopted from research on financial capability, I test whether literacy can explain differences in daily economic behavior.

Literature suggests countless factors that may impair judgment and rational thinking. In the current study I focus on variables: financial constraints, self-control, and financial avoidance. Each factor has its own influence on financial behavior, but they all explain the limited influence of financial literacy on financial capability as they influence consumers' ability to act according to their knowledge.

\section{Explaining variables}

The first variable is the financial constraints. Ample evidence has shown the negative effect of financial troubles on financial decisions and behavior. Explanations for this effect vary between culture, personality, self-efficacy, and cognitive abilities (Haushofer \& Fehr, 2014; Loibl 2017; Chakravarti, 2006).

A cognitive explanation by Shafir, Mullainathan, and coauthors, suggests that financial constraints lead to cognitive overload, which impairs thinking and cognitive abilities (Mani, Mullainathan, Shafir, \& Zhao, 2013; Mullainathan \& Shafir, 2013; Shah, Mullainathan, \& Shafir, 2012). A unique feature of this "scarcity approach" makes it highly appropriate for the current study. Rather than focus on income or living conditions, the theory defines poverty as the "gap between one's needs and the resources available to fulfill them" (Mani et al., 2013). This description suggests that under the right circumstances, non-poor individuals would produce the same short-sightedness that characterizes the poor, enabling us to apply its principles on members of the general public who experience financial hardship. In accordance with this theory, 
I would like to argue that financial constraints explain the deviation from the expected influence of financial literacy, as it hinders the mental processes required for literate behavior.

The second variable used to explain deviations from the expected literate behavior is self-control. Lack of self-control is associated with poor consumption and planning (Baumeister, 2002; Vohs, 2013), and is also related to deviations from reasoning and rational behavior (Kahneman, 2011; Schmeichel, Vohs, \& Baumeister, 2003). Hence, I conjecture that low self-control would hurt individuals' ability to act according to their financial knowledge and would reduce the influence of financial literacy on behavior.

The last explaining variable is financial avoidance. People who have negative emotions toward financial manners are passive and indifferent to their financial mistakes (Shapiro \& Burchell, 2012). A nice demonstration by Rosen and Sade (2017) shows that Israelis with low financial confidence were not aware of a temporary opportunity to withdraw money from an inactive retirement account; hence they lost a meaningful sum of money. The authors argue that this behavior is explained by negative emotions toward financial matters, which creates financial avoidance. I assume that financial avoidance would weaken the influence of knowledge on behavior, since negative emotions induce inadequate financial behavior such as time discounting, risk aversion, and impatience (for a detailed review see Haushofer \& Fehr, 2014).

Low-income may explain financial avoidance. According to Webb, Chang, \& Benn (2013), financial avoidance stems from the will to escape negative emotions associated with the desire to preserve self-perception and avoid a sense of personal failure. Galai \& Sade (2006) used the term "ostrich effect" to describe investors' avoidance of negative information about their assets, a tendency explained by Karlsson, Loewenstein, \& Seppi (2009) as a will to escape psychological discomfort. In a similar vein, low-income may explain why certain individuals prefer not to monitor their finances and avoid planning for the future, in order to avoid negative feelings associated with poor financial achievements. Based on this notion I hypothesized that financial avoidance would mediate the link between low income and financial management such as monitoring, keeping track, and planning future expenditures. 


\section{Complexity and timing gratification of financial engagements}

The characteristics of the economic task being conducted strongly influence the ability to apply financial knowledge. Research has shown that people prefer immediate gratification over future extended payoffs. For instance, the concept of Hyperbolic Discounting describes the tendency to discount the value of future rewards (Loewenstein \& Prelec, 1992; Thaler \& Shefrin, 1981). Mischel's classic "Marshmallow experiments" showed that preference toward immediate gratification could be tracked at childhood and remains stable throughout adulthood (Mischel, 2014). Hence, I expect that the time of gratification would influence individuals' propensity to invest time and effort in a given task.

Further, it is known that complex tasks are aversive (Kahneman, 2011). People are therefore less likely to conduct complicated financial tasks. I propose that a categorization of financial capabilities based on those two dimensions could explain contrasting performances in the financial domains. Complicated tasks that provide delayed gratification pose more difficulties and therefore are more likely to be affected by habits, heuristics, and false perceptions. Thus, I expect to find a stronger influence for knowledge on simple tasks that provide immediate rewards. In this way the complexity and timing of gratification of financial engagements may explain conflicting findings regarding the effectiveness of financial education.

To test this hypothesis, I adopted Atkinson, McKay, Collard, and Kempson's (2007) categorization of financial capabilities:

a. managing money - people's ability to make ends meet, and their ability to keep track of their finances;

b. planning ahead - financial precautions taken for the future;

c. choosing products - choice and purchase of financial products;

d. staying informed - engagement with current economic developments.

Let us now contrast two common financial practices - comparing prices, an essential part of the category "choosing products", and budgeting, a task that stands at the heart of the "planning ahead" category. Budgeting involves data collection and numerical calculations and requires future orientation and planning. Price comparison also requires attention, but it is focused on 
one specific product and takes less time and effort. Budgeting is, therefore, a more complex task than a price comparison.

The two tasks differ also in the gratification timing. When a person chooses to buy a cheap product rather than a highly regarded brand, she might have to resist temptation, but she also knows exactly how much money she saves and receives immediate positive feedback. On the other hand, while a consumer can save a great deal of money by keeping track of bills and planning future expenses, it is hard to recognize the amount saved thanks to these activities. Whereas any customer can evaluate the savings offered at a discount, the implications of proper money management and planning are apparent only in the long run, and not during the act itself.

Table 3.1 presents a categorization of financial capabilities based on the two proposed dimensions. Note that the category "money management" was sub-divided into "management" and "making ends meet", and that "choosing products" was also sub-divided into "choosing products" and "Choosing financial products" in order to make a finer-grained categorization.

Table 3.1. Categorization of financial capabilities based on complexity and delayed gratification.

$\begin{array}{lll} & \text { Complexity } & \text { Gratification } \\ \text { Planning ahead } & \text { High } & \text { Delayed } \\ \text { Management } & \text { High } & \text { Delayed } \\ \text { Making ends meet } & \text { High } & \text { Immediate } \\ \text { Choosing financial products } & \text { High } & \text { Variable } \\ \text { Staying informed } & \text { Low } & \text { Delayed } \\ \text { Choosing products } & \text { Low } & \text { Immediate }\end{array}$

The division enables making precise predictions about the influence of knowledge on economic behaviors. Behaviors that are more complicated and provide delayed gratification require more 
mental resources, and would, therefore, be affected by a lack of financial resources, self-control, and negative emotions, but not by knowledge. Tasks that are simple and provide immediate gratification do not require the same resources, and people could, therefore, apply their knowledge when engaging in those types of behaviors.

In this chapter, I test the role of different types of determinants of economic behavior - three explaining variables represent personal characteristics of the individual (i.e., income, self-control, financial avoidance), and two features of the economic task that is being delivered (complexity and timely gratification). The common denominator of all of those factors is that they influence the individual's ability to conduct knowledge-based behavior due to scarcity of mental and cognitive resources. The integration of financial knowledge and mental resources explains the divergent influence of financial literacy among different populations and on different occasions. I named this new model for financial literacy the Cognitive Modulation for Economic Behavior [CMEB], since it expresses the need to include cognitive and mental resources in the investigation of financial literacy.

The current study is composed of several surveys that were delivered to an international group of respondents using Amazon's MTurk platform, and measured financial literacy, financial capability, and psychological and demographic factors. The purpose of the study is to delineate a map of relations between financial behavior and other factors based on the theoretical assumptions described above. I expect that knowledge would have limited influence on behavior compared to income, self-control, and financial avoidance, especially for practices that provide delayed feedback and are hard to perform. Moreover, I assume that those variables would play a less significant role in practices that provide immediate feedback and are quite easy to perform, enabling consumers to use their knowledge and skills. Therefore, I expect to find the strongest impact for financial literacy on financial capability at the "Choosing Products" category, which provides immediate gratification and is easy to perform.

\section{Method}

The research was conducted online using Amazon's Mechanical Turk platform. The survey was programmed on the Qualtrics website and distributed to an international sample of respondents 
in February 2016. 164 out of 189 respondents completed the survey and were rewarded 90 cents for their participation. The vast majority of the respondents - 73 percent - are Americans, 23 percent from Asia, and the rest come from other countries or did not want to answer. Most respondents are males (56 percent), 53 percent are married, and 64 percent hold a college degree or higher. Most respondents consider their household's income to be less than (38 percent) or equal to (37 percent) the average income in their region. Average age is 33 , ranging from 18 to 64 .

\section{Variables}

Subjects were asked about their current financial situation and several economic characteristics and filled in several surveys (see Appendix 3A). Self Control Survey - Adapted from Tangney, Baumeister, \& Boone (2004); Financial Anxiety Scale (FAS) - Shapiro \& Burchell (2012); Financial Literacy Survey - 8 questions taken from Atkinson \& Messy (2012). Respondents also answered a short financial capability survey. The modified version of the survey is based on work done by Atkinson, McKay, Collard, \& Kempson (2007) and was adapted for the purposes of the current study. It includes four categories of financial capability: Management, Making Ends Meet, Choosing Products, Staying Informed. This categorization bound together "money management" with "planning ahead", while excluding questions strongly related to income and wealth. Those questions were labeled separately as Making Ends Meet. Economic characteristics of the respondents include their reported household income relative to average salary and subjective assessment of their relative financial situation.

\section{Results}

\section{Financial knowledge and financial capability}

The first set of analyses looked at the relationship between knowledge and behavior. First, I developed financial knowledge and financial behaviors scales. The financial literacy scale is based on the sum of correct responses where each question received equal weight, following Atkinson and Messy's (2012) technique. Results indicate that a third of the respondents (32 percent) answered all 8 questions correctly, a surprisingly high rate compared to the study reported in the previous section, in which only 11 percent were able to answer all questions correctly. Table 3.2 
reports the percentages of correct responses to knowledge questions. As a reference point, the table also reports the results found in Germany (based on Atkinson and Messy, 2012).

Table 3.2. Percentage of correct responses for financial knowledge questions.

\begin{tabular}{|c|c|c|c|c|c|c|c|c|}
\hline & Division & $\begin{array}{l}\text { Time- } \\
\text { value } \\
\text { of } \\
\text { money }\end{array}$ & $\begin{array}{l}\text { Interest } \\
\text { paid on } \\
\text { loan }\end{array}$ & $\begin{array}{l}\text { Calculation } \\
\text { of interest }\end{array}$ & $\begin{array}{l}\text { Compound } \\
\text { interest - } \\
\text { corrected } \\
\text { to the } \\
\text { previous } \\
\text { answer }\end{array}$ & $\begin{array}{l}\text { Risk } \\
\text { and } \\
\text { return }\end{array}$ & Inflation & Devitrification \\
\hline $\begin{array}{l}\text { North } \\
\text { America }\end{array}$ & 89 & 62 & 93 & 86 & 65 & 84 & 82 & 77 \\
\hline Asia & 89 & 39 & 68 & 55 & 39 & 81 & 66 & 66 \\
\hline Total & 89 & 56 & 87 & 79 & 57 & 82 & 79 & 73 \\
\hline Germany & 84 & 61 & 88 & 64 & 47 & 79 & 87 & 60 \\
\hline
\end{tabular}

Comparison to Germany is based on a study done by Atkinson and Messy (2012).

Next, I used cluster analysis to test whether the modified version of the financial capability survey matches the expected four dimensions of financial capability. I used Pearson correlation as a distance measure, and clustering was performed according to Ward's method that minimizes the sum of squares of any two clusters on each step. The analysis revealed two main clusters, one that contained the "management" and "making ends meet" categories, and another branch that included "choosing products" and "staying informed". Subdivision of each branch shows that the questions cluster as expected (see Appendix 3B).

Cronbach's alpha test was performed for each of the four categories separately to test the reliability of the proposed categories, and several statements were excluded from the survey to achieve sufficient internal consistency. Standardized alpha for the final version of the survey is 
0.844 for "management", 0.753 for "staying informed", 0.841 for "making ends meet", and 0.741 for the "choosing product" category. Calculating a general reliability score for the entire survey produced a lower score of 0.645 , supporting the notion that the survey measured distinct dimensions instead of one general behavior.

Table 3.3 present financial capability scores. The analysis shows significant differences between the making ends meet and choosing products categories, and the other two categories $(F(3$, $652)=17.770, p<.0001 ; \eta_{p}^{2}=.07 ;$ post-hoc $\left.p<.05\right)$. Break down according to income revealed that people with high income are superior in most financial capabilities - a point I will elaborate later.

Table 3.3. Financial capability by income group.

$\begin{array}{lccccc}\text { Income } & \mathrm{N} & \text { Management } & \begin{array}{c}\text { Making Ends } \\ \text { Meet }\end{array} & \begin{array}{c}\text { Choosing } \\ \text { Products }\end{array} & \begin{array}{c}\text { Staying } \\ \text { Informed }\end{array} \\ \text { Below average } & 62 & 2.84(.68) & 2.36(.69) & 2.87(.60) & 2.17(.61) \\ \text { Average } & 59 & 2.97(.64) & 2.76(.65) & 2.76(.60) & 2.59(.58) \\ \text { Above average } & 37 & 3.16(.49 & 3.17(.67) & 2.84(.55) & 2.68(.62) \\ \text { Total } & 158 & 2.97(.63) & 2.70(.74) & 2.82(.59) & 2.45(.64)\end{array}$

To validate the predictive power of financial literacy and financial capability, I used self-reports regarding the respondents' current financial situation as a dependent variable (1-5 Likert scale). As seen in Table 3.4, a multiple regression that includes financial literacy and the four financial capabilities explains a substantial part of the variance of peoples' financial state (adjusted $R^{2}=$ .449). Naturally, the best predictor of financial situation is the ability to make ends meet. A model of regression that excludes "making ends meet" shows a smaller, yet still significant, predictive power for this model (adjusted $\mathrm{R}^{2}=.166$ ). Financial literacy alone cannot predict financial situation $(\beta=-.13, p>0.05)$. 
Table 3.4. Two regression models that include financial literacy and financial capability explain the variance of peoples' financial state.

Dependent Variables

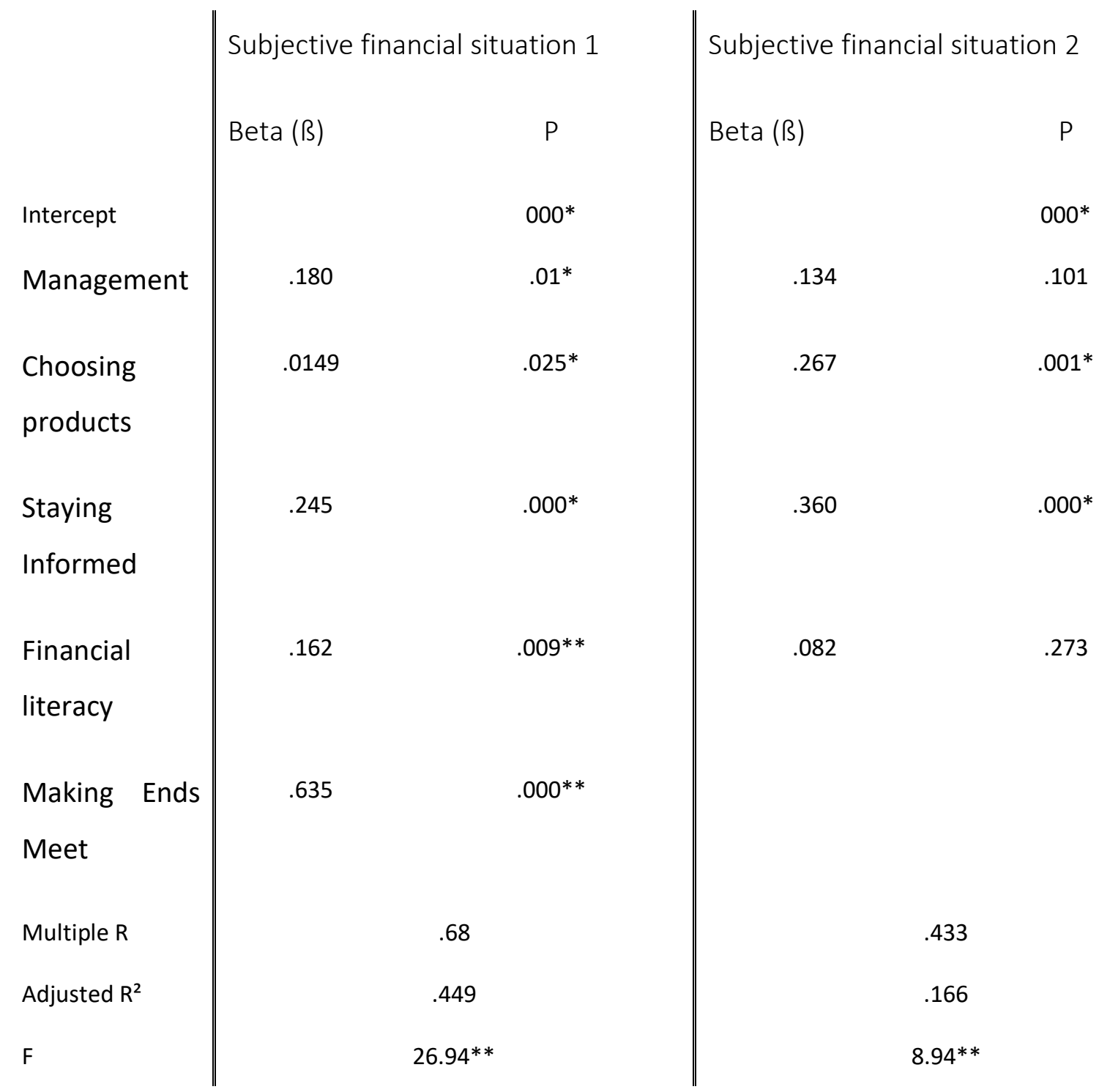

The second model does not include the category "making ends meet".

Table 3.5 presents the relations between literacy and behavior on 24 behavioral statements. The results indicate that high financial literacy is related to financial resources, non-impulsive purchases, and a positive attitude toward financial knowledge. Core aspects of households' economic behavior, such as working with a budget or planning for the future, do not differ between the groups. 
Table 3.5. Financial capability statements by level of financial literacy.

\begin{tabular}{|c|c|c|c|c|c|}
\hline & & Financia & literacy & & \\
\hline & Low & Low-Med & High-Med & High & $p$ \\
\hline Organize documents & 2.59 & 3.07 & 2.82 & 2.83 & 0.196 \\
\hline & $(-1.16)$ & $(-0.98)$ & $(-0.76)$ & $(-0.93)$ & \\
\hline Keeping track of income and & 2.87 & 3.34 & 3.24 & 3.28 & 0.110 \\
\hline expenses & $(-0.99)$ & $(-0.82)$ & $(-0.82)$ & $(-0.83)$ & \\
\hline Annual planning & 2.65 & 2.88 & 2.42 & 2.69 & 0.252 \\
\hline & $(-1.1)$ & $(-1.04)$ & $(-0.79)$ & $(-0.93)$ & \\
\hline Follow budget & 2.81 & 3.05 & 2.88 & 3.2 & 0.108 \\
\hline & $(-0.98)$ & $(-0.8)$ & $(-0.84)$ & $(-0.63)$ & \\
\hline At the end of the month, I have & 2.5 & 2.83 & 2.94 & 2.87 & 0.297 \\
\hline money left in my account & $(-1.08)$ & $(-1.01)$ & $(-0.86)$ & $(-1.06)$ & \\
\hline Have enough resources to pay bills & 2.66 & 2.95 & 3.26 & 3.19 & $0.013^{*}$ \\
\hline on time & $(-1)$ & $(-0.76)$ & $(-0.71)$ & $(-0.87)$ & \\
\hline My income is higher than my & 2.52 & 2.43 & 2.94 & 3.13 & $0.001^{* *}$ \\
\hline expenses & $(-1.09)$ & $(-1.02)$ & $(-0.81)$ & $(-0.89)$ & \\
\hline Know approximately how much & 2.71 & 3.1 & 3.45 & 3.5 & $0.000 * *$ \\
\hline money I owe & $(-1)$ & $(-0.79)$ & $(-0.75)$ & $(-0.67)$ & \\
\hline Short-term preparation & 2.53 & 3.19 & 3.03 & 3.26 & $0.001 *$ \\
\hline & $(-1.05)$ & $(-0.8)$ & $(-0.87)$ & $(-0.68)$ & \\
\hline Long-term preparation & 2.85 & 2.83 & 2.41 & 2.72 & 0.133 \\
\hline & $(-0.93)$ & $(-0.93)$ & $(-0.74)$ & $(-0.88)$ & \\
\hline Save for pension & 2.47 & 2.14 & 2.12 & 2.31 & 0.470 \\
\hline & $(-0.99)$ & $(-1.03)$ & $(-1.07)$ & $(-1.16)$ & \\
\hline Have funds allocated for emergencies & 2.55 & 2.36 & 2.76 & 2.72 & 0.260 \\
\hline & $(-1.06)$ & $(-1.1)$ & $(-0.85)$ & $(-1.05)$ & \\
\hline I know how to prepare for & 2.64 & 2.65 & 2.94 & 2.94 & 0.219 \\
\hline unexpected expenses & $(-0.96)$ & $(-1.08)$ & $(-0.5)$ & $(-0.88)$ & \\
\hline
\end{tabular}




\begin{tabular}{|c|c|c|c|c|c|}
\hline \multirow[t]{2}{*}{ Compare prices } & 2.59 & 3.32 & 3.18 & 3.31 & $0.000^{* *}$ \\
\hline & $(0.97)$ & $(0.72)$ & $(0.87)$ & $(0.67)$ & \\
\hline \multirow[t]{2}{*}{ Consult before purchase } & 2.65 & 2.91 & 3.01 & 2.89 & 0.267 \\
\hline & $(0.82)$ & $(0.85)$ & $(0.73)$ & $(0.66)$ & \\
\hline \multirow[t]{2}{*}{ Impulsive purchase } & 2.08 & 1.89 & 1.53 & 1.58 & $0.006 *$ \\
\hline & $(0.93)$ & $(0.88)$ & $(0.68)$ & $(0.63)$ & \\
\hline Compare prices of service providers & 2.46 & 2.66 & 2.54 & 2.49 & 0.726 \\
\hline occasionally & $(0.69)$ & $(0.92)$ & $(0.92)$ & $(0.92)$ & \\
\hline Looking for alternatives before & 2.52 & 2.79 & 2.61 & 2.74 & 0.555 \\
\hline purchase & $(0.79)$ & $(0.95)$ & $(0.93)$ & $(0.87)$ & \\
\hline \multirow[t]{2}{*}{ Plan prior to shopping } & 2.68 & 3.13 & 3.29 & 3.25 & $0.001 *$ \\
\hline & $(0.83)$ & $(0.68)$ & $(0.64)$ & $(0.7)$ & \\
\hline \multirow[t]{2}{*}{ I read my bank statements. } & 2.81 & 3.29 & 3.03 & 3.07 & 0.117 \\
\hline & $(0.93)$ & $(0.89)$ & $(0.79)$ & $(0.8)$ & \\
\hline Consult a professional before making & 2.32 & 2.02 & 1.84 & 1.69 & $0.024 *$ \\
\hline important financial decisions & $(0.89)$ & $(1.15)$ & $(0.97)$ & $(0.82)$ & \\
\hline Consult a family member before & 2.54 & 2.75 & 2.52 & 2.15 & $0.026^{*}$ \\
\hline making important financial decisions & $(0.9)$ & $(0.98)$ & (1) & (1) & \\
\hline \multirow[t]{2}{*}{ Follow financial news } & 2.37 & 2.45 & 2.06 & 2.17 & 0.266 \\
\hline & $(0.91)$ & $(1.04)$ & $(0.93)$ & $(0.95)$ & \\
\hline I believe it is important to have & 2.79 & 3.27 & 3.16 & 3.21 & $0.023^{*}$ \\
\hline financial knowledge & $(0.74)$ & $(0.75)$ & $(0.71)$ & $(0.71)$ & \\
\hline Follow the changes in financial & 2.39 & 2.3 & 2.24 & 2.44 & 0.746 \\
\hline products & $(0.83)$ & $(1.02)$ & $(0.9)$ & $(0.94)$ & \\
\hline
\end{tabular}

A correlations matrix in Table 3.6 indicates that financial capabilities and financial literacy are weakly correlated. Self-control heavily correlates with managing money, whereas income is strongly associated with making ends meet. Surprisingly, financial literacy was not correlated with income and education. 
Table 3.6. Correlations between financial capabilities, financial literacy, and personal features.

Literacy Management Making Ends Meet Choosing Products Staying informed

\begin{tabular}{llllll}
\hline Self-control & 0.05 & $0.60^{*}$ & $0.36^{*}$ & $0.24^{*}$ & $0.29^{*}$ \\
Literacy & 1.00 & 0.15 & 0.14 & $0.21^{*}$ & -0.07 \\
Age & 0.09 & 0.13 & 0.07 & -0.14 & -0.09 \\
Avoidance & -0.11 & $-0.42^{*}$ & $-0.47^{*}$ & -0.06 & $-0.28^{*}$ \\
Income & 0.01 & 0.15 & $0.46^{*}$ & -0.04 & $0.38^{*}$ \\
Education & -0.02 & $0.16^{*}$ & $0.16^{*}$ & -0.08 & $0.29^{*}$ \\
$* p<.05$ & & & & &
\end{tabular}

The analyses above show that financial knowledge is a poor indicator for either financial state or financial habits. Nevertheless, a combination of measurements that includes financial knowledge with financial capability explains a large part of the variance in peoples' financial situation.

\section{Income, self-control, and financial avoidance}

We now turn to test our prediction that financial literacy predicts the ability to choose products wisely but not success in demanding management tasks. Table 3.7 shows results of a multiple regression that includes financial literacy, income, self-control, and financial avoidance for each category of financial capability. The predictions are confirmed, as financial literacy predicts consumption but not management. Interestingly, financial literacy is also a significant predictor of making ends meet, perhaps because the ability to make ends meet relates to a demographic background that provides financial support and also helps to develop financial literacy during childhood. 
Table 3.7. Multiple regression of financial capabilities. Dependent variables include financial literacy, income, self-control, and financial avoidance.

Dependent Variables

\begin{tabular}{|c|c|c|c|c|c|c|c|c|}
\hline & \multicolumn{2}{|c|}{ Management } & \multicolumn{2}{|c|}{$\begin{array}{l}\text { Choosing } \\
\text { products }\end{array}$} & \multicolumn{2}{|c|}{$\begin{array}{c}\text { Making Ends } \\
\text { Meet }\end{array}$} & \multicolumn{2}{|c|}{ Staying informed } \\
\hline & Beta $(ß)$ & $p$ & Beta ( $ß$ & $p$ & Beta (ß) & $p$ & Beta $(ß)$ & $p$ \\
\hline Intercept & & $.003 * *$ & & $.000 * *$ & & $.000^{* *}$ & & $.000^{*}$ \\
\hline Literacy & .105 & .106 & .18 & $.011^{*}$ & .154 & $.029 *$ & .117 & .108 \\
\hline $\begin{array}{l}\text { Self- } \\
\text { Control }\end{array}$ & .540 & $.000 * *$ & .415 & $.000 * *$ & .154 & .081 & .150 & .100 \\
\hline Income & .050 & .448 & -.140 & .062 & .197 & $.006^{* *}$ & .322 & $.00 * *$ \\
\hline Avoidance & -.064 & .437 & .056 & .547 & -.266 & $.003^{* *}$ & .128 & .169 \\
\hline Multiple R & \multicolumn{2}{|c|}{.61} & \multicolumn{2}{|c|}{.44} & \multicolumn{2}{|c|}{.50} & \multicolumn{2}{|c|}{.45} \\
\hline Adjusted $\mathrm{R}^{2}$ & \multicolumn{2}{|c|}{.35} & \multicolumn{2}{|c|}{.17} & \multicolumn{2}{|c|}{.23} & \multicolumn{2}{|c|}{.18} \\
\hline $\mathrm{F}$ & \multicolumn{2}{|c|}{$22.07 * *$} & \multicolumn{2}{|c|}{$9.24 * *$} & \multicolumn{2}{|c|}{$13.33 * *$} & \multicolumn{2}{|c|}{$10.08^{* *}$} \\
\hline
\end{tabular}

$* p<.05 ; * * p<.001$

A series of GLM analyses confirmed the differences between "choosing product" and "management". A Multivariate GLM that tested the effect of income on the two dependent variables reveals a significant difference between management and choosing products $[\mathrm{F}(4$, $308)=3.139, p<.05]$, and confirmed a significant main effect for income on management $(p<.05$; $\left.\eta_{\mathrm{p}}{ }^{2}=.04\right)$, but not on choosing products $(p>.05)$ (see Figure 3.1). Higher income makes it more likely to make ends meet, but has a negative (if not significant) effect on product selection.

Similar analyses reveal the same difference for the two other explaining variables - self-control and financial avoidance. High self-control induces high scores in all four types of financial capabilities when compared to people with low self-control $[F(1,162)=5.1237, p<.05]$, yet the 
magnitude of the effect is larger for management. The partial eta squared $\left(\eta_{p}{ }^{2}\right)$ is 0.27 for "management", but only 0.08 for "making ends meet", and 0.03 for the other two categories. A multivariate GLM analysis that uses management and choosing products as dependent variables confirms that self-control affects each of the behaviors differently $(F(2,161)=30.261, p<.001$, $\eta_{\mathrm{p}}^{2}=.27$, Wilks' $\lambda=.72$, power $=1$.

Likewise, financial avoidance produces dissimilar main effects for the two capabilities in question. A multivariate GLM analysis that uses "management" and "choosing products" as dependent variables confirms that avoidance has a different effect on the two $\operatorname{DVs}(F(2,161)=12.741, p<$ $.0001, \eta_{p}{ }^{2}=.13$, Wilks' $\lambda=.86$, power $\left.=99\right)$. Analysis of univariate effects shows a significant main effect of financial avoidance for management $\left[F(2,162)=25.601, p<.0001, \eta_{p}^{2}=.136\right.$, power $=$ $.998]$, but not for choosing products $\left[F(2,162)=2.98, p>.05, \eta_{p}{ }^{2}=.018\right.$, power $\left.=.403\right]$. 


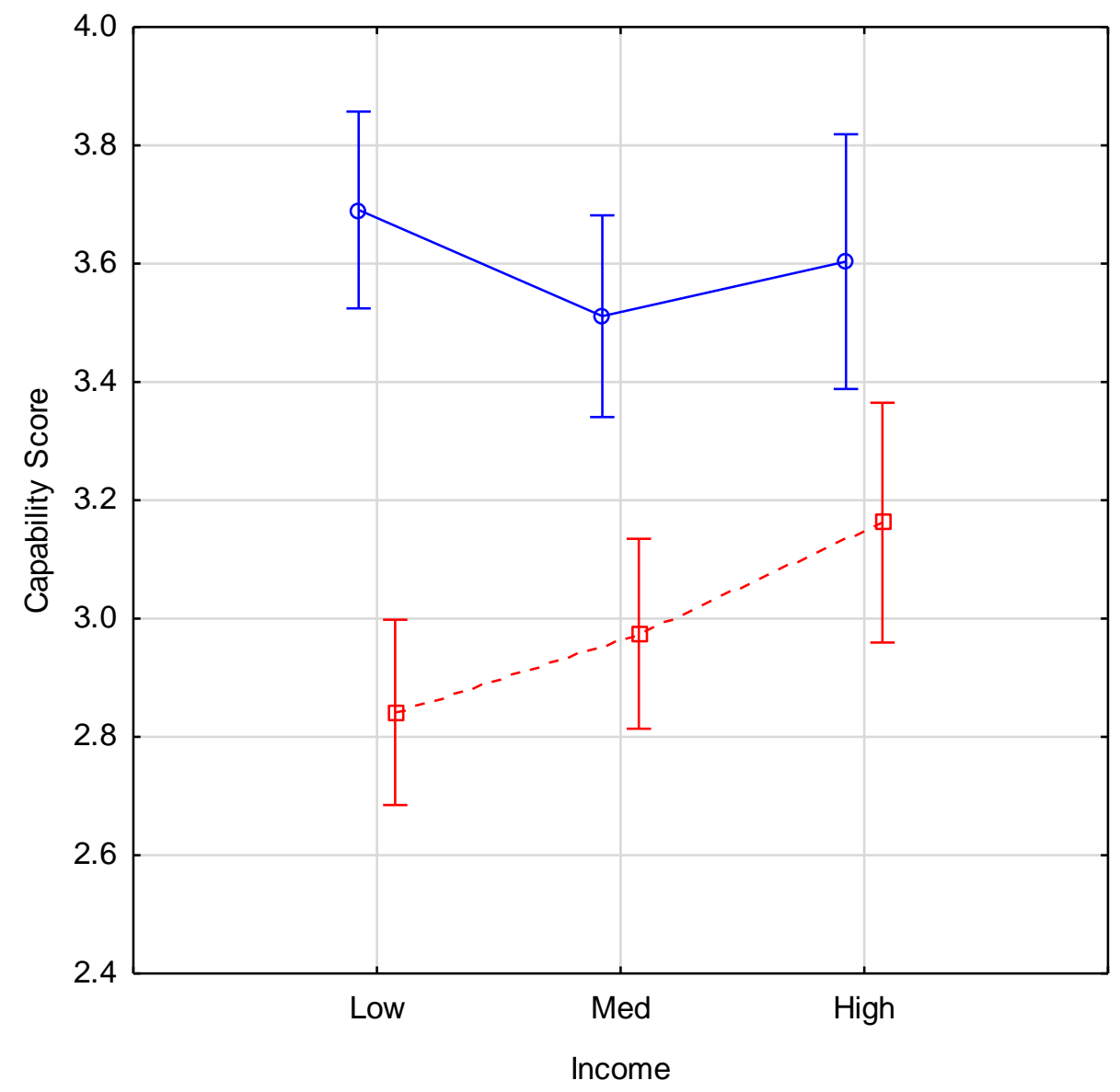

Choosing Products Management

Figure 3.1. the effect of income on choosing product and management.

Analysis of the interactions between financial literacy and the three explaining variables reconfirms the relationship between financial literacy and making ends meet. While the interaction between financial literacy and income is insignificant for all four financial capabilities $(p>.05)$, this change when income is controlled. When controlled for income, financial literacy shows a significant main effect for making ends meet $\left[F(1,152)=5.8876, p<.05 ; \eta_{p}{ }^{2}=.056\right]$, and a post hoc analysis reveals a meaningful difference among low-income participants $(p<.05)$. The results suggest that people with low income and high financial literacy are more likely to make ends meet compared to people with similar income but low financial literacy. Similarly, selfcontrol does not interact with financial literacy $(p>.05)$, yet again financial literacy shows a significant main effect on making ends meet when controlled for self-control $(F(1,160)=4.0616$, 
$\left.p<.05 ; \eta_{p}{ }^{2}=.025\right)$. Finally, Figure 3.2 presents a significant interaction between financial literacy and financial avoidance when using "making ends meet" the dependent variable $[F(1$, $\left.160)=4.8900, p<.05 ; \eta_{p}^{2}=.03\right]$. People who suffer from financial avoidance have trouble making ends meet regardless of their financial literacy, but financial literacy helps people with low avoidance. Other dependent variables show no similar interactions.

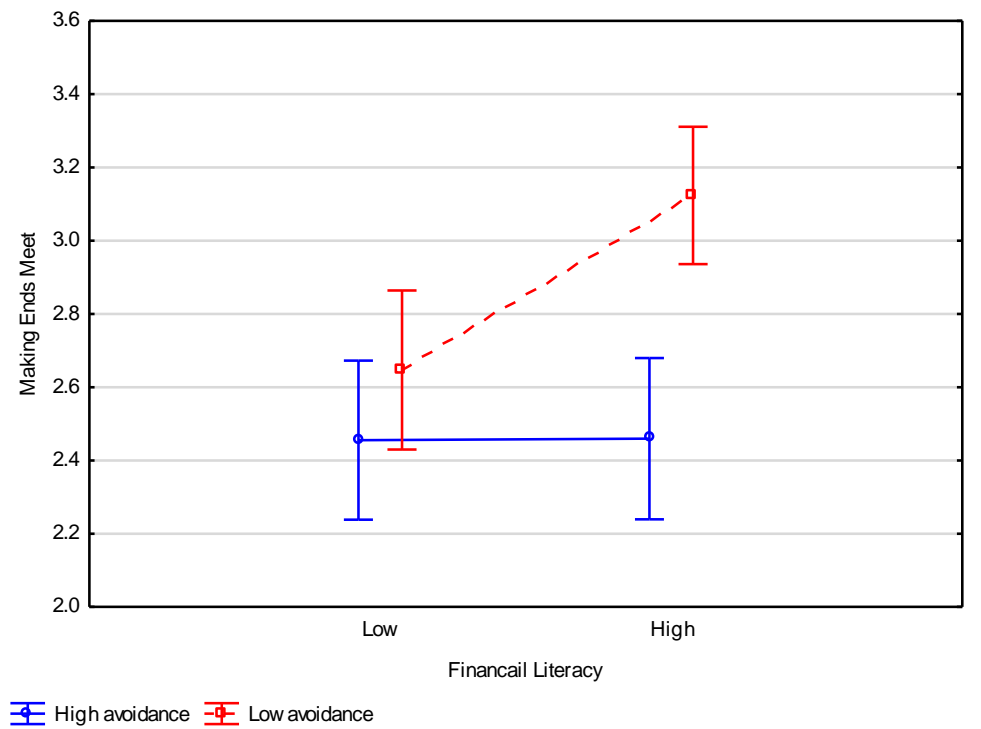

Figure 3.2 Interaction between financial literacy and avoidance

\section{Summary}

While most studies use knowledge to measure financial literacy, this study demonstrates that knowledge is not a sufficient indicator for financial skills. Clearly, the common research tools that focus on numeracy and familiarity with prominent economic concepts need to be complemented with explicit indicators of actual financial behavior. A regression model of the measurements of financial literacy and financial capability produced a fairly high predictive power of actual financial state, indicating the contribution of financial capability as a research tool for the investigation of financial behavior.

By further separating financial capabilities into four distinct dimensions, we can determine the boundaries of influence of financial literacy. As expected, personal features such as income, selfcontrol, and financial avoidance affect economic behavior more than does financial literacy, 
though knowledge does correlate with one particular economic domain, as financial literacy is associated with being a wise consumer.

This pattern of results is readily understandable when considering how resource depletion enhances the role of System 1 processing (Pocheptsova, Amir, Dhar, \& Baumeister, 2009). It results from differences in complexity and deferred gratification between the various financial capabilities we examined. A division of financial capabilities based on the level of complexity and deferred gratification (Table 3.1) enables to estimate the difficulty of a given financial task and to predict individuals' economic behavior. For instance, choosing products consumes relatively few mental resources and provides immediate gratification. Customers can, therefore, rely on their financial understanding and behave in accordance with their level of financial literacy. By contrast, tasks involving planning and managing money are often complex and gratification is delayed. Consequently, financial literacy does not play a meaningful role in those types of financial engagements.

Financial literacy was found to moderate the influence of three factors on the ability to make ends meet: low income, weak self-control, and financial avoidance. Two different interpretations suggest themselves. The first is that financial knowledge positively contributes to adequate financial behavior after all, albeit it only for one segment of the population, the one that is not precluded to benefit from it. The other interpretation would be that financial knowledge reflects certain skills or personal background that help people meet their financial obligations. For example, people from high socioeconomic background might receive financial support from an external resource, in addition to better education and modes of family socialization that increased their financial knowledge. Support for the second interpretation comes from the observation that financial literacy does not influence money management, but the question remains open for now.

The findings raise questions regarding the ability to support disadvantaged populations using financial education. Critics of the financial literacy approach claim that investments in financial education do not pay in terms of cost-effectiveness due to biases, heuristics, and human weakness (Willis, 2008; 2011). The current study presents a more complex picture, indicating that 
despite those flaws, financial literacy does have a significant relationship with selected economic behavior, namely simple activities that provide immediate gratification.

The CMEB model proposes a dual system theory as a framework to investigate financial literacy that enables us to recognize situations in which financial literacy would have a positive impact over behavior. The two-dimensional classification of financial capabilities enables separation between activities that are most affected by personal features, to other engagements that could be affected by knowledge. The results support with the proposed model. The negative effects of limited cognitive and mental resources leave low wage earners and people with limited selfcontrol to rely on habits and impulsive behavior rather than knowledge. However, findings should be interpreted with caution, due to the lack of instrumental variables or experimental setting that would enable us to determine a causal relationship between variables. For example, we cannot determine the direction of influence between avoidance and financial capabilities. Our model conjecture that financial avoidance leads to bad money management. However, an alternative explanation would argue that bad management creates negative financial dynamic and sense of financial distress which in turn makes costumers avoid thinking about their finance. 


\section{Chapter 4: The Influence of Financial Intervention}

So far, I have challenged the link between knowledge and behavior and proposed a way to explain why certain behaviors are less affected by financial knowledge using the dual system theory framework. In the following part of this work, I delve into the issue of financial education while focusing on a special case study - a unique and intensive intervention program aiming to help people who experience financial hardship. Unlike many programs that are knowledge concentrated, in this program each participant receives personal treatment; the program emphasizes the acquisition of new habits and encourages its members to change their behavior. The NGO who delivers the program has years of experience working with thousands of families and is regarded as the leading entity in the area of financial education in Israel.

The combination of intensive process, experienced organization, and personally tailored solutions brings hope that the intervention would have long-lasting positive influence. But the purpose of this research is not to conduct program evaluation in its classic form. Evaluation of program effectiveness requires certain conditions, especially the existence of an appropriate control group that would overcome the issue of selection bias (Cochran \& Rubin, 1973; Collins \& O'Rourke, 2010), and this was not available. While I do present data about changes in peoples' financial situation due to the program, lack of a randomized control trial $(\mathrm{RCT})$ and proper data for matching analysis forces me to be cautious with the interpretation of the general impact of the program. Instead, my work focuses on factors that influence behavior, and the data I have allows me to compare participants with different personal and demographic characteristics to determine who gains the most out of the intervention in the short and in the long run.

To make it easier to follow, I divided the study into two separate chapters. The first deals with the short-term outcome of the intervention and uses information regarding participants' financial condition and behavior before and after the intervention. This chapter focuses on the effect of financial constraints on participants' routes to recovery. It referred to the issue of resources depletion and scarcity only briefly and proposed two distinct paths for successful intervention, according to the household income. 
The next chapter tests the prediction of the CMEB model. Based on two follow-up surveys the study aims to determine the influence of self-control, financial avoidance, and financial difficulties on the long-term adoption of economic principles that were delivered at the intervention.

\section{Short-term effect of the financial intervention}

The "Paamonim" Households Training Program The study relies on data collected from participants in an intervention program delivered by an NGO named Paamonim. ${ }^{2}$ The intervention includes personal guidance and supervision by trained volunteer mentors. Each mentor works with one or two households who experience financial hardship. The mentors help them form a clear picture of their financial situation, take actions to improve it, advise on how to deal with outstanding debt, and how to plan for the future. The program has two objectives, to lead participants to financial recovery, and to develop their financial capabilities so they will act responsibly after the completion of the intervention (for a detailed description of the program see Appendix 4A).

Financial education and interventions are less effective for low-income populations for several reasons. They have limited margin of error, they are exposed to more financial shocks and job instability, and they have less financial experience and limited access to mainstream financial systems (Fernandes et al., 2014; Sherraden, 2013; Zhan, Anderson, \& Scott, 2006). In this part of the study, I compare participants' performance in the program based on their financial constraints in order to identify the determinants of the relative failure of low-income participants. I apply several statistical methods to learn how financial limitations affect participants' performance in the program. First, I compare low and high-income participants on different financial capabilities, including their ability to balance between income and expenses, changes in their earnings and expenditures during the program, and their perception of their financial situation. Later, I use cluster analysis to create four profiles of program participants that

\footnotetext{
2 Paamonim ("bells" in Hebrew) is the leading organization operating in the area of financial literacy in Israel. In 2010 the organization received the President's Volunteers Award for its contribution to society.
} 
take into account their financial characteristics at the beginning of the program and track their behavior and performance at the end of the program.

Finally, I use the data to test a specific prediction of the theory of financial scarcity. According to Mullainathan and Shafir, financial constraints create tunneling - paying attention to the most pressing needs while losing a broader perspective. This effect often makes people better consumers since they compare prices more carefully, reduce impulsive consumption, and keep track of their expenditures (Shah et al., 2012). Based on the tunneling effect I hypothesize that at the beginning of the program, participants with severe financial difficulties would get higher scores in consumption than other members of the program. I do not expect to find the same pattern at the end of the program, due to the influence of the intervention.

\section{Population and data}

The information used in this study consists of two types of data:

1. Administrative data. The organization collected the data during the program, including demographic and financial information on 6499 participants who participated in the intervention between 2011 and 2015 (with the exclusion of 2012, for which data was unavailable due to technical issues). In order to overcome inaccurate records and typing errors, I conducted Grubbs' outlier test. I excluded records that did not cover all the information about the participant's income and expenses and those concerning participants who completed less than three sessions during the program. The final dataset contained information on up to 3,645 households, a number that varies among different variables.

2. Financial capability surveys. Data includes 432 surveys that were taken by participants before $(N=251)$ or after $(N=181)$ the program.

\section{Measurements}

Socio-Economic ranking for Councils and Municipalities [SECM]. SECM is an index that ranks 255 localities based on multiple variables, covering the subject of demography, education, 
employment, regional average income, and standard of living (CBS, 2012). The index was constructed by the Israel Central Bureau of Statistics and is equivalent to commonly used socioeconomic measurements, often named SES or SEIFA. ${ }^{3}$ The socio-economic ranking is related to health, financial behavior, academic achievement, mortality rate, parental habits, and other domains not directly related to income, and is often considered as an indicator of the influence of culture and environment (Duflo, 2006; Jaffe, Eisenbach, Neumark, \& Manor, 2005; Sirin, 2005).

Financial indicators. The financial information was collected by Paamonim. Data includes income, expenditures, and debt. To calculate the Equivalent household income, I used the "square root scale", which divides household income by the square root of household size (Forster, Chen, \& Llenanozal, 2011).

Proportional Gap between Income and Expenses. A proportional gap [PG] index indicates the financial difficulties of the participants while eliminating income differences between them. The index conveys the relative disparity between income and expenses by calculating the net monthly balance for each household, divided by the household's monthly income, and multiplied by 100 :

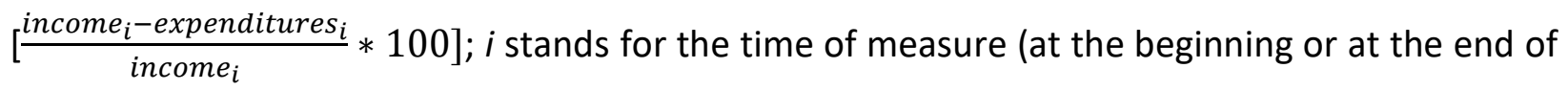
the program). The two new variables were named PGB [Proportional Gap Beginning] and PGE [Proportional Gap End].

Financial capability survey. The survey was developed by the organization and was divided into three categories using factor analysis: "management" - budgeting, short- and long-term preparations, and keeping track of records; "consumption" - performing wise and informed consumption behavior; "competence" - a sense of competence in one's ability to manage one's financial affairs. (For details on the survey and factor analysis, see Appendix 4B.)

\section{Results}

Participants in the program have diverse backgrounds. Mean age of the participants according to the database is 39 ( $S D=9.25)$, ranging from 17 to 88 . Most households are married couples (69

\footnotetext{
${ }^{3}$ For more information about the development of the SECM see the following link to the CBS Israel website: http://www.cbs.gov.il/reader/?MIval=cw_usr_view_SHTML\&ID=446
} 
percent), 23 percent are divorced or separated from their spouse, and the rest are singles or widowed. Each household has 2.6 children on average, and the mean monthly income per household is 13,967 ILS (SD=5558ILS), close to the income of the general population in Israel (CBS, 2013). Income distribution of program participants shows misrepresentation of the lowest and the highest income deciles compared to the general population (see Appendix $4 \mathrm{C}$ ). Twelve percent of the households were labeled as dropouts and excluded from the rest of the analysis since they attended fewer than three meetings during the treatment.

\section{Changes in Financial Capability}

Assessments of participants' financial capabilities show a meaningful improvement by the end of the intervention (Table 4.1). To test the assumption that financial scarcity would make people focus on consumption before the program, I ran two analyses, one that uses equivalent income as a proxy for financial scarcity, and another that uses financial shortfall - the proportional gap between income and expenses, while holding debt constant - to measure scarcity.

Table 4.1. Financial capability scores at the beginning and at the end of the program. Between-group design.

\begin{tabular}{|c|c|c|c|c|}
\hline & $\begin{array}{l}\text { Begin } \\
(n=251)\end{array}$ & $\begin{array}{l}\text { End } \\
(n=181)\end{array}$ & F-value & $\begin{array}{l}\text { Partial eta } \\
\text { squared }\end{array}$ \\
\hline Management & $2.45(.80)$ & $3.41(1.01)$ & 119.9* & .21 \\
\hline Competence & $2.36(.89)$ & $3.18(.96)$ & $84.4^{*}$ & .14 \\
\hline Consumption & $3.29(.88)$ & $3.78(.85)$ & $33.5^{*}$ & .07 \\
\hline
\end{tabular}

A median split of equivalent income shows that in line with my expectation, high-income participants received lower scores in consumption before the program $(F(1,102)=4.2531, p<.05$; $\left.\eta_{\mathrm{p}}{ }^{2}=.04\right)$, comparing to low-income participants. No similar differences were found in the management category. Again as expected, the two income groups did not differ in either 
management $(F(1,102)=1.14, p>.05)$ or consumption $(F(1,102)=0.001, p>.05)$ at the end of the intervention.

Evaluation of behavioral changes based on differences between income and expenses show similar findings with stronger effects. Participants who suffer from high shortfall received a higher score in consumption before the program comparing to low shortfall participants. A Multivariate GLM analysis (MANCOVA) that used PGB as a grouping variable, and consumption and management as dependent variables, while controlling for the household's total debt, revealed a significant multivariate main effect for categorical PGB $[F(2,99)=4.332, p<.05$, partial eta squared $=.08$, Wilks' $\lambda=.919$ (power to detect the effect was .740)]. Analysis of univariate effects indicates a significant main effect of shortfall for consumption, $F(2,99)=6.148, p<.015, \eta_{p}{ }^{2}$ $=.058$, power $=.689$; but not for management, $F(2,99)=0.59, p>.05, \eta_{p}^{2}=.005$, power $=.11$. The left panel in Figure 4.1 shows the differences between the groups in all three financial capabilities before the program. As one would expect, individuals with a lower gap between income and expenses also display better competence $\left[F(1,100)=4.577, p<.05 ; \eta_{p}{ }^{2}=0.04\right]$.

These findings contrast with a parallel Multivariate GLM analysis (MANCOVA), this time with shortfall at the end of the program (based on PGE). This time no difference was observed between the two shortfall groups after the program, $\mathrm{F}(2,127)=1.348, p>.05, \eta_{\mathrm{p}}{ }^{2}=.02$, Wilks' $\lambda=.97$, power $=280$. (Univariate analyses were of course not significant, $p>.05$ ). (See the right panel in Figure 4.1.) 

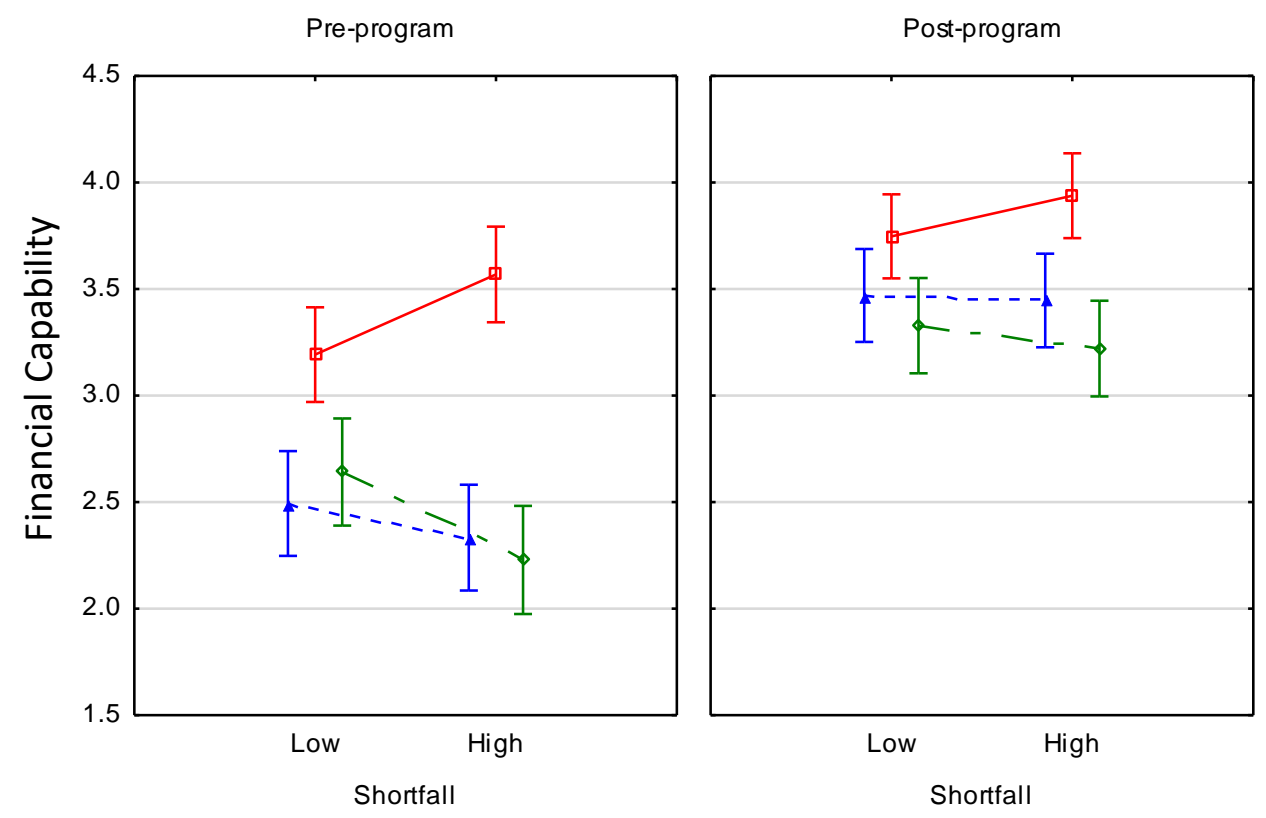

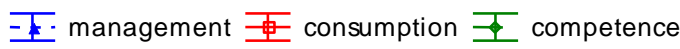

Figure 4.1. Financial capability scores at the beginning (left graph) and at the end (right graph) of the program. Covariate means debts: 79220.8 Between-group design.

\section{Comparison of financial indicators before and after the program}

Comparison of the gap between income and expenses at the beginning and at the end of the intervention indicates a dramatic change in participants' ability to balance their expenditures. The participants $(N=3488)$ moved from a negative gap of -783 ILS (SD=3261) [222 USD] at the beginning of the program, to a positive difference of +841 ILS (SD=4051) [239 USD] at the end of the intervention. A one way repeated measured ANOVA confirmed a significant difference between the groups $\left[F(2,3489)=204.90, p \leq .00001, \eta_{p}{ }^{2}=-.105\right]$.

The program impact was also reflected in the Proportional Gap (PG) variable that eliminates the effect of income differences. The analysis shows a significant difference between participants' $P G$ at the beginning (PGB; $M=-8.78, S D=29.01$ ) and at the end $(P G E ; M=1.42, S D=29.09)$ of the program. Again, a one way repeated measured ANOVA confirmed a significant difference between the groups $\left[F(2,3503)=182.63, p<.0001 ; \eta_{p}{ }^{2}=-.09\right]$. 
A GLM analysis that includes income, adjusted debt, and SECM, uncovered the effect of demographic variables. The dependent variables, PGB and PGE, indicate participants' ability to cover their expenses at the beginning and at the end of the intervention, respectively. In order to determine the influence of demographic variables on the gap between income and expenditure at the end of the program (PGE), two models are presented. Both models use the same PGE as a measure of success but contain different independent variables. In the first model [PGE $]$ PGE is predicted by participants' income when they entered the program, and debt is adjusted according to their initial income; in the second model [PGE 2 PGE is predicted by participants' income when they completed the program, and debt is being adjusted according to income at the end of the intervention (Table 4.2). The reason for the two models is that income and debt change dramatically during the intervention.

Table 4.2. Regression analysis of three dependent variables: PGB, PGE1, PGE2.

\begin{tabular}{|c|c|c|c|c|c|c|}
\hline & & & DepeI & Variable & & \\
\hline & $\begin{array}{c}\text { PGB } \\
\text { Beta (ß) }\end{array}$ & $\begin{array}{c}\mathrm{PGB} \\
p\end{array}$ & $\begin{array}{c}\mathrm{PGE}_{1} \\
\text { Beta (ß) }\end{array}$ & $\begin{array}{c}\mathrm{PGE}_{1} \\
p\end{array}$ & $\begin{array}{c}\mathrm{PGE}_{2} \\
\text { Beta (ß) }\end{array}$ & $\begin{array}{c}\mathrm{PGE}_{2} \\
p\end{array}$ \\
\hline Intercept & & $.000 * *$ & & .93 & & $.000^{*}$ \\
\hline $\log S E C M$ & -.042 & $.032^{*}$ & .004 & .858 & -.07 & $.000 * *$ \\
\hline $\begin{array}{l}\text { Log Equivalent } \\
\text { Income Beginning }\end{array}$ & .345 & $.000^{* *}$ & .001 & .710 & & \\
\hline $\begin{array}{l}\text { Log Equivalent } \\
\text { Income End }\end{array}$ & & & & & .336 & $.000 * *$ \\
\hline Adj. Debt Begin & -.136 & $.000 * *$ & -.121 & $.000 * *$ & & \\
\hline Adj. Debt End & & & & & -.18 & $.000 * *$ \\
\hline Observations & & & & & & \\
\hline Multiple $R$ & & & & & & \\
\hline Adjusted $R^{2}$ & & & & & & \\
\hline$F$ & & & & & & \\
\hline
\end{tabular}


The SECM and the equivalent income variables were adjusted using a log2 transformation, in order to keep the assumption of normality. The adjusted debt was calculated as the proportion of households' equivalent income and the sum of debt. Since debts were reported only at the beginning of the program, we recalculated the adjusted debt for the second PGE analysis according to the income at the end of the program, assuming that the debts are likely to be treated equally among all program participants. ${ }^{*} p<.05 ;{ }^{* *} p<.001$.

Results show that SECM and income of the participants when entering the program can predict their ability to balance between income and expenses at the beginning [PGB], but not at the end $\left[\mathrm{PGE}_{1}\right]$ of the intervention. Debt, on the other hand, does impact the outcome of the program, showing that the program is less effective for participants with very high debt. $\mathrm{PGE}_{2}$ shows that the ability to attain financial balance is predicted by households' income at the end of the intervention, suggesting that in order to escape their troubles, low-income participants need to increase their earning, management skills are not enough.

The importance of income is evident from an analysis of the ratio between income before and after the program. The analysis reveals a remarkable change in participants' earning due to the intervention, and the differences between income groups are significant $[F(3,3585)=83.43, p=$ $0.0001 ; \eta_{p}^{2}=.07$ ] - low-income participants increased their earnings by close to 30 percent, while those of the wealthiest participants remained relatively stable. In contrast, low-income participants hardly changed their expenditures, whereas the high-income group cut their expenses significantly $\left[F(3,3646)=3.8955, p<.05 ; \eta_{p}{ }^{2}=.001\right]$. Figure 4.2 presents the ratio of income and expenses before and after the intervention.
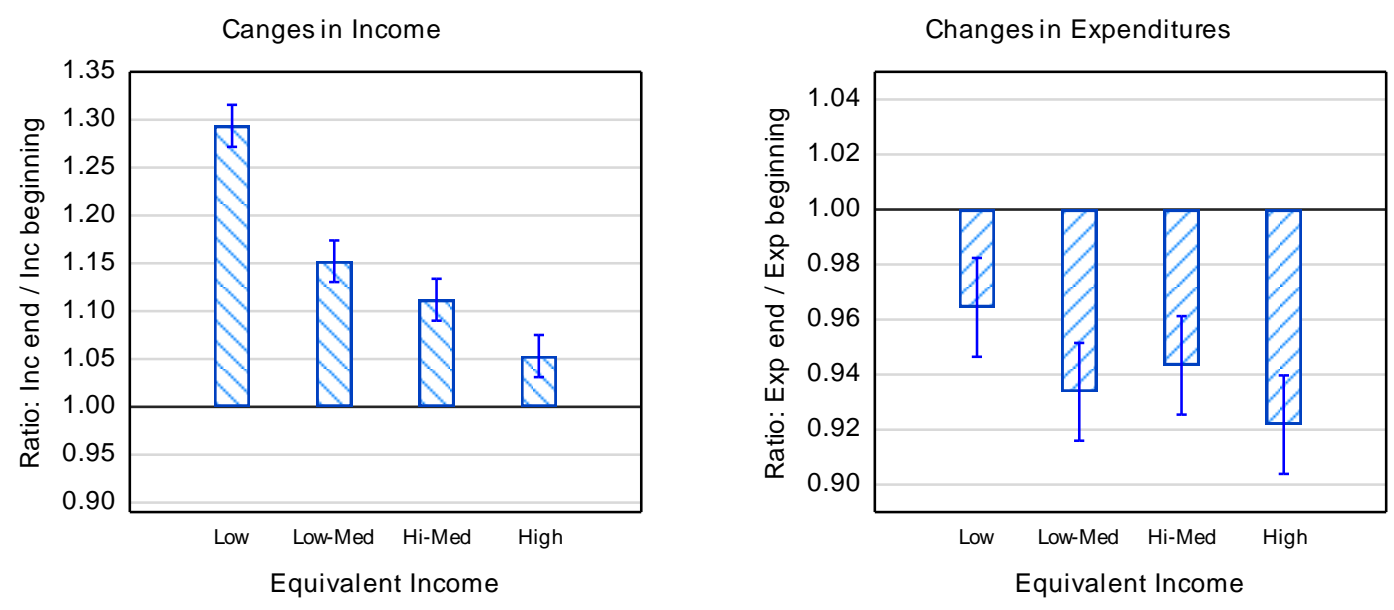
Figure 4.2. The ratio between financial indicators before and after the program According to the left graph, the lowest-income participants increased their earnings by 29 percent (ratio $M=1.29, S D=0.44$ ), while highincome participants show a moderate increase of 5 percent (ratio $M=1.05, S D=0.27)(N=3589)$. The right graph shows expenditures changes, indicating that the low-income group had on average a 4 percent decrease in their expenditures (ratio $M=0.96, S D=0.29$ ) compared to 8 percent decrease among the highincome group (ratio $M=0.92, S D=0.28)(N=3650)$.

The analysis reveals the different paths participants need to follow during the intervention. Low-income participants need to increase their earnings, while high-income participants need to learn how to control their expenditures. The program encourages low-income participants to work more hours or take another job, resulting with a monthly increase of 1381ILS [243 USD] in earnings from secondary occupations among this group. On the other hand, high-income participants show a moderate decrease in earnings [-158ILS, close to 54USD]. The differences between income groups are significant $[F(3,374)=4.3090, p<.05]$ and point to a major obstacle for long-lasting financial recovery among low-income populations - maintenance of a demanding routine that includes working in two jobs for a long time.

A nice demonstration of the different features of low and high-income participants comes from their estimations of financial difficulties before the program. When signing up for the program, participants were asked to report their income, expenses, and debts. Those reports, named "perceived financial state", indicate participants' knowledge about their personal finances, and could be compared with their real financial situation based on data that was collected by the mentors at the beginning of the intervention. A wide gap between "perceived" and "actual" reports implies misperception of financial situation. As seen in Figure 4.3, participants from all income levels underestimated the gap between their income and expenses. However, while the two lowest income groups reported a negative gap between income and expenses, the two highest income groups reported a positive difference. By contrast, no comparable differences between the income categories were found regarding the estimated and actual debts ( $F(1$, $1563)=.88593, p<.05)$. 
Gap betw een Income and Expenses

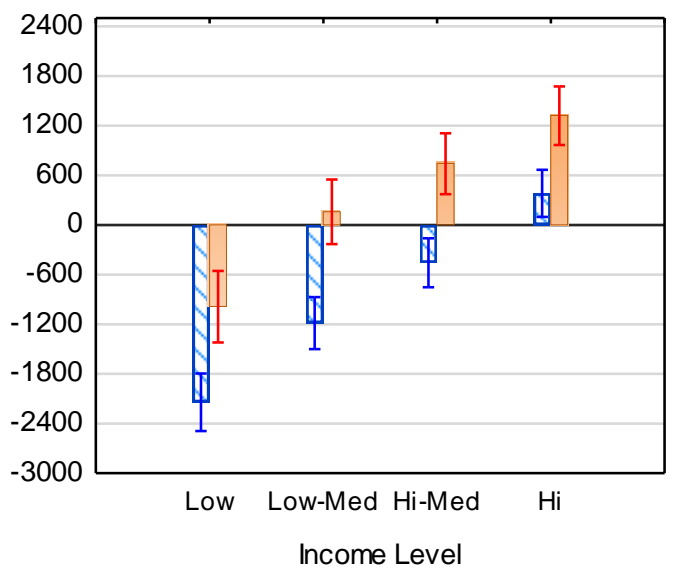

Actual Gap/Debt

Perceived Gap/Debt

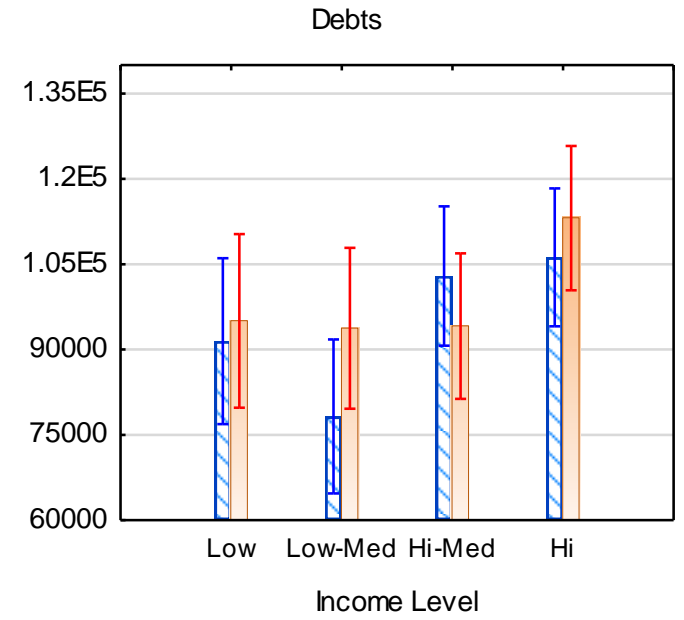

Figure 4.3. The left graph shows the differences between perceived and actual gap between income and expenses among four equivalent income groups $(N=1413)$. The right graph presents differences between perceived and actual debt among the same four groups ( $N=1747)$.

The findings suggest that while high-income participants are aware of their debt, they do not relate their financial troubles with their daily financial practices, mistakenly believing that they are actually saving money each month. The reflection of their financial behavior during the intervention forced them to confront their habits and to cut-down their expenses.

\section{Cluster Analysis}

The next part uses a different statistical approach to explore the determinants of the intervention's outcomes. Using K-means cluster analysis, I created four distinct profiles of participants on the basis of their initial income, the gap between their income and expenses, their debt, and the final outcome of the intervention. The $K$-means algorithm is a partitioning technique that creates $\mathrm{K}$ distinguished groups out of a large set of data. The analysis aims to minimize variability within clusters while maximizing variability between clusters.

The variables used for the analysis were equivalent income, adjusted debt, PGB, and PGE. Despite intercorrelations between the variables, each of them indicates a different aspect of participants' 
financial situation. Income indicates the financial resources of the participants; debts indicate liabilities; PGB - the ability to cover expenses before the program, and PGE the ability to do so at the end of the intervention. Unfortunately, the data does not contain Information about savings, assets, investments, or other types of accumulated wealth. Data was converted into Z-scores before the analysis to compare variables' scales.

Table 4.3 shows means and standard deviations of each cluster, and a one-way ANOVA confirms that the differences between clusters for all the indices are highly significant $(p<.00001)$. The four profiles describe the realm of influence of the program. The debt-ridden, who face outstanding debts, gained nothing from the intervention, indicating that this type of problem cannot be solved by the program. The stretched disorganized represents the typical participant ( $N=1545 ; 54$ percent of the sample) who struggles with moderate debt and is unable to save money $(P G B=0)$. As shown by the positive and high $P G E$, the program does a fairly good job helping such cases. The good earners hold a high salary and do not carry severe debts. Members of this group have a comfortable starting point and are likely to complete the program successfully and to attain financial balance. The low earners are doing badly at balancing between income and expenses before the program but haven't accumulated high debt. At the end of the program their PGE is 0 , indicating that they are able to cover their expenses, but still face financial fragility in case of unexpected expenditure. For a graphic illustration of the four profiles see Figure 4.4 .

Table 4.3. Means and standard deviations (in parentheses) of the income, debt, PGB, and PGE for each cluster.

$\begin{array}{lccccc}\begin{array}{l}\text { Cluster } \\ \text { sample }\end{array} & \begin{array}{c}\text { Equivalent } \\ \text { Income }\end{array} & \begin{array}{c}\text { Adjusted } \\ \text { Debt }\end{array} & \text { PGB } & \text { PGE } \\ \begin{array}{l}\text { Debt-ridden } \\ \text { Stretched disorganized }\end{array} & 54 & 6591(1482) & 5(5.1) & 0(15.7) & 9(17.6) \\ \text { Good earners } & 20 & 11702(2774) & 4(4.5) & 5(18) & 6(21.2) \\ \text { Low earners } & 15 & 5106(1629) & 6(7.1) & -51(30.8) & 0(21.8)\end{array}$




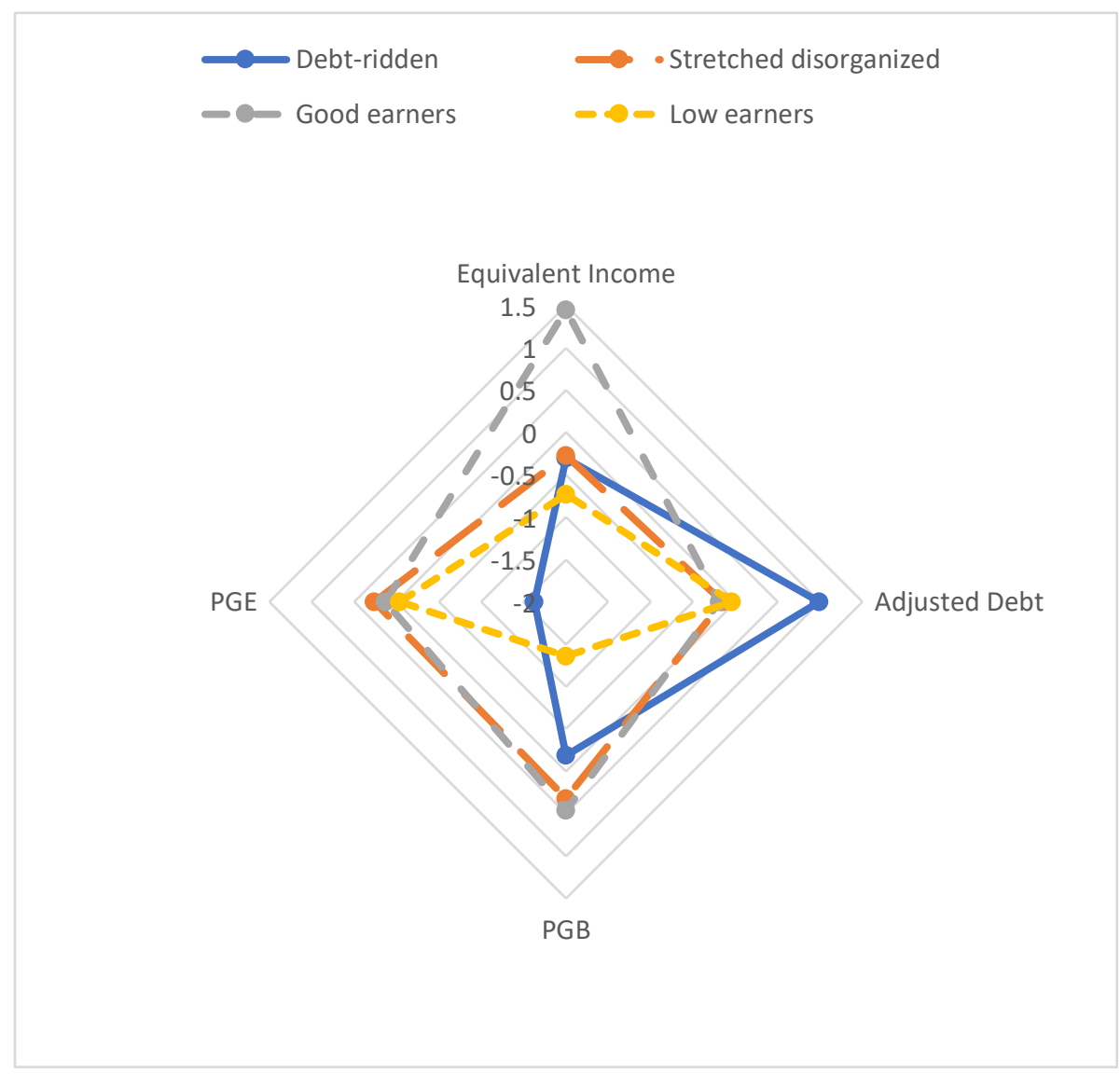

Figure 4.4. Graphic illustration of the four clusters.

The analysis enables setting the upper bound of the intervention. While most participants can balance between income and expenses at the end of the intervention, members of the "Debtridden" group are far from financial recovery. Their debts place a heavyweight over their shoulders and prevent a successful intervention, resulting with a negative PGE of 1.5 standard deviations below the total average of the sample. The average ratio between monthly equivalent income and debt in this group is 18 , which means that their debt equals a year and a half annual salary. The recognition of "untreatable" participants enables the NGO to take specific measures and to reassess their assets allocation for special cases to increase productivity.

Members of the four clusters differed in their demographic features. More than 60 percent of the "Good earners" live in Israel's' Center district and in the Tel-Aviv area, which is characterized 
by high SES (see Figure 4.5). In contrast, "Debt-ridden" and "Low earner" participants live in the peripheral parts of the country and in Jerusalem county, characterized by less wealth and more financial difficulties. Comparing with other program participants, the "Good earners" are also older ( $M=41.3)$ and have smaller family size $(M=3.3)$.

The differences between clusters reflect in their treatment. Treatments of participants from the "Low earners" group are longer (11.7 months vs. 10.6) and include more meetings (10.5 vs. 9.6) than treatments of other members in the program (all differences are significant at $p<.00001$ level). They have increased workplace participation from an average of 1.55 workers per household to 1.62, while members of the "stretched disorganized" and the "good earners" groups kept a stable level of 1.73 workers per household during the intervention. Surprisingly, "debt-ridden" participants significantly reduced workplace participation from 1.71 to an average of 1.57 workers per household at the end of the intervention $(p<.00001)$. 


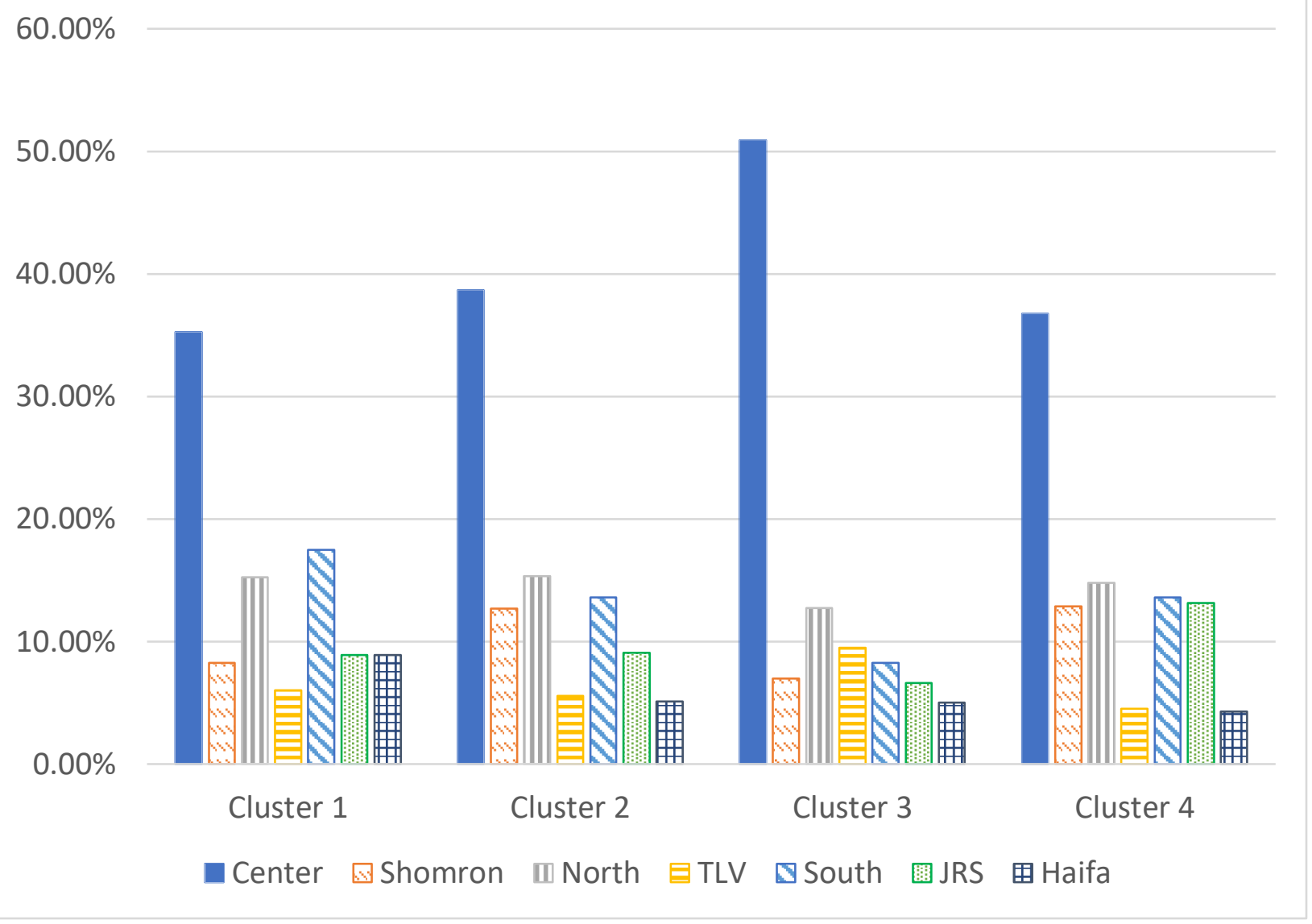

Figure 4.5. Clusters' demographic distribution of program participants.

\section{Discussion}

The current chapter analyzed the influence of a financial intervention program aiming to help people who face financial hardship. Using a wide range of measurements and indicators, the analysis provides a clear picture of the way different populations are affected by the intervention, and the specific challenges each group is facing.

The findings support the sometimes-positive effect of financial constraints. Highly financially constrained individuals demonstrated cautious consumption prior to the program due to the tunneling effect. Interestingly, when financial pressure was measured as a gap between income and expenses the effects were stronger compared to an income-based analysis. The finding supports the pertinence of the definition of scarcity as the "gap between one's needs and the 
resources available to fulfill them" (Mani et al., 2013), instead of a supposedly more objective evaluation that is based on income.

A comparison of income and expenses at the beginning and at the end of the intervention reveals two "paths to recovery". High-income participants entered the program with little awareness of their real financial situation, and report that their income is significantly higher than their expenditures. For them, a reflection of their financial situation was an effective motivator to make a real change and to develop management skills, resulting in a significant cut in expenses. In contrast, for the low-income participants who can barely cover their basic needs, development of financial capabilities is not the solution. For them, cutting expenses, monitoring of their bank account, and planning are a necessary yet not sufficient aspect of the process. Rather, it was the increase in their income that helped them to restore financial balance, as low-income participants who completed the program had an outstanding 28 percent growth in households' earnings. This increase did not happen by accident. One of the organization's main Key for Success is an increase in households' earnings. The striking differences between the income groups shed light on the different challenges each group has to face on its way to recovery.

An analysis that focuses on several variables that influence the outcome of the intervention shows that the program can bridge environmental effects and is effective for people from diverse backgrounds. Nevertheless, a cluster analysis that creates distinctive profiles of participants reveals a robust negative effect for outstanding debt. Participants with a very high debt to income ratio were the least likely to recover. In a similar vein, low-wage participants with a manageable debt were able to attain financial recovery but had a small margin of error that might put them at risk of relapse.

The analysis set the upper bound of financial intervention. While it could be very effective in changing a negative financial dynamic, its ability to help people who carry a substantial financial burden is restricted. Moreover, the rapid increase in low-income participants' salary raises questions regarding their feasibility to preserve the change. The program relies on mentors that work closely with the families and are "... required to use both economic and emotional skills. To be sensitive and empathetic but also systematic and targeted in the rehabilitation process of the family ..." (from Paamonim Website). The mentors guide and support the family during the 
process, explain to them how to exhaust entitlements and push them to make a career change or to work more hours. Their presence alone can lead to a dramatic shift in the family financial state. Unfortunately, if the intervention's contribution for low-income populations relies on personal assistance, it might be less effective in the long run. A close to thirty percent increase in earnings during several months of treatment suggests that participants are working at full capacity. Just like a crash diet, this type of lifestyle has an expiration date. At the end of the program, the families are back on their own, without the mentor's support and encouragement, and are at risk of slipping into a new cycle of arrears, loans, and debts. The next chapter looks at the long-term effect of the intervention to find whether the change is sustained. 


\section{Chapter 5: Long-term Effects of Financial Intervention}

The current chapter focuses on the long-term influence of financial intervention and proposes a dual system theory-based mechanism to explain the economic behavior of program graduates several years after the intervention. The assumed long-term impact of the program is grounded in the CMEB model, which proposes that depletion of mental and cognitive resources reduces the likelihood of conduction knowledge-based financial behavior. In addition, I propose that the knowledge has a weak influence on complicated financial engagements that provide deferred gratification instead of immediate rewards. Therefore, I conjectured that people who face depletion of mental resources would be less likely to apply complex knowledge acquired during the intervention.

Study 1 - Follow-up survey

The first study tests the impact of financial shortfall and of two psychological factors - self-control and neuroticism - on long-term adoption of financial practices. As we saw, scarcity has been shown to produce cognitive load that makes individuals focus on their most urgent needs and to adopt a narrow perspective regarding their finances (Mani et al., 2013; Shah et al., 2012). I proposed earlier in this work a distinction between financial activities based on task complexity and timely gratification. Since lack of financial resources is believed to create cognitive load and myopia, I expect to find a strong influence for shortfall on management and planning practices, which are complicated activities that provide only long-term revenue. I do not expect to find the same influence on adoption of wise consuming habits, which are less complicated and provide an immediate financial reward. The current study is an opportunity to test these predictions in a field setting while uncovering the influence of financial shortfall on the long-term outcome of the intervention.

Self-control positively influences achievements in educational programs and is related to better consumer behavior, superior financial management, adequate retirement preparation, and high credit scores (Baumeister, 2002; Hastings \& Mitchell, 2011; Israel et al., 2014; Mischel, 2014). 
Yet, the interaction between self-control and financial shortfall is unclear. Vohs (2013) and Loibl (2017) label the theory of financial scarcity as part of the limited-resource model of self-control (Baumeister, Vohs, \& Tice, 2007; Muraven \& Baumeister, 2000), claiming that financial burden leads to a mental fatigue that creates ego-depletion. While a lively debate has recently arisen around this model (Inzlicht, Schmeichel, \& Macrae, 2014), the general idea that self-regulation is expected to be exhausted over time appears to be generally accepted. Nevertheless, it is unclear how people with high self-control react to situations that create ego-depletion. Some researchers argue that people with self-control do not develop resistance to those types of situations and that self-control may even lead to adverse effects in some cases (Ent, Baumeister, \& Tice, 2015; Imhoff, Schmidt, \& Gerstenberg, 2014). Study 1 examines the interplay of financial difficulties and self-control. It does so by looking at their effects on different dimensions of financial behavior.

The second psychosocial variable tested in this study is neuroticism, which is described as "the tendency to experience negative, distressing emotions and to possess associated behavioral and cognitive traits" (Costa \& McCrae, 1987), and is related to stress, anxiety, and negative emotions (Muris, Roelofs, Rassin, Franken, \& Mayer, 2005). Studies relate neuroticism with temporal discounting and short-sightedness (Lee, Kelly, \& Edwards, 2006; Whiteside \& Lynam, 2001); thus, it is reasonable to expect that high level of neuroticism leads to poor management behavior but does not influence wise consuming behavior. Neuroticism is a stable personality trait; hence it can point to a causal relationship between negative emotions and economic behavior.

The study also tests the relation between financial literacy and the outcome of the intervention.

\section{Data and measures}

Paamonim, the training NGO, sent emails to 940 graduates of the program, who had completed the program 2-4 years before, inviting them to participate in an academic study. Participants were sampled based on the area of residence and income to produce a distribution similar to the target population. Participants were rewarded with a 50 ILS (= 15 USD) coupon.

The 121 respondents who agreed to participate in the study received a phone call with general explanations about the study, followed by a link to an online survey. This survey, completed by 
98 individuals, contained questions regarding their current financial situation, financial habits, and general attitude toward the program. A week later, respondents took another survey that included questions related to self-control [SC], personality traits, and financial literacy. Eightyeight people completed the second survey (a 10 percent drop-out rate). Appendix 5A describes the distributions of income and residential area of the sample, indicating a great similarity to the target population.

\section{Independent variables}

The survey contained two assessments of financial shortfall. The first measure is based on respondents' reports of income and expenses in the past month. Based on the proportional differences between income and expenditures, a median split yielded two levels of financial shortfalls: high shortfall $(P G=-15.6, S D=15.19)$ vs. low shortfall $(P G=14.59, S D=11.26)$.

The second financial shortfall measurement is based on respondents' subjective assessment of financial difficulties based on the question: "How would you define your current financial situation on a 1-5 Likert scale? (1-very bad; 5-very good)". Respondents were then divided into three categories of shortfall (1-2 = high shortfall; $3=$ medium shortfall; $4-5=$ low shortfall).

To distinguish between the two types of financial shortfall, I labeled the first measure "calculated shortfall" and the second measurement "reported shortfall".

Self-control was assessed by the Brief SCS, a 13-item measurement developed by Tangney, Baumeister, and Boone (2004). Two questions from the BFI-10, a short version of the widely-used BFI-44, were used to evaluate neuroticism (Rammstedt \& John, 2007).

Financial literacy was determined by six questions regarding basic economic knowledge, such as inflation, compound interest, and insurance. The questions were taken from Lusardi and Mitchell (2007) and from Carmel, Carmel, Leiser, and Spivak (2015).

\section{Dependent variables}

Financial capability survey. The survey is identical to the one reported in Chapter 4 and contains three categories: "management" - budgeting, short- and long-term preparations, and keeping 
track of records; "choosing products" - performing wise and informed consumption behavior; "competence" - a sense of competence in one's ability to manage one's financial affairs.

Z-scores. In order to overcome biased reports due to extreme response styles, the raw scores of each respondent were converted into z-scores. This technique provides values that reflect the respondent's relative performance in the different domains (Brinker, 2002).

\section{Results}

\section{Program Long-Term effect - General}

As mentioned in Chapter 4, participants showed a dramatic improvement in their ability to cover their expenditures and pay their debts by the end of the intervention. However, a couple of years after the program, participants were not able to keep the same level of thriftiness, and had a small negative proportional gap between income and expenses $(M=-2.4 ; S D=20.38)$. A one-way ANOVA followed by post hoc comparisons of the pre, post, and long-term proportional gaps between income and expenditures [PG] shows a significant difference at all three-time points $\left[\mathrm{F}(2,7413)=180.15, p<.001 ; \eta_{\mathrm{p}}{ }^{2}=.03 ;\right.$ Post-hoc: $\left.p<.05\right]$.

The ability to balance between income and expenses several years after the intervention is explained by household income. Figure 5.1 shows the percentage of respondents who reported that their earnings exceeded their spending in the month prior to the follow-up survey. A oneway ANOVA shows a significant main effect for household's equivalent income, even when debt is held constant $\left[F(3,87)=3.8898, p<.05 ; \eta_{p}{ }^{2}=.12\right]$. Post-hoc comparison shows that the two lowincome groups were less likely to balance their income and expenses than the two high-income groups $(p<.05)$. Measure of subjective perception of financial state produced the same result low-wagers rated their financial situation to be worse, compared to high-income respondents $\left[F(3,87)=3.0172, p<.05 ; \eta_{p}{ }^{2}=.09\right]$. 


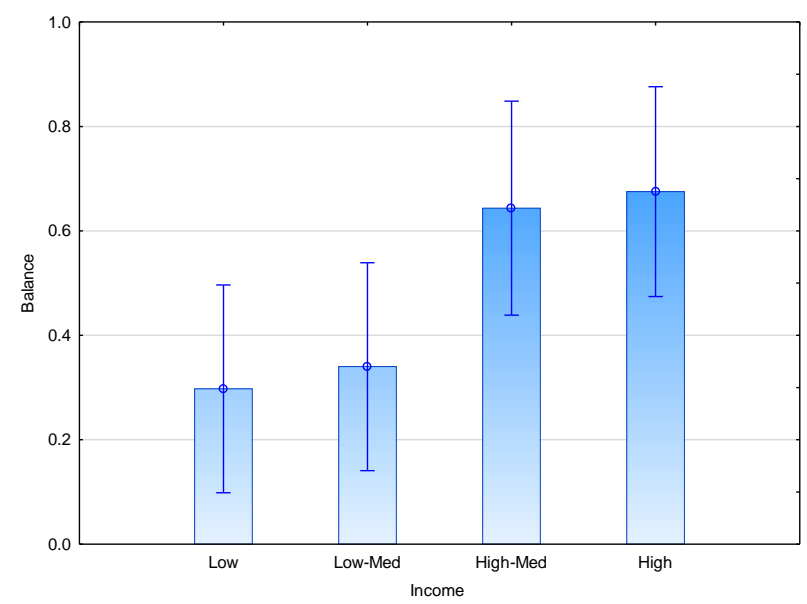

Figure 5.1. The percentage of respondents who reported that their earnings exceed their spending in the month prior to the survey. Income-based split. Debt held constant, covariate debts sum: 85190.77.

\section{The Effect of Financial Shortfall on Financial Capabilities}

Evaluation of financial capabilities a few years after the intervention shows a decline over time, especially in the management and confidence categories, although scores were high compared to the pre-program evaluation (see Table 5.1. and Figure 5.2.).

Table 5.1. Financial capability over time. Between-group design (total $\mathrm{N}=527$ ).

$\begin{array}{llllll} & \text { Begin } & \text { End } & \text { Follow-up } & \text { F-value } & \text { Partial eta- } \\ & (\mathbf{n = 2 5 1 )} & \mathbf{( n = 1 8 1 )} & \mathbf{( n = 9 5 )} & & \text { squared } \\ \text { Management } & 2.45(.80) & 3.41(1.01) & 3.23(.83) & 119.9^{*} & .21 \\ \text { Competence } & 2.36(.89) & 3.18(.96) & 2.92(.92) & 84.4^{*} & .14 \\ \text { choosing products } & 3.29(.88) & 3.78(.85) & 3.87(.66) & 33.5^{*} & .07\end{array}$

$* p<.0016$ 


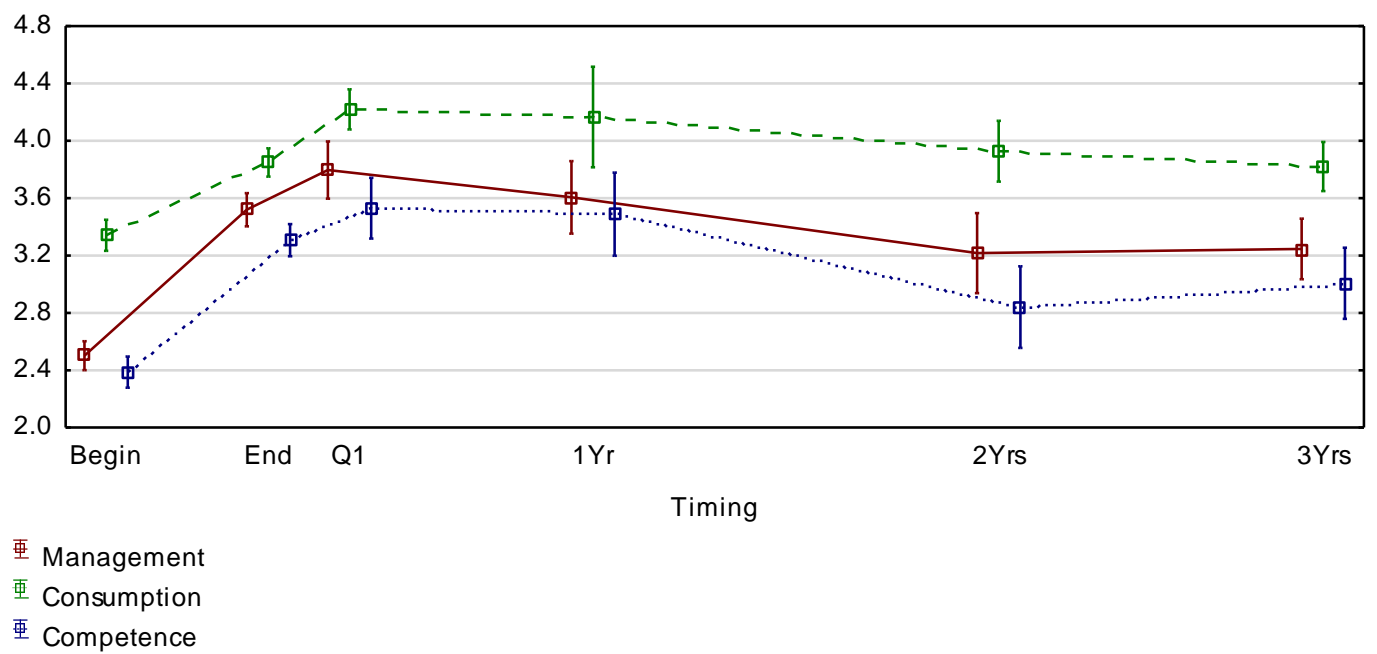

Figure 5.2. financial capabilities over time. Between-group design (total $\mathrm{N}=592$ ).

Income cannot explain differences in financial capability at the follow-up survey. A median split of households' equivalent income does not show a significant main effect when tested against management and choosing products $[F(2,87)=.01155, p<.05]$. However, "financial shortfall" does have a strong effect on management and wise consumption behavior. The difference was confirmed by two Multivariate General Linear Model analyses that used management and choosing products as dependent variables. The first analysis tested main effect for calculated shortfall based on the proportional gap between income and expenses, while controlling for the household's debt. The analysis shows a main effect for shortfall on management and consumption behaviors $[F(2,86)=5.9976, p=.00364$, Wilks' $\lambda=.877$, power $=.87]$, yet effect size was larger for management $\left[\eta_{p}^{2}=.108\right]$ than for choosing products $\left[\eta_{p}^{2}=.063\right]$.

The second analysis used the reported shortfall (i.e., "How would you define your current financial situation on a 1-5 Likert scale?") as an independent variable. Again, management and choosing products served as dependent variables while controlling for the household's equivalent income. The analysis demonstrated a different pattern for management and wise consumption behaviors $\left[F(4,182)=5.008, p<.01, \eta_{p}{ }^{2}=.09\right.$, Wilks' $\lambda=.824$, power $\left.=.92\right]$. While people with high shortfall reported worse management than those in a good financial situation, no such difference was found in the choosing products category. Accordingly, a significant 
univariate main effect for shortfall was obtained for management $\left[p<.0001, \eta_{p}{ }^{2}=.172\right.$, power $=$ $.967]$, but not for choosing products $\left[p>.05, \eta_{p}^{2}=.018\right.$, power $\left.=.184\right]$.

A z-scores-based comparison brings out the differences between the groups even more sharply. The gap between the choosing products and management scores in the low-shortfall categories is not statistically different from zero $(D=.14, S D=.98, C l=-.24, .53)$, but that gap sharply increases as the size of the shortfall increases $(\mathrm{d}$ Med $=.70, \mathrm{SD}=71, \mathrm{Cl}=.47, .87$; $\mathrm{d} \mathrm{High}=.81, \mathrm{SD}$ $=.65, \mathrm{Cl}=.43,1.21)$. Figure 5.3 presents the differences between the shortfall groups in both standardized scores (per respondent) and absolute raw values. The finding is consistent with the prediction that people with a low financial shortfall are better at financial management.

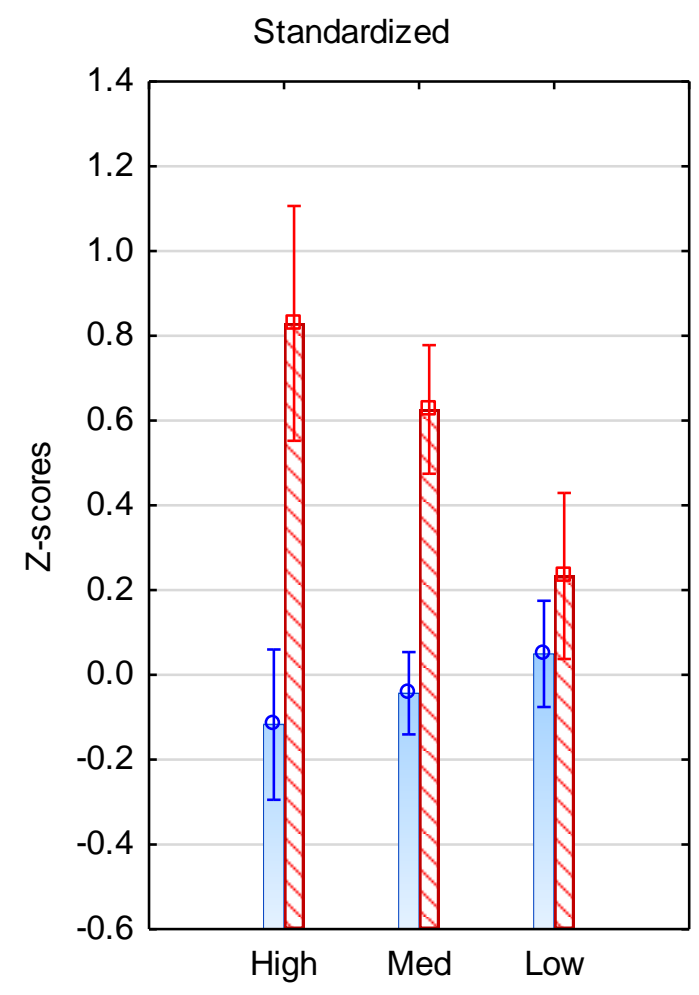

0 Z - management $\mathrm{Z}$ Z - consumption

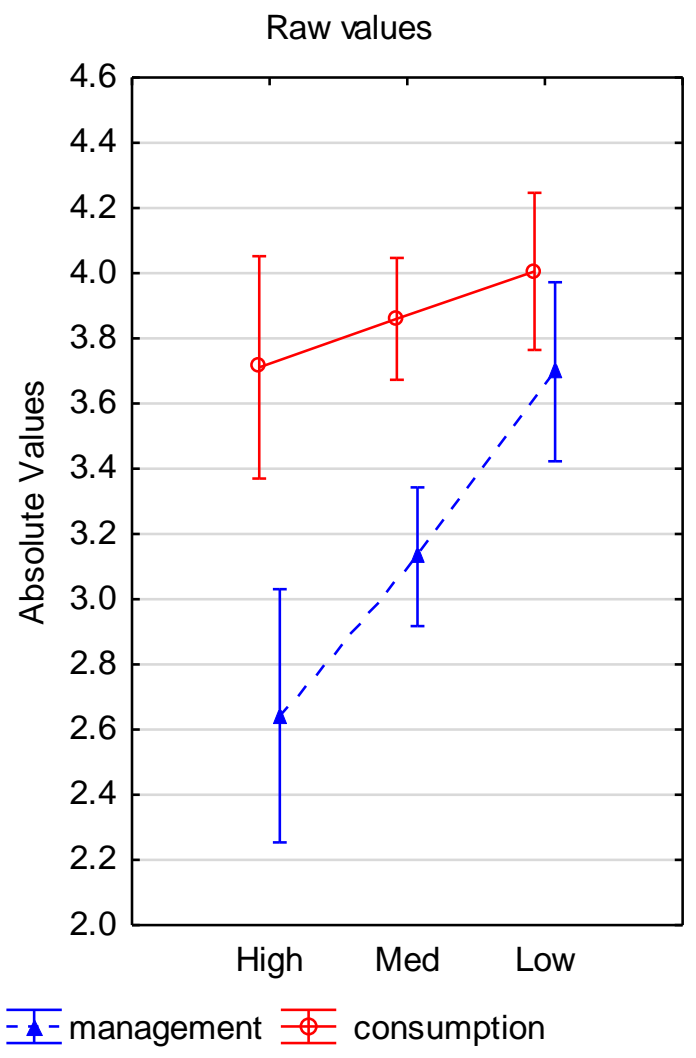

Figure 5.3. The left panel shows the differences in terms of z-scores. Respondents with severe financial troubles reported lower values for management practices than for choosing products. The right panel shows the differences between the groups in absolute raw values. High shortfall respondents received lower scores in the management category, but no significant difference between the groups was found in the choosing products category. 
Figure 5.4 demonstrates the evolution of financial capabilities over time as a function of financial shortfall. An interaction between level of financial shortfall and time of measurement was found in all three categories $\left[F(6,542)=3.300, p<.01, \eta_{p}^{2}=.10\right.$, Wilks' $\lambda=.930$, power $\left.=.934\right]$. As may be seen a few years after the intervention, individuals with high shortfall neglect financial management and focus exclusively on choosing products. For the low-shortfall group, on the other hand, scores in all three categories are just as good as they were at the end of the intervention (post hoc comparisons, $p>.05$ ).

High Distress

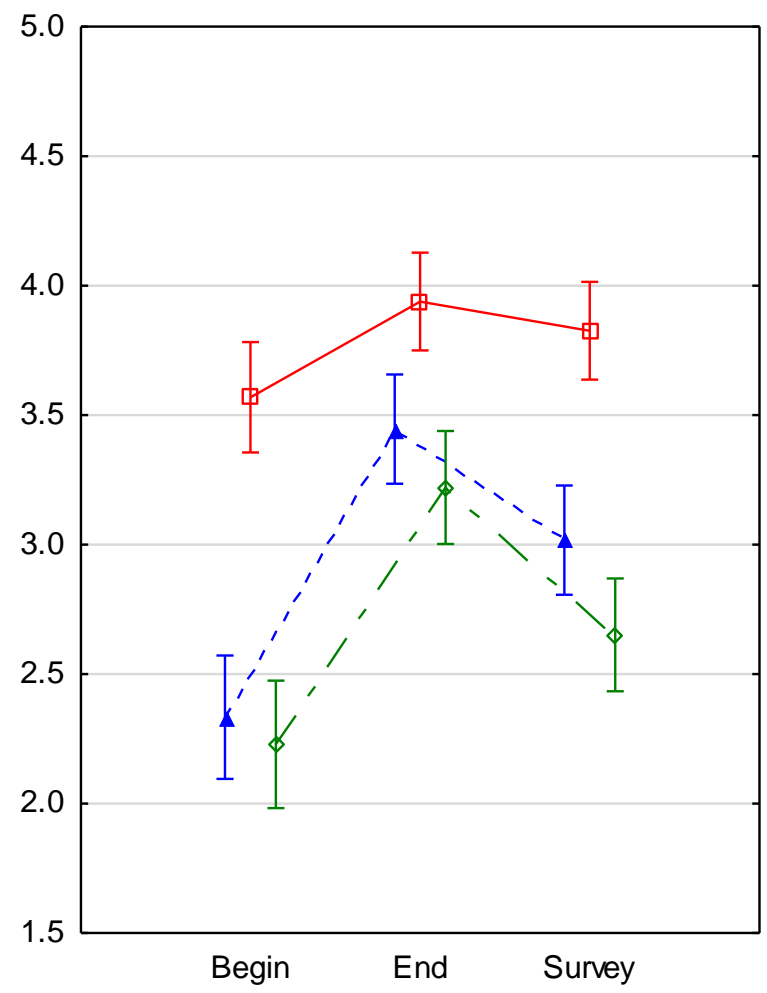

Low Distress

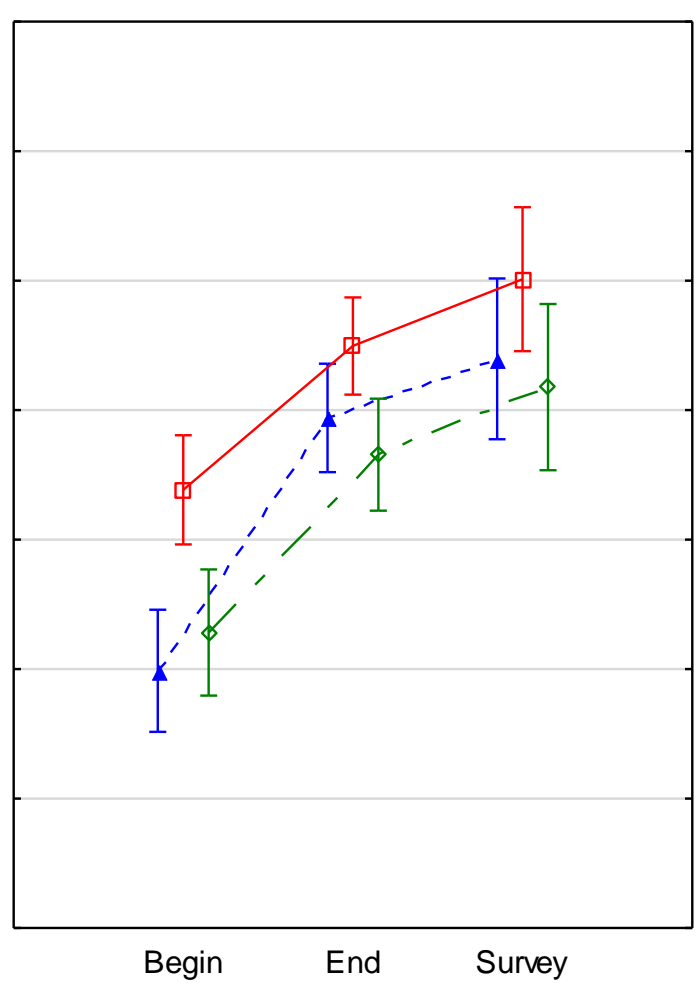

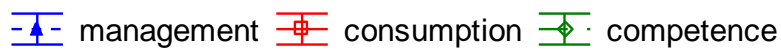

Figure 5.4. Long-term trends in financial capabilities. The left panel shows the differences in financial capability scores for the high shortfall group; the right panel shows trends for the low-shortfall group.

Note: Pre/post measurements are based on the median split of GP variables. Survey groups are based on self-report indicators (High shortfall: 3 or lower on a 1-5 Likert scale, $N=60$. Low shortfall: $N=35$ ). 


\section{Self-control, Neuroticism, and Financial Literacy}

The next part of the analysis tested the relation between self-control [SC], financial hardship, neuroticism, and financial behavior. A multivariate analysis of variance [MANOVA] that tested the impact of SC on management and choosing products reveals significant differences between the two dependent variables $[F(2,83)=4.595, p<.05, \mathrm{np} 2=.09$, Wilks' $\lambda=.900]$. While high selfcontrol increased management practices, it did not affect consumers' behavior [Management: $p$ $<.005, \mathrm{np} 2=.097 ;$ Choosing products: $p>0.5, \mathrm{np} 2=.02]$. No interaction was found between selfcontrol and financial shortfall on management behavior $(F(2,82)=.35856, p>.05, \eta p 2=.000)$, and the two variables did not correlate either $(r=0.04, p>.05)$.

Analysis of the impact of neuroticism reveals a striking resemblance between the behavior of people in a state of financial shortfall and people with high neuroticism. Respondents received fairly similar scores on choosing products regardless of their neuroticism, but highly neurotic individuals had significantly depressed scores on management. Analysis of univariate effect shows a significant main effect of neuroticism for management, but not for choosing products [Management: $p<.005, \mathrm{np} 2=.08$; Choosing products: $p>0.5, \mathrm{np} 2=.026]$, indicating that neuroticism interrupts management practices but does not hamper wise consumer behavior.

In contrast to SC and neuroticism, financial literacy was found to be unrelated to either shortfall, choosing products, or management. Simple regressions that included each of the three dependent variables were not significant $(p>.05)$ with minimal explained variance $\left(R^{2}<.001\right)$.

\section{Discussion}

Participants' scores 2-3 years after the intervention show a positive influence for the program and a clear improvement in their behavior compared to the baseline that was measured before the intervention. Nevertheless, it appears that certain situational and personal features prevent the adoption of some of the principles delivered during the intervention. Financial hardship, selfcontrol, and neuroticism were clear barriers for engaging in management tasks. By contrast, consumption practices were not affected by any of those factors. 
The results support the assumption that stands at the basis of this study - management and choosing products are two economic domains that differ by nature and are affected in different ways by financial education. A strained financial situation did not harm consumption behavior. These findings fit with the notion that financial hardship directs attention toward urgent needs wise consumption saves money at the time of the decision, and people have a clear incentive to follow those principles. Nevertheless, program graduates who face financial troubles did not engage in proper management, perhaps due to lack of cognitive resources needed for that type of complicated and not immediately rewarding task (Mullainathan \& Shafir, 2013). Similarly, low self-control reduces the likelihood of proper management but not of choosing products.

High self-control does not moderate the effect of a financial shortfall. Under the assumption that economic scarcity is a specific form of ego-depletion (Vohs, 2013), these findings concur with claims regarding the limited contribution of self-control for coping with stressful situations that lead to ego depletion (Imhoff et al., 2014). The theory of scarcity focuses on cognitive processes, whereas the effect of neuroticism stresses the importance of emotions. In this spirit, the following study relied on the measure of financial avoidance to explicitly test the relations between financial constraints, negative emotions, and financial behavior.

\section{Study 2 - Enhanced replication}

The second study included a single short survey, without requests for personal information such as income, expenses, and debt, and was conducted without a preliminary phone call. This modified survey was meant to increase the number of respondents by approaching past participants who would rather keep their privacy and didn't care to invest much time answering the survey. The survey included a financial capability questionnaire, the brief SCS to assess selfcontrol, and questions adapted from Shapiro and Burchell (2012) to assess financial avoidance. These authors defined financial avoidance (also known as a financial phobia or financial anxiety) as "a psychosocial syndrome whereby individuals have an uneasy and unhealthy attitude toward engaging with and administering their personal finances". People with high financial avoidance feel insecure about their financial abilities, tend to avoid financial information, and present 
slower cognitive response for money-related words (Shapiro \& Burchell, 2012; Sochos \& Latchford, 2016). Based on the relationship between negative emotions and time discounting, financial avoidance is expected to produce short-sightedness and to deteriorate financial engagements that produce deferred, rather than immediate, gratification. Understanding the relation between financial avoidance and the outcome of the intervention could contribute to future treatment, since, as pointed out by Shapiro and Burchell, therapists who have developed means to help people deal with phobias and fears.

To better understand financial avoidance, the study tested a mediation model that includes financial avoidance, perceived shortfall, and management. I conjecture that avoidance influences one's subjective perception of his financial situation, which in turn influences money management. The model is based on two assumptions. First, that negative emotions such as stress and anxiety are related to a less optimistic view of reality (e.g., anxious people tend to judge their situation to be riskier compared with non-anxious individuals) (Helweg-Larsen \& Shepperd, 2001). Second, subjective socioeconomic status has stronger influence on psychological functioning than objective social status (Adler, Epel, Castellazzo, \& Ickovics, 2000). Similarly, I assume that subjective, rather than objective SES influences financial behavior. Therefore, I propose that financial avoidance leads to a negative perception of the financial situation, which in turn impairs financial management.

\section{Data and measures}

13,000 people who participated in any activity done by the NGO during the years 2012, 2014, and 2015 received an email that contained a link to a ten-minute survey. More than 600 respondents completed the survey, but we retain for the analysis only 390 respondents who had participated in the households training program and attended at least three sessions.

The differences in sampling method affected the sample distribution. The current wave contains a smaller proportion of low-income participants compared to the previous study sample, and a slightly different geographic distribution. For a detailed description see Appendix 5A. 
Independent variables. In order to determine the level of financial shortfall, respondents were asked to rate their ability to pay their debts and to balance between income and expenses on a 1-5 Likert scale. The two questions were summed together so that low scores indicate a low level of shortfall, and a high score indicates a high level of financial hardship. Financial shortfall scores were then transformed into a categorical variable. The extended sample used in this study enabled splitting the sample into four shortfall categories based on quartiles.

The financial capability survey was identical to the one used in the other two studies and divided into the same three categories - management, choosing products, and confidence.

For this study, self-control [SC] was again assessed by Brief SCS, the financial literacy instrument used in the previous study. Three questions assessing financial anxiety based on Shapiro and Burchell (2012) were subtly modified to focus on attitude toward general financial matters instead of direct personal finances. For example, the statement "Discussing my finances can make my heart race" became "Discussing financial issues can make my heart race." Other statements were: "When people talk about financial manners I rather stay away" and Thinking about financial manners can make me feel stressed".

Dependent variables were raw scores and z-scores of three categories of financial capability, similarly to the variables used in the two previous studies.

Results

Program Long-Term effect - General

The first step was to test the pattern found in the previous study, but with a larger sample. I ran a MANOVA containing one independent variable (small and large shortfall) and two dependent variables (management and choosing products) while controlling for household's equivalent income. The findings confirm the pattern found in the previous study, but this time, with the larger sample, it shows clear statistical significance: differences in financial shortfall indicate differences in financial management, but not in choosing products. $\mathrm{F}(6,724)=8.260, p<.0001$, $\eta p 2=.06$, Wilks' $\lambda=.876$, power $=.999$. A significant univariate main effect for shortfall was found for management $[F(3,363)=16.377, p<.0001, n p 2=.119$, power $=.999]$, but not for 
choosing products $[\mathrm{F}(3,363)=0.77, p>.05, \mathrm{np} 2=.006$, power $=.217]$. Figure 5.5 shows that people beyond the median level of shortfall suffer a rapid decrease in their management abilities.

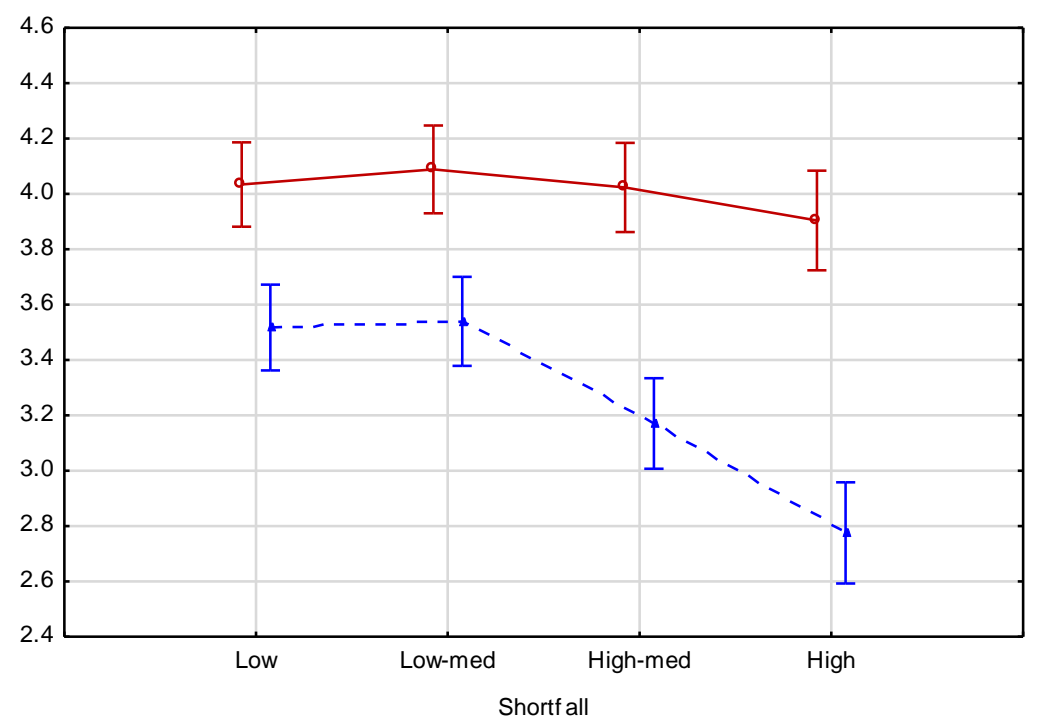

$\Phi$ consumption $\overline{\text { 토 management }}$

Figure 5.5. The differences between the groups in absolute raw values. High shortfall respondents received lower scores in the management category, but no significant difference between the groups was found in the choosing products category. Covariate means - income: 7.423

Evaluation of the long-term impact of the program shows that this pattern is enduring. Betweengroup analysis of the shortfall impact on financial capabilities shows variations throughout the years. The high shortfall is associated with better consumption habits at the beginning but not at the end of the intervention, while differences in management are observed only a few years after the treatment. The effect of shortfall on management behavior is significant $[F(3,466)=20.184$, $p<.0001, \eta_{\mathrm{p}}^{2}=.11$, Wilks' $\lambda=.885$, power $\left.=1\right]$, and for management alone $\left(p<.0001 ; \eta_{\mathrm{p}}{ }^{2}=.04\right)$, but again, not for choosing products alone $\left(p>.05 ; \eta_{p}{ }^{2}=.00\right)$. Figure 5.6 shows the changes in financial capabilities over time. 
High Shortfall

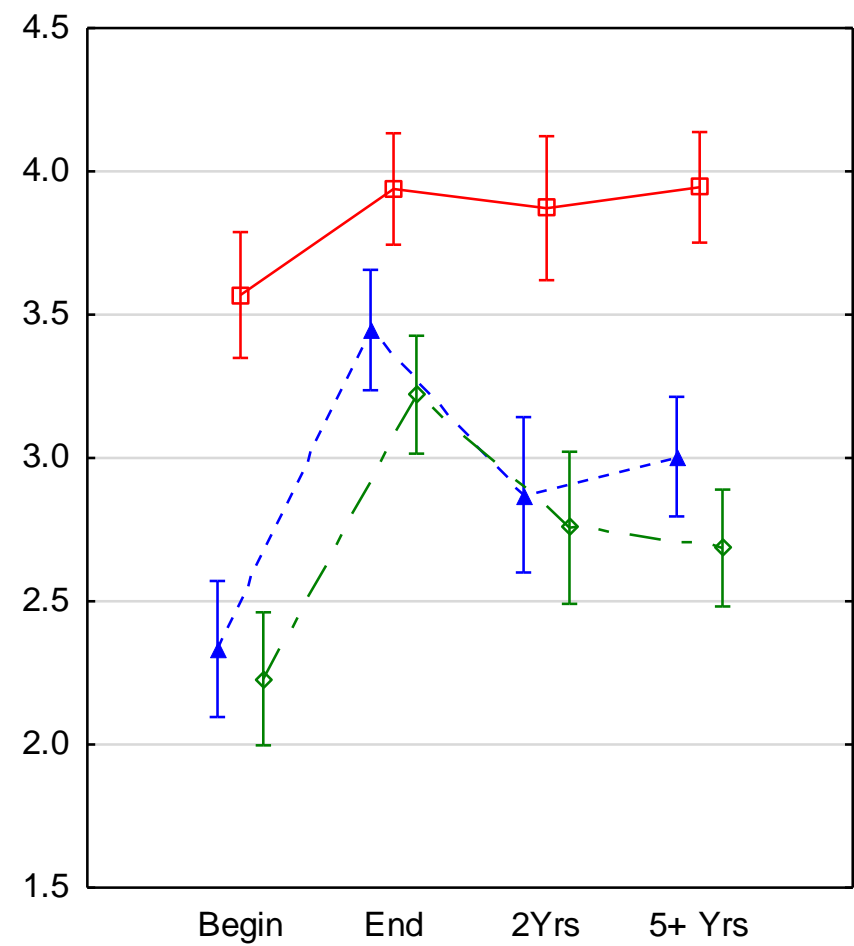

Low Shortfall

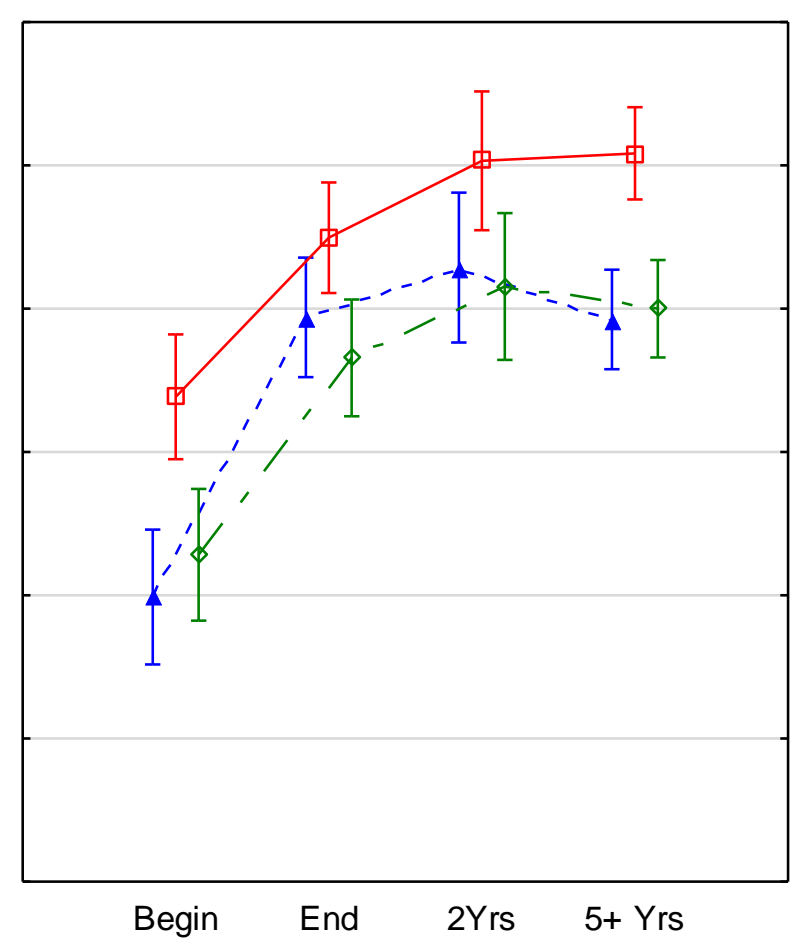

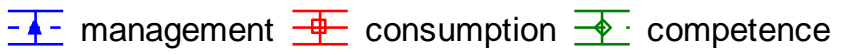

Figure 5.6. Long-term trends in financial capabilities. The left panel shows the differences in financial capability scores for the high shortfall group; the right panel shows trends for the low-shortfall group.

The results fit with the idea that financial deprivation limits the ability to conduct complex economic behaviors. Yet, it does not prove causality since the analysis was cross-sectional. Hence, I analyzed the differences in financial capability a few years after the program, based on the financial situation at the end of the intervention. This within-subject analysis is based on a relatively small number of participants who gave permission to match their survey responses with data that was gathered during the intervention several years beforehand. The analysis shows that respondents' financial situation at the end of the program has a significant main effect on their financial capabilities a few years later. Participants who were able to balances between earning and spending (including debts) at the end of the program outperformed other participants' management at the follow-up survey $\left[F(1,90)=6.53, p<.05 ; \eta_{p}{ }^{2}=.07\right]$. Yet again, no differences were found at the choosing products category $[F(1,90)=1.80, p>.05]$. Interestingly, 
neither income $[F(3,93)=.43105, p>.05]$ nor financial situation before the program $[F(1$, $94)=1.5647, p>.05]$ produced the same effect on management.

\section{Self-control, Financial Literacy, and Financial Avoidance}

While the first study shows an effect of self-control on management only, the current analysis shows that SC affects both management and choosing products $[F(2,381)=22.0242, p<.0001$, $\eta \mathrm{p} 2=.10$, Wilks' $\lambda=.896$, power $=.999]$. Again, shortfall and SC are additive effects, and no interaction was found for either choosing products or management $(p>.05)$.

As with the previous study, simple regression showed no relationship between financial literacy and choosing products or management $\left(p>.05 ; \mathrm{R}^{2}<.001\right)$.

As expected, financial avoidance produced the same outcomes as level of financial hardship - it had an impact on management, but not on choosing products $[F(2,381)=10.677, p<.0001, \eta p 2$ $=.05$, Wilks' $\lambda=.946$, power $=.989$. Univariate main effects for shortfall: management $-F(1,382)$ $=19.302, p<.0001, \mathrm{np} 2=.048$, power $=.999]$; choosing products $-\mathrm{F}(1,382)=0.15, p>.05, \mathrm{np} 2=$ .004 , power $=.067]$. A significant, yet moderate, correlation between shortfall and financial avoidance $(r=.229)$ was also found.

Two mediation analyses were performed to test the relationship between financial shortfall, avoidance, and financial management. The first analysis model is based on the assumption that avoidance mediates the influence of income on financial management. The second analysis tested the intermediations between avoidance, perceived financial situation, and economic behavior. The first mediation model was confirmed by a bootstrapping procedure that computed unstandardized indirect effects for 5000 samples. The bootstrapped unstandardized indirect effect was .026. The 95\% confidence interval ranged from .015 to .044 . Adj $R^{2}=.095$. Thus, the indirect effect was statistically significant, indicating that financial avoidance mediates that effect of income on management. No such impact was found for choosing products, and neither income nor financial avoidance influence wise consuming.

To test whether financial avoidance created a negative view of the financial situation, which in turn impairs financial management, I used "subjective shortfall" as a mediator between avoidance and management. To overcome differences in socioeconomic status I used income as 
control variable. As Figure 5.7 illustrates, the standardized regression coefficient between avoidance and shortfall was statistically significant, as was the standardized regression coefficient shortfall and values in the management category. The partial effect of the control variable income on management was not significant $(b=-.021, p>05)$. A bootstrapping procedure tested the significance of this indirect effect. Unstandardized indirect effects were computed for each of 5,000 bootstrapped samples, and the $95 \%$ confidence interval was computed by determining the indirect effects at the 2.5th and 97.5th percentiles. The bootstrapped unstandardized indirect effect was -.108. The $95 \%$ confidence interval ranged from -.153 to -.067 . Thus, the indirect effect was statistically significant.

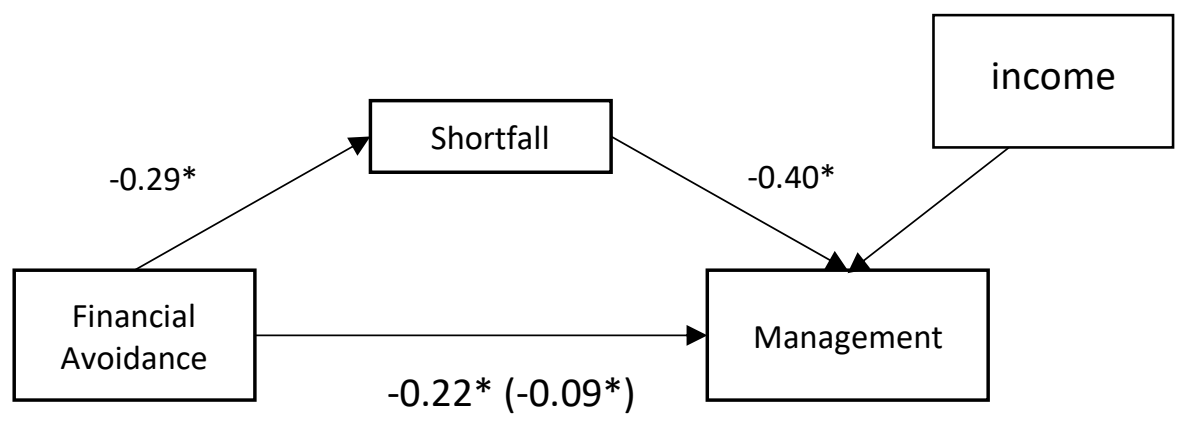

Figure 5.7. Standardized regression coefficients for the relationship between financial avoidance and management as mediated by the shortfall. The standardized regression coefficient between anxiety and management, controlling for the shortfall, is in parentheses. Approximately 22\% of the variance in management was accounted for by the predictors $\left(R^{2}=.216\right) p<.05$. Mediation was confirmed using the bootstrap procedure. The partial effect of the control variable income on management was not significant $(b=-.021, \mathrm{p}>.05)$.

\section{Discussion}

Study 2 demonstrates again the difference between management and wise consumption. Whereas participants received high scores in choosing products, engaging with management practices was related to the financial situation of the survey respondents, as high shortfall individuals demonstrate inferior performance in management practices comparing to low shortfall respondents. The findings confirm the previous study and show the robust effect of the program on consumption behaviors - participants' behavior remained stable even five years after the intervention. 
The division into four categories of financial shortfall shows that the drop in management ability is very steep. Scores of the low-moderate group are similar to those of the low shortfall group, while scores of the high-moderate shortfall group are significantly lower. This pattern raises an interesting question regarding the level of financial worries one could carry and which seem to lie in the vicinity of the median of our range. Given that most humans have some financial worries in their lives, yet manage to function, identifying the breaking point is an important question.

The study has also considered the emotional aspects of personal finances. A mediation model uncovers the relation between financial avoidance and economic behavior. The financial shortfall, which is based on a subjective evaluation of financial hardship, mediates between negative attitude toward personal finance and management. This model suggests that the impact of financial avoidance is related to the personal experience of financial hardship, rather than to the actual balance in one's bank account. Using income as a control variable reduces the influence of confound variables on our model. Nevertheless, we should consider other possible alternative models, especially, other causal directions within our model, and our attempt to test this cannot be considered definitive.

\section{General Discussion}

The study relies on a posited distinction between simple economic practices that provide immediate benefits, and complicated behaviors. The results confirm the pertinence of this distinction. While we witness a significant drop in management ability over-time, choosing products scores are stable among all participants. Moreover, financial difficulties, self-control, neuroticism, and financial avoidance impeded the adoption of principles of management and planning but proved of little importance for proper consumers' behavior.

It is easy to understand why low-income populations gain less from interventions (Fernandes et al., 2014), but income differences do not explain differences in participants' behavior in the long term. Adoption of the concept of "scarcity" does a much better job in predicting differences between consumption and management behaviors. Financial distress should not be considered in mere objective values of income and expenses but has a clear dimension of subjective, emotional experience. The inclusion of neuroticism and avoidance in this study reveals the 
influence of emotions on economic behavior, which is surprisingly similar to the impact of financial hardship. Since neuroticism is a stable personality trait, it can confirm a causal relationship in which stress and negative emotions toward financial manners are the source of bad management, and not the other way around. A mediation model suggests that avoidance impacts financial behavior through a subjective interpretation of the economic situation. Previous studies have shown that financially anxious individuals prefer not to think of their financial situation (Sochos \& Latchford, 2016). The proposed model suggests that this might hurt them, not only because this leads to poor planning and monitoring, but also because their emotions cause them to overestimate the severity of their situation.

The practical application of the impact of financial avoidance is self-evident. Treatment that teaches participants how to face their fears could lead to a significant improvement in management and planning. Indeed, OPEN comments made by participants in the intervention indicate that one of the things the program taught them was that financial affairs are not as challenging or frightening as thought.

As expected, self-control has a significant influence on behavior. The results indicate that despite the positive influence of high self-control on management, it does not moderate the effect of shortfall. This finding supports Imhoff et al.'s (2014) claim that high self-control cannot overcome the influence of depletion of resources. Interestingly, the influence of self-control was inconsistent in the two studies, as it had a significant main effect on choosing products in the second, but not the first study. This might simply be a matter of sample sizes, since Study 2 had a markedly larger population. Alternatively, the difference could be explained by the elapsed time between the program and the follow-up survey, which was 2-3 years in the first study but five years or more for most respondents in the second study. It is conceivable that after so many years, the intervention no longer moderated the negative impact of low self-control on consumer behavior.

The study provides a new way to think and evaluate the contribution of financial education. By adopting a dual-theory model this work proposes a mechanism with significant applicability. We are now in a position to understand the inconclusive evidence regarding the impact of financial education and realize that financial education will be beneficial for behaviors that provide 
immediate positive returns. On the other hand, among certain populations, we cannot expect financial education to be effective when it comes to behaviors such as planning and managing that provide only long-term benefits. Specifically, for low-income populations or for individuals that experience insolvency, financial education that focuses on those types of behaviors is ineffective. 


\section{Chapter 6: Money Cash-out During Job Replacement - an experimental approach}

Throughout this work, I analyzed surveys and administrative data to reveal the connections between knowledge, personal and situational features, and economic behaviors. The current chapter takes a different approach, as it combines customers' survey with two behavioral experiments designed to recognize the motives behind savers' decisions to cash-out money from their retirement savings account while changing their workplace. The first study presents results of a survey delivered to savers of a leading pension fund and compares their responses with actual data that was reported by the company. The results indicate that knowledge is both rare and highly masked by other influential factors such as financial constraints. The second part of the chapter uses a "nudge-alike" technique to influence savers' behavior. By using different forms of information display, I was able to reduce participants' desire to conduct early withdraw in two behavioral experiments. Together, the studies presented in this chapter shed light on several factors that overshadow financial knowledge and influence economic behavior. In return, the two experiments suggest that by adopting simple and well-known principles, we can increase the influence of knowledge and help savers make informed financial decisions.

\section{Study 1: Motives behind money cash-out}

When leaving their job, Israeli employees can withdraw (tax-free) severance payments that were accumulated in their retirement saving account. Historically, only workers who were fired had the opportunity to cash-out the funds. However, due to major reforms in the Israeli pension system, since 2008 most employees are entitled to withdraw the money even if they quit their job of their own will. The Hebrew term for "compensation" (Pitsuyim) is used to describe those early withdrawals, and according to assessments by the Israel Ministry of Finance, those withdrawals reduce retirees' pensions by up to 30 percent (Krill, 2016).

The motives for early withdrawals are yet to be determined. A study by Hurd, Lillard, and Panis (1998) shows that money leakage from retirement savings correlates with race, gender, and 
income. A series of lab experiments by Beshears, Choi, Laibson, Madrian, and Sakong (2011) highlighted the role of self-control, while others found that financial constraints are the main reason for cash-out from retirement savings (Ghilarducci, Radpour, Fisher, \& Webb, 2016). In addition, common explanations for pension behaviors and undersaving could account for early withdraw as well. For example, lack of knowledge (Lusardi \& Mitchell, 2007) and hyperbolic discounting (Laibson, 1997).

The current study tests motives to withdraw by 470 clients of a major insurance company. Each respondent filled in a survey about his pension behavior and view regarding compensation withdrawal, while the company indicated whether he or she had cashed-out compensation in the past. The survey included several ways to assess savers' pension engagements and their perception of the pension system in Israel. In addition, respondents were asked what would happen to the compensation in case they would not take the money, in order to determine their basic understanding of the concept of compensation.

Based on the public financial illiteracy, I expected to find little knowledge regarding compensation funds. Moreover, since pension decisions are complex and have an impact that could only be traced in the long run, I assumed that knowledge would have limited influence on early withdrawals, even for the more literate savers. This expectation fits with the general assumption that knowledge has a meager influence on complex financial behaviors that provide delayed revenue.

\section{Methodology}

A telephone survey was delivered to 471 individuals aged 50 or older, who were randomly selected from a leading pension fund's database. Half of the respondents had cashed out money in the past from their retirement savings account after they left their last job, and the other half had not. An outside professional survey research center conducted the interviews to conform with confidentiality requirements.

\section{Tools}

The survey contained 40 questions regarding respondents' view of the Israeli pension system, their general opinion on the mandatory pensions law, and their pensions' skills and management 
habits ("pension engagement "). In addition, respondents reported their likelihood to withdraw during work replacement, their motives for early withdrawal ("Why would you like to cash-out?"; "What will you do with the money?'), and their understanding that severance payments are part of their pensions. To determine time preference, respondents ranked their agreement with the statement "I would rather receive 5000 ILS now over 5500 ILS six months from now" on a 1-5 Likert scale.

Finally, participants were asked four questions about their trust in the Israeli pension system, reported their financial habits on different categories of financial capability, and answered demographic questions about their income, age, gender, and financial situation.

The study used two dependent variables to assess money cash-out:

(1) "tendency to withdraw" was determined by the question: "If you have moved to a different working place, how likely are you to pull out the compensation funds from your account?"

(2) "actual withdrawals". Reports from the insurance company that runs the pension fund indicated whether the respondent had pulled out compensation from his account in the past (binary variable - yes/no).

Results

The sample contained 471 respondents, 229 who had cashed out their compensation funds in the past and 242 who did not. Mean respondent age was 59 (SD=6.2), 273 respondents were females (57 percent), and 40 percent of the respondents hold an academic degree. The majority of participants reported an average (27 percent), below average (26 percent), or way below average (23 percent) income.

\section{General attitude toward pensions}

The vast majority of the respondents support mandatory pensions. Overall, 95 percent of the sample indicated that they support the $\mathbf{2 0 0 8}$ mandatory pension act that forces all employees to save for retirement, and the majority (76 percent) define their support as very strong. Support rate among the cash-out group is 94 percent, and a close to the 96 percent support rate in the non-cash-out group. 
Seventy percent of the respondents mention that they would not change the way their pension account is being managed, 13 percent would rather take the money for personal use, and 10 percent would rather manage their savings by themselves. Interestingly, personal management did not differ between people who did or did not cash-out money from their account, indicating the people do not consider the opportunity to withdraw compensations as a means to direct money into personal management.

\section{Pensions engagements}

The next part was intended to test savers' knowledge and pensions engagement. Respondents generally report that they have little knowledge concerning their own pensions $(M=2.6, S D=1.4$; 1-5 Likert scale: 1-low, 5-high), and indicate that they did not spend much time choosing their saving plan ( $M=1.7, S D=1.17$; 1-5 Likert scale: 1-little time, 5-much time). In a similar vein, threequarters of the respondents never consulted a pension advisor, and only 25 percent would consider doing so in the future. When asked to indicate the rate of management fee they pay on their accumulated funds, only 5 percent of the respondents gave a feasibly correct answer. Sixtyfour percent answered that they do not know, and 31 mentioned a number above 0.5 , which is the maximum management fee from accumulation allowed by the Israeli law.

It appears that the level of pensions engagements of savers in our sample is very low, resulting in lack of knowledge, passive behavior, and tendency to ignore their pensions savings.

\section{Money Cash-Out}

The results show a broad misunderstanding of the concept of "compensation". The majority of the sample expressed low desire to take the compensation, with fifty-four percent of the respondents who indicated that they are quite unlikely, or very unlikely, to withdraw compensation if they had changed their workplace. Yet, subjects were not able to answer a simple question about compensation. When asked what would happen to the money if they would not withdraw it, only fifty-two percent mentioned that they would get the money at their retirement. Almost half of the respondents could not answer (39 percent) or falsely assumed that the money would go the state ( 4 percent) or be kept by the employer ( 5 percent). Interestingly, a comparison between the tendency to withdraw compensation and the desire to withdraw 
money from the pensions saving account show a strange inconsistency. Seventy-one percent of the sample reported that they would not take money from their pension account, while only 52 percent are unlikely to withdraw compensation.

Lack of knowledge alone cannot explain this inconsistency. Even respondents who mentioned that they would get the compensation at their retirement treat the compensation funds differently than pensions. 37 percent of the "knowledgeable" respondents would withdraw compensation but would not touch their pension funds, while 10 percent would take money from their pension account but would not touch the compensation.

\section{Desired vs. Actual Behavior}

The tendency to withdraw is only moderately related to actual withdrawals in the past. The average willingness to withdraw is higher among respondents who cashed-out compensation in the past $(M=2.8, S D=1.7)$ comparing to those who did not cash-out in the past $(M=2.4, S D=1.5)$. The difference is significant with a medium effect size $\left[F(1,468)=9.765, p<.005 ; \eta_{p}{ }^{2}=.05\right]$. Yet, the determinants of the reported "tendency to withdraw" are quite different from those that govern "actual withdrawals". While the tendency to cash-out is related to several personal features, income is the only significant predictor of actual withdraws. Regression of the determinants of the two indicators of withdrawals suggests that personal features explain savers' preference, but actual behavior really is determined by financial need. See Table 6.1. 
Table 6.1. Predictors of money cash-out. For the tendency to withdraw dependent variable, a multilinear regression model was conducted.

\begin{tabular}{|c|c|c|c|c|c|c|}
\hline & \multicolumn{3}{|c|}{ Tendency to withdraw } & \multicolumn{3}{|c|}{ Actual withdrawals } \\
\hline & B* & S.E. & $p$ & B* & Wald & $p$ \\
\hline Intercept & 59.2 & & $0.001 * *$ & 0.49 & 0.35 & 0.545 \\
\hline Income & 0.05 & 0.06 & 0.31 & -0.22 & 4.41 & $0.035^{*}$ \\
\hline Time preference & 0.14 & 0.06 & $0.009 * *$ & 0.09 & 1.71 & 0.190 \\
\hline Trust & -0.06 & 0.05 & 0.31 & -0.11 & 0.27 & 0.60 \\
\hline Pension engagement & -0.17 & 0.06 & $0.002 * *$ & 0.06 & 0.18 & 0.671 \\
\hline Knowledge & -0.16 & 0.06 & $0.002 * *$ & -0.164 & 1.8 & 0.163 \\
\hline$N$ & & 318 & & & 317 & \\
\hline $\begin{array}{l}\text { Adjusted } R^{2} / \\
\text { Nagelkerke } R^{2}\end{array}$ & & 0.083 & & & 0.035 & \\
\hline
\end{tabular}

The model to predict actual withdrawals is based on logistic regression, since the dependent variable is binary.

${ }^{*} p<.05 ; * * p<.001$

Further analyses confirm that financial needs overshadow personal preferences. For example, 41 percent of the high-income respondents report that they would use compensation money for leisure activities, while two-thirds of the low-income group would use it to cover daily expenses $\left[\chi^{2}(1, N=121)=9.11, p<.05 ; O R=3.5\right]$ (see Figure 6.1). Furthermore, the interaction between income and time preference reveals that time preference determined the tendency to withdraw of high-income savers, but has no influence on the low-income savers $(F(1,224)=5.4751, p<.05$; $\eta_{p}{ }^{2}=.02$ ) (see Figure 6.2). It appears that the low-income savers cannot give up the opportunity to receive a substantial amount of money in the immediate term, regardless of their personal 
preferences. As a result, 54\% of the low-income respondents have cashed-out in the past, compared to only $42 \%$ percent of the high-income group $\left[\mathrm{x}^{2}(1, \mathrm{~N}=301)=3.96, p<.05 ; \mathrm{OR}=1.6\right]$.

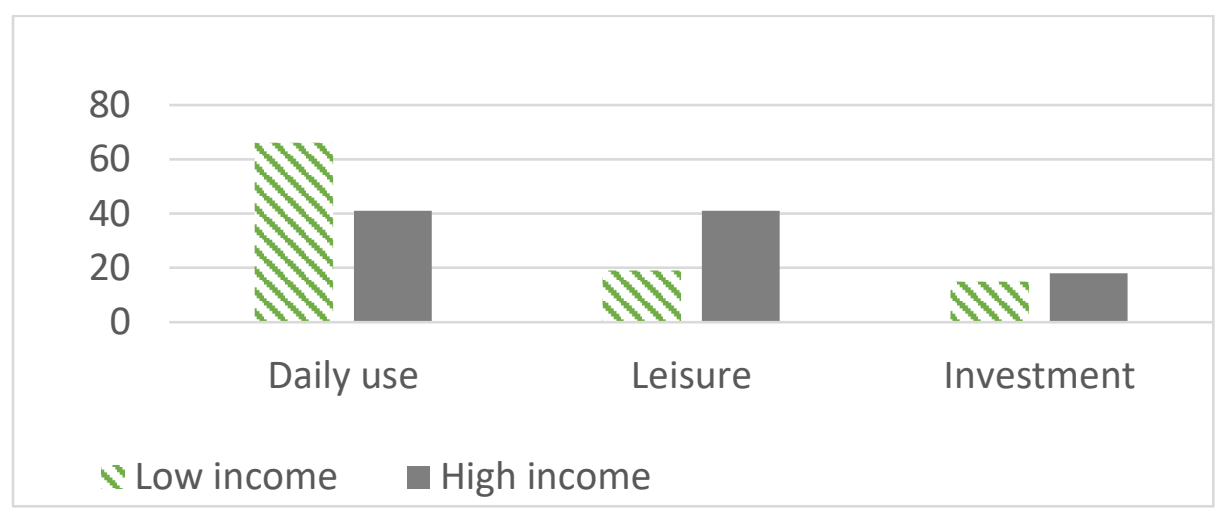

Figure 6.1. Answers to the question "How would you use the compensation in case of early withdrawals?"

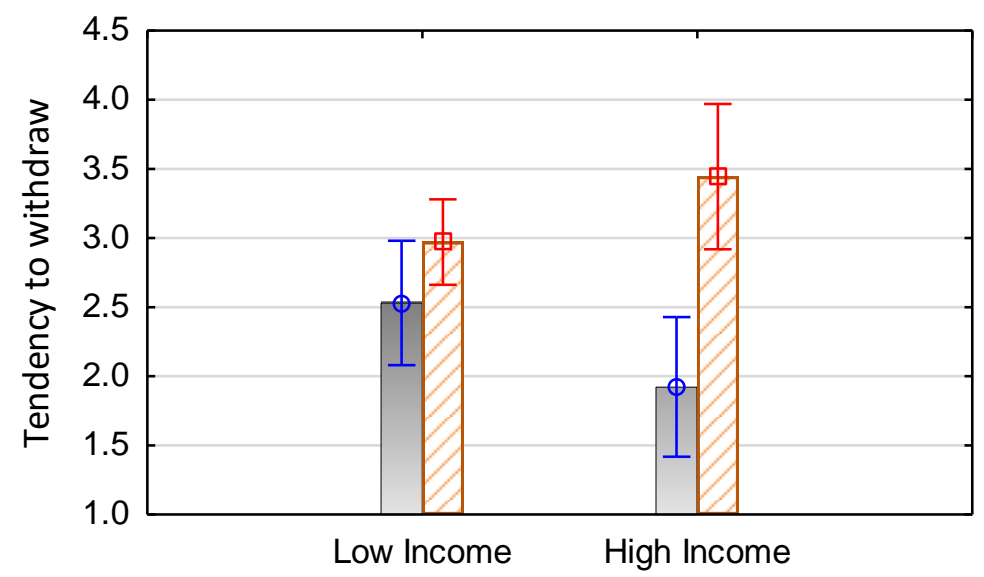

D. Present preference

Future preference

Figure 6.2. "Tendency to withdraw" as a function of income and time preference. The time preference categories include "future preference" ( $N=140)$, and "present preference" $(N=80)$. The analysis does not include participants who gave a neutral response to the time presence question.

\section{Conclusions}

By and large, our respondents were financially illiterate, and knowledge by itself is not a good indicator of adequate financial behavior. The respondents present poor pension management, careless scheme selection, and minimal understanding of the concept of compensation. 
Moreover, respondents were reluctant to take money out of their pension savings account, but felt quite comfortable taking the compensations, although the two actions are practically the same.

The comparison between actual withdrawals and the desire to withdraw brings to the fore the role of financial constraints. While several factors explain the reported tendency to withdraw, actual withdrawals are predicted by income only. Low-wagers withdraw money to cover their basic needs, indicating that early withdrawals often reflect actual need for the money rather than short-sightedness or time discounting.

The next part of this chapter uses behavioral economic techniques to reduce the tendency to cash-out money during work replacement. Two lab experiments simulated a situation in which an employee needs to decide if he wants to conduct an early withdrawal. The first experiment investigates the contribution of timely information delivered to decision-makers while thinking to cash-out compensation funds. The second experiment investigated the role of framing of compensation as an integral part of pension savings. Together the two studies show that subtle changes in the presentation of information can reduce savers' willingness to conduct early withdrawals.

\section{Study 2: Financial literacy and money cash-out}

In the current study, customers were asked to decide whether to cash out money during work replacement. Some of them were informed prior to the decision that the compensation funds come from their pension account. The advantage of knowledge display at the moment of decision is twofold. First, as we have already seen, people are ill-informed about compensation, so they would find this knowledge useful. Second, people are often incapable of appropriately applying existing knowledge at the time of their decision. For instance, Gick \& Holyoak (1983) showed that in a problem-solving task, subjects poorly applied principles which they have learned earlier unless an explicit reminder of this knowledge was presented. In a similar vein, Kahneman and Tversky have argued that individuals perform judgment based on heuristics and simple rules of thumb while ignoring crucial information. Kahneman describes this behavior as meant to avoid mental effort (Kahneman, 2011; Tversky \& Kahneman, 1974). Those principles were also applied 
to the field of economics. For example, James, Lahti, \& Thaler (2006) used the term "narrow scope" to describe investors' tendency to isolate the risk posed by a specific gamble from other, preexisting risks. This neglect of information is explained by cognitive limitations and restricted working memory capacity that hinder retrieval of relevant information when needed (Leiser \& Shemesh, 2018). Therefore, it is plausible to assume that directing customers' attention to the fact that severance payments are part of their retirement savings, at the time of choice, would make them reconsider whether they should cash-out their funds. Moreover, directing peoples' attention to the future can change their time orientation and promote a preference for larger, though delayed, utilities (Cheng, Shein, \& Chiou, 2012; Liberman, Sagristano, \& Trope, 2002; Trope \& Liberman, 2000). I conjecture that the explicit reference to customers' long-term saving account can, therefore, change their time orientation and make them inclined to save the money for their retirement.

The study includes assessment of financial literacy, financial avoidance and an evaluation of the tendency to withdraw compensation. The study was conducted under the expectation that financial literacy would not influence the likelihood of cash-out, and that timely information would moderate subjects' tendency to withdraw compensation from their retirement savings account. Since financial avoidance makes people focus on the short term, I expect that subjects with high avoidance would tend to withdraw compensation. Yet again, presentation of information during the act itself can moderate this tendency, as it provides important knowledge, and shifts individuals' attention to the future.

\section{Method}

\section{Participants}

One hundred thirty-three undergraduate students from Ben-Gurion University signed up for an online study that included two surveys. One hundred twenty-nine participants completed the two surveys, and were granted course credit for their participation. Participants who completed the study were 23 years old on average (115 women). 
Tools

Financial Avoidance To measure avoidance I used the Financial Anxiety Scale (FAS) taken from Shapiro \& Burchell (2012). While financial anxiety and financial avoidance have different definitions, the FAS evaluates negative emotions toward engagement with personal finance, hence serving as an appropriate instrument for the purposes of this study.

Financial Literacy Survey Financial literacy was measured by eight questions that were adopted from several financial literacy surveys (Carmel, Carmel, Leiser, \& Spivak, 2015; Chen \& Volpe, 1998; Lusardi \& Mitchell, 2007). The survey includes 1-2 questions on each of the following aspects of financial knowledge: compound interest, pensions, diversification, insurance, mortgage, and inflation. Cronbach's $\alpha$ shows a relatively low inter-reliability of 0.66 . One question was excluded from the survey analysis due to low inter-correlations (for success rates see Table 6.2, for the full survey see Appendix 6A).

\section{Procedure}

Subjects were invited to participate in a study about choices that workers have to take when they start working for a new employer. They received a link for a preliminary survey that included a financial literacy questionnaire and the FAS. A week later, subjects received another link that was presented to them as a study about "decision making during work replacement".

Subjects were asked to make decisions that characterized people who change their workplace. For example, to choose between company car or vehicle reimbursement, to consider whether they want to join group health insurance, and to decide if they want to take part of their salary in employee stock options. Finally, subjects were asked if they would like to cash out their compensation funds. Half of the subjects were asked to report their likelihood to withdraw fifty thousand ILS worth of compensation funds during work replacement, while the other half first saw a description that informed them that the compensation payment comes straight from their retirement savings account:

"During work replacement employees are often entitled to withdraw money from their pension saving account, often defined as 'compensation' ... Imagine that you switch jobs 
and need to decide whether to withdraw up to fifty thousand ILS worth of compensation from your pension account ...

How likely are you to withdraw compensation funds instead of leaving them in your pension account?"

All subjects were then asked: "In case you decide to withdraw compensation funds, what portion of the money would you take?".

Results

Financial literacy

Financial literacy scores were low. Only ten subjects (13\%) had more than seven correct responses, and only one was able to answer all nine questions correctly. On some questions, close to 20 percent of the respondents answered "don't know" instead of taking a calculated guess. Table 6.2 reports the success rate for each question.

Table 6.2. Respondents' success rate in the financial literacy survey.

\begin{tabular}{l|ccc} 
& CORRECT (\%) & INCORRECT (\%) & DO NOT KNOW (\%) \\
\hline COMPOUND INTEREST 1 & 13 & 76 & 11 \\
* MORTGAGE & 53 & 32 & 16 \\
DIVERSIFICATION & 42 & 54 & 4 \\
COMPOUND INTEREST 2 & 41 & 41 & 18 \\
INSURANCE 1 & 68 & 31 & 2 \\
PENSION & 39 & 50 & 11 \\
INSURANCE 2 & 10 & 74 & 17 \\
INFLATION & 39 & 44 & 20 \\
INFLATION 2 & 80 & 0 & \\
* Item was excluded from the survey due to low reliability, based on Cronbach's alpha analysis.
\end{tabular}




\section{The Tendency to Withdrawal Compensation}

On average, subjects' cash-out score was $3.3(S D=1.3)$ on a 1-5 Likert scale (1=very likely to withdraw; $5=$ very unlikely to withdraw). In accordance with expectations, subjects who were told that the withdrawals come out of their pension account were less likely to withdraw $(M=3.8$, $S D=1.14)$ than subjects who did not receive such explanation $(M=2.8, S D=1.09), F(1,125)=25.814$, $p<.001 ; \eta_{\mathrm{p}}^{2}=.17$.

A categorical comparison of the tendency to withdraw between the two groups brings out the differences in their perception: 62 of the no-explanation group mentioned that they are likely or very likely to withdraw their funds, while fifty percent the explanation group reported that they are unlikely or very unlikely to cash-out the compensation funds. For a full comparison, see Table 6.3. Naturally, the group that was reluctant to cash out also wished to take a smaller portion of their savings in case of money withdrawn. While members of the no-explanation group cashed out 73 percent of their compensations (SD=35.1), the average cash-out rate of the other group was 44.6\% (SD=25.6), $\left.F(1,100)=21.791, p<.0001 ; \eta_{p}{ }^{2}=.17\right)$. Exclusion of subjects who reported that they are unlikely to withdraw increased the size of the effect (With explanation: $M=49.3$, $S D=27.3 ;$ No explanation: $M=80.1, S D=30.2) F(1,74)=20.092, p<.0001 ; \eta_{p}{ }^{2}=.21$

Table 6.3. Categorical tendency to withdraw. A comparison between subjects who saw an indication that the compensation is coming out of their pension, and subjects who did not see such indication.

$\begin{array}{ccc}\text { NO } & \text { WITH } & \text { TOTAL } \\ \text { EXPLANATION } & \text { EXPLANATION } & (\mathrm{N}=129) \\ (\mathrm{N}=66) & (\mathrm{N}=63) & \end{array}$

VERY LIKELY TO WITHDRAW

LIKELY TO WITHDRAW

SAME LIKELIHOOD TO WITHDRAW OR NOT

UNLIKELY TO WITHDRAW
38

23

23

14
6

26

18

44
22

24

20

28 
As expected, financial literacy did not moderate the tendency to withdraw. In fact, subjects with high financial literacy expressed slightly higher, but not significant, likelihood to withdraw comparing to less literate subjects (With explanation: $M=3.6, S D=1.1$; No explanation: $M=3.2$, $\mathrm{SD}=1.3 ; p>.05)$. On the other hand, comparison of the portions of the money cashed-out by the groups reveals a significant interaction between knowledge and explanation $(F(1,98)=4.3650, p$ $\left.<.05 ; \eta_{\mathrm{p}}^{2}=.04\right)$. While literate subjects wished to cash out smaller portions of their funds under the no-explanation condition $\left(p<.0001, \eta_{p}{ }^{2}=.21\right)$, the explanation eliminated the difference between the two groups (see Figure 6.3). An analysis that excludes participants who did not wish to withdraw their funds reveals a similar pattern, but the effect is only close to significance, presumably due to small sample size $\left.F(1,72)=3.6025, p=.06 ; \eta_{p}^{2}=.05\right)$.

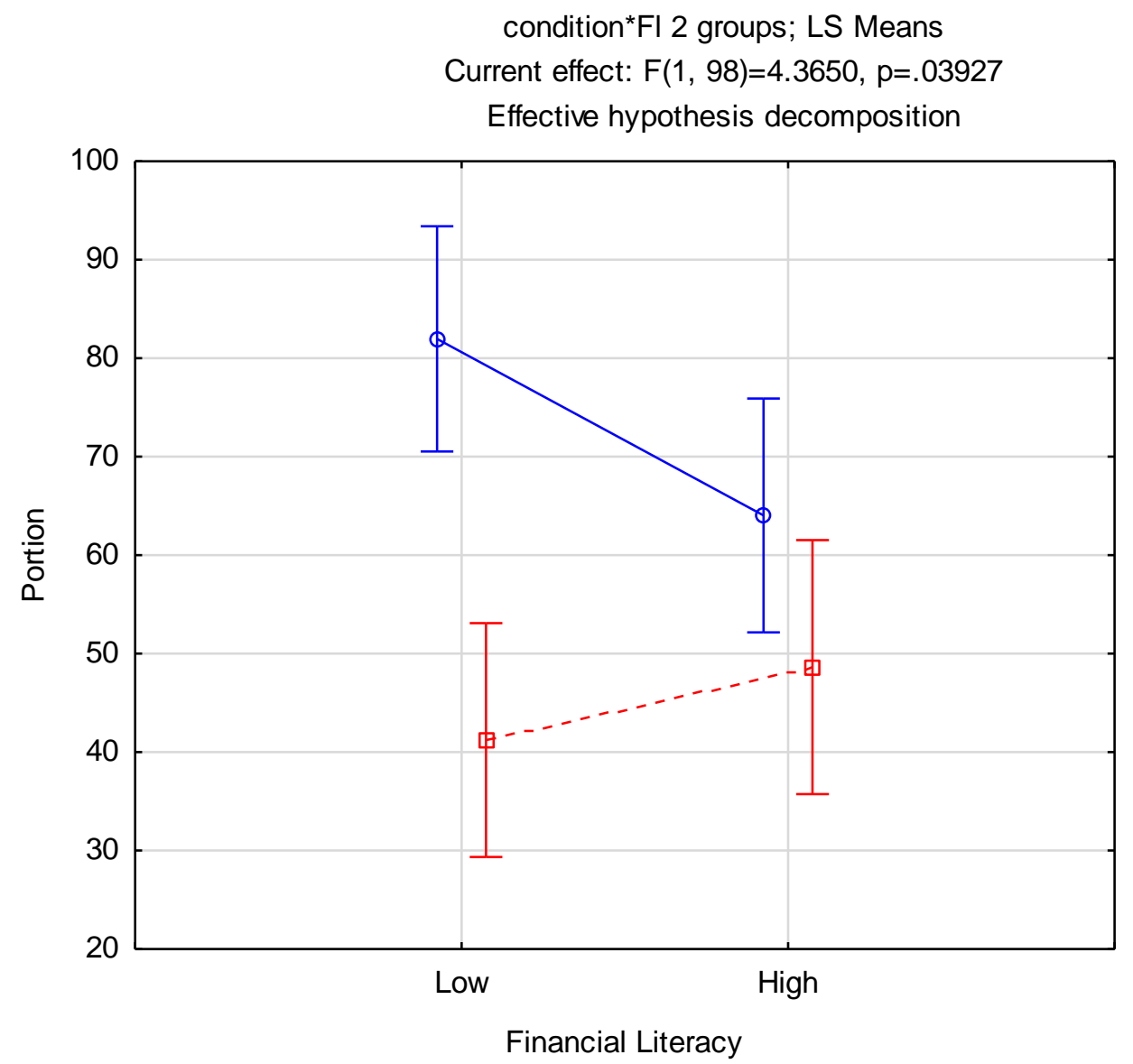

Æ No explanation 更- With explanation 
Figure 6.3. The portion of compensation that was withdrawn as a function of financial literacy and information display.

\section{Financial Avoidance}

A one-way ANOVA shows that financial avoidance does not impact the tendency to withdraw ( $p$ $>.05)$, and an analysis of the interaction between explanation and avoidance did not reach the threshold level of significance $(p=.07)$. Yet, a post hoc analysis reveals a significant difference between subjects with high and low avoidance level in the no-explanation group. Without explanation, members of the high avoidance group expressed higher likelihood to withdraw than members of the low avoidance group $\left(p<.05, \eta_{\mathrm{p}}^{2}=.08\right)$. Financial avoidance does not correlate with financial literacy $(r=-.08, p>.05)$.

\section{Conclusions}

The study confirms the hypothesis that by providing relevant information to savers we can reduce money leakage from their retirement saving accounts. Relevant and timely information had substantial effect, whereas financial literacy did not moderate the tendency to withdraw, suggesting that providing information next to the time of the decision promotes knowledgebased behavior. Further, the presentation of information moderated the negative influence of financial avoidance. While high-avoidance participants wanted to cash-out the money from their account in the no-explanation condition, subjects who received the explanation chose to keep the money in their retirement savings account, regardless of their emotions.

The study was conducted among university students who currently have little interest in their pension. The next study replicates the findings on a representative sample of Israeli savers, while manipulating savers' perception toward their pension using different framing of their mental accounts.

\section{Study 3: The effect of framing on money cash-out}

One possible explanation for savers' behavior is lack of understanding that they would get the money at their retirement. Therefore, it is reasonable that savers would rather take the money 
when no information is given. On the other hand, in the previous study I proposed that the message presented to savers not only informed them that they would get the money at their retirement but also changed their perspective and made them think about their compensation funds in term of long-term savings.

In the current study, I manipulate savers' perception of compensation funds using two different framings: one that proposes that subjects take compensations out of their pension saving account, and another that offers to add the money to their pension saving account. In both conditions, subjects were told that they would receive the money at their retirement and their expected utilities were identical for both cases. According to Shefrin and Thaler $(1988 ; 2004)$ people have varied perceptions of fungibility, which makes them evaluate money presented as liquid differently than money presented as savings. The term "mental accounts" was coined to describe this behavior. I assume that subjects who would be offered to add money to their pension would consider it as "liquid" - money that is now in their pocket and not an integral part of their retirement savings. On the other hand, I assume that the proposition to take money out of their pension savings account would make savers reluctant to hurt their long-term savings, hence reducing their tendency to withdraw.

Another objective of the study was to test Lemelson's (2017) proposition that the term "compensation" encourages savers to cash-out money from their account. According to the Cambridge Dictionary, compensation is defined as "money that is paid to someone in exchange for something that has been lost or damaged or for some problem". Lemelson argue that the association of the word compensation with recompense for a negative event makes people take the money as a "gift for themselves". I tested his explanation by comparing the tendency to withdraw from subjects who saw the term "compensation" with that of subjects who saw the term "some money".

The study was conducted on a representative sample of the Israeli population. The sample included respondents aged 18 to 60 . The sample and survey delivery were conducted by a professional survey research center. 


\section{Methodology}

\section{Participants}

The survey was delivered by a professional survey research center to three hundred and eightythree individuals aged 18 to 60 (age $M=37.99, S D=12.00$; female=201) who were sampled from an extensive consumer panel. The panel includes more than 75,000 members who receive a fee for their participation. The sampling was based on age and income in order to create a representative sample of the Israeli population.

\section{Procedure}

Similarly to the previous study, subjects were invited to participate in a study about "decision making during work replacement". Subjects in this version of the study did not answer a preliminary survey, and their financial literacy was not measured.

Respondents saw the same scenarios and answered the same questions as the previous study but were assigned to different conditions. Subjects in the control group were asked if they would like to cash out their compensation funds, while other participants were informed that they would get the compensation funds at their retirement, if they would not cash-out the funds earlier. To manipulate the effect of wording, respondents in one experimental group saw the term "compensation", while respondents on the second experimental group saw the term "some money". To manipulate framing, half of the respondents on each wording group were asked if they would like to withdraw the money, while the other half were offered to add the money to their pension account.

For example, subjects were offered to add the compensation \{money\} to their account, suggesting that the money is already in their pocket [i.e., the liquid money group].

"During work replacement, the employee is often entitled to accept compensation ... Imagine that you switch jobs and need to decide whether to accept up to fifty thousand ILS worth of compensation $\{$ sum\}...

... How likely are you to accept the compensation \{money\} instead of adding it to your pension account?" 
Alternatively, here is an example of the "long-term saving" condition in which subjects were offered to take money \{compensation\} from their pension account:

"During work replacement, the employee is often entitled to withdraw money from their retirement saving account ... Imagine that you switch jobs and need to decide whether to take 50,000 ... How likely are you to withdraw \{accept\} the money \{compensation\} instead of leaving it in your pension account?"

All subjects were then asked: "In case that you decide to withdraw \{accept the compensation funds $\{$ money\}, what portion of the money would you take?"

\section{Results and discussion}

\section{Wording effect}

A one-way ANOVA that was followed by post hoc comparisons shows that the average likelihood to withdraw in the control group exceeded the two other groups $[F(2,348)=5.3724, p<.01$, $\eta_{p}{ }^{2}=.02$; post hoc $\left.p>.05\right]$. Average inclination to withdraw among subjects who saw the word "compensation" was similar to the mean score of subjects who received the term "money" $(\mathrm{M}=2.94, \mathrm{SD}=1.54, \mathrm{M}=3.02, \mathrm{SD}=1.44$; respectively). However, the desire to cash-out in the control group was 4.28 out of 5 (SD=1.06). Table 6.4 shows categorical differences between the groups. Interestingly, subjects from all three groups had relatively similar scores in the "unlikely/very unlikely to withdraw" category, but on the other side of the scale, members of the control group demonstrated extreme preference toward "very likely to withdraw".

Table 6.4. Categorical tendency to withdraw.

\section{COMPENSATION MONEY CONTROL}

VERY LIKELY TO WITHDRAW

LIKELY TO WITHDRAW

SAME LIKELIHOOD TO WITHDRAW OR NOT

UNLIKELY TO WITHDRAW
22

25

25

3
19

17

32

4
59

3

6

10 
A comparison between subjects who were not informed about the connection between compensation and pension saving account, but were exposed to different descriptions of severance payments ("compensation" or "some money"), and a control group who did not receive such explanation.

\section{Framing effect}

A one-way ANOVA reveals a significant main effect for framing (see Figure 6.4). Again, subjects in the control group differed significantly from the two other conditions $\left[p<.001 ; \eta_{\mathrm{p}}{ }^{2}=.18\right]$, yet this time the analysis indicates a significant difference between the two groups as well $[p<.001$; $\left.\eta_{\mathrm{p}}{ }^{2}=.03\right]$. The analysis also shows that high likelihood to withdraw indicated bigger withdrawals for subjects from the "liquid money" group compared to the "long-term saving" group (79 vs. 66 percent) $p<.05, \eta_{p}^{2}=.03$.

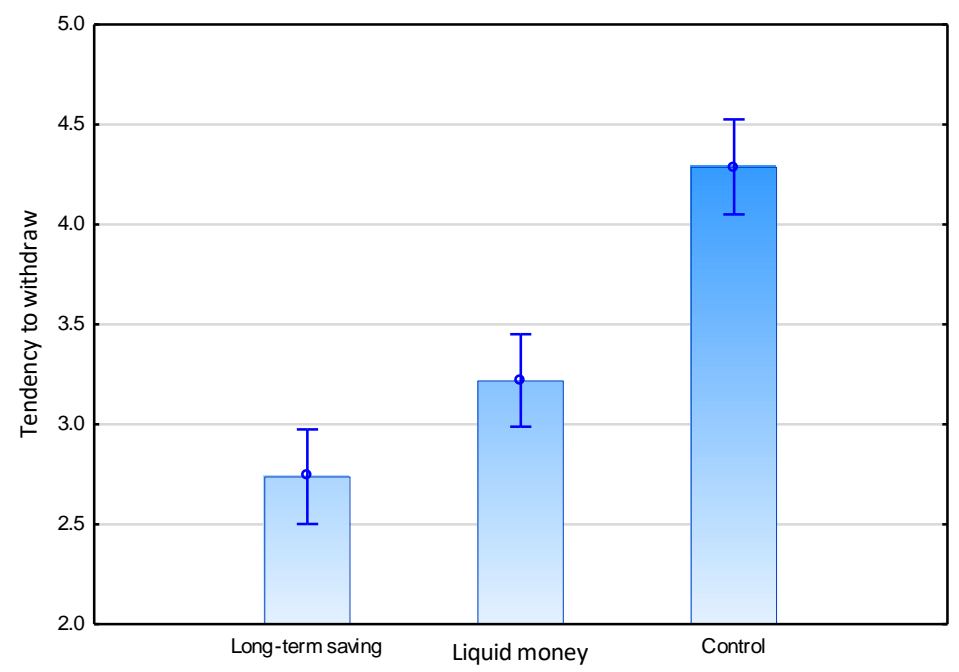

Figure 6.4. "Tendency to withdraw" as a function of framing. Subjects of the "liquid money group" were offered to take the compensation/money instead of adding it to their account. Subjects of the "long-term saving group" were offered to withdraw the compensation/money from their pension account.

The study confirms that the decision to cash out is not only a result of limited knowledge but is related to savers' perception of funds as part of retirement savings. When savers perceived the 
money as part of their long-term savings, they were more likely to leave it in their retirement savings account. When, on the other hand, the money was described as a job replacement allowance, people were more reluctant to add it to their pension.

Again, the study reveals that without proper explanations, people would withdraw compensation funds when they have the chance, yet it rejects the assumption that the term "compensation" damages savers' decisions.

\section{General Discussion}

The current chapter proposes a unique arena to look at the dependence between knowledge and behavior, as it focuses on pension decisions that often involve uncertainty, very long time-frame, and high complexity. The first study reveals that people are poorly informed about their pensions and that knowledge by itself has a weak influence on behavior. Many savers show inconsistent behavior, as they would like to cash out compensation funds, but at the same time are reluctant to take money out of their pension funds. Lack of knowledge does not explain this as contradictory since this behavior characterized all types of savers, including clients who know that they would get the compensation at their retirement. Overall, knowledge has a very limited predictive power, and its influences are overshadowed by financial constraints.

Based on the results of the customer survey, one might wonder if savers are doomed to take out money from their pension account. However, two behavioral experiments indicate that timely display of information to savers can reduce their willingness to conduct early withdrawals. The first experiment presents a positive impact of presentation of knowledge that associates compensation with pension savings account. While financial literacy has no impact on savers' decisions, providing timely information reduces subjects' likelihood to withdraw. The second study generalizes the findings on a representative sample of the Israeli population and reveals a framing effect that influences savers use of mental accounting when they decide what to do with their compensation funds. Together, the two experiments propose simple "nudges" to reduce money leakage from retirement saving accounts. While the survey indicated the knowledge has only limited influence on pension behavior, timely presentation of knowledge did have a significant impact on the tendency to withdraw. Similarly, clarity and simplicity of withdrawal 
request forms, and smart framing of mental accounts are tools that could be easily implemented on the compensation withdrawal process. The results indicate that those simple changes would increase savers ability to make an informed decision about their compensation funds.

To some extent, the growing interest in financial literacy is related to pension behavior. Lusardi and Mitchell's seminal work concentrated on financial literacy and financial preparation for retirement. Yet, more than a decade later, scholars are questioning the link between knowledge and behavior. In this work, I proposed to shift the focus from knowledge-based models of economic behavior to psychology-based models. While the first study confirms that people are poorly informed about their pension, it also suggests that amplifying general background knowledge is not the solution. Instead, the remaining two studies present a different approach that takes human limitations and cognitive biases into account. By rethinking the way people decide whether to cash-out money from their account, I was able to make a substantial reduction in their desire to withdraw. The idea of using psychological limitations to increase adequate financial behavior is obviously not new and relies on the highly popular "nudge" approach (R. Thaler \& Sunstein, 2008). Yet, in addition to the practical aspect of the two studies, I also proposed an account of the poor influence of knowledge, which conforms to the general approach of this work. According to this theory, knowledge is ineffective because (i) people struggle to impose self-control for complex behaviors that provide delayed gratification, and (ii) cognitive limitations make it hard to retrieve relevant knowledge when needed. Today, in order to cash-out their compensation funds, customers are asked to fill in many forms that do not include an explicit statement regarding the source of the funds. Customers are unaware that those withdrawals would hurt their pension, and given the poor influence of prior knowledge, do not take it into consideration even if they do understand the association between compensations and future annuity. The next step for this research would, therefore, be to develop an applicable protocol for early withdrawal that informs savers about the implications of their actions and to test the proposed theory. Further research should test the importance of the time of presentation display (before or during the decision), and the interactions between task complexity and time of information display. 


\section{Chapter 7: $\quad$ Summary and Conclusions}

In an economically complex world, the will to provide people with adequate financial skills has become a central objective for many social activists and policymakers (OECD, 2016). Up until recently, financial literacy training was considered the obvious solution for this aspiration, but lately, this perception is being challenged by a growing number of scholars. To be sure, knowledge is a virtue, but for most people, financial activity is not necessarily based on an understanding of inflation or on interest calculation, but is more a case of emotions, biases and short-term decisions (De Meza et al., 2008; Fernandes et al., 2014). The present work, too, criticizes the traditional role ascribed to financial literacy. However, it aims to go beyond criticizing this approach, and proposes a theoretical account of the way knowledge impacts behavior. The novel Cognitive Modulation of Economic Behavior [CMEB] could enhance the efforts made by so many to develop better and more effective financial education programs.

\section{Main findings}

Let us quickly review the chapters of this dissertation. Chapters 2 and 3 present findings from several surveys. In Chapter 2, an evaluation of financial literacy in Israel confirms the weak correlation between financial literacy and financial behavior, while careful analysis of the data yields further insights. Whereas the influence of financial literacy on management was mediated by income, investment behavior depended on financial literacy, but not on income.

The notion that the influence of financial literacy varies according to the type of economic task was confirmed in Chapter 3, which also presents a theoretical explanation. According to the theory, labeled as the CMEB - the Cognitive Modulation of Economic Behavior model individuals' ability to act according to their knowledge is mediated by two factors. The first is the amount of cognitive resources available to them, and the second is the type of financial task involved. The availability of cognitive resources depends on personal traits, such as self-control and emotional state, and on situational features such as income and financial condition. Moreover, these two dimensions are linked, inasmuch as the features of a financial task also influence the amount of cognitive resources required for the decision maker. Complicated behaviors and behaviors that provide only long-term advantages require self-regulation and 
deliberate thinking. The resources needed for the specific task, and the resources available to the individuals, due to situation or personality, jointly determine their ability to deploy financial knowledge when needed. When mental resources are scarce, people tend to operate intuitively and to rely on their habits and perceptions rather than their knowledge. The results of the surveys support this model. Knowledge is associated with wise consumption, but not with financial management. While the former includes simple tasks such as comparing prices at the store, the latter includes complicated behaviors such as creating an annual budget and planning for the future. The different time frames of the two tasks are also clear. The contribution of wise consumption could be felt immediately but recognizing the positive influence of annual planning is much harder and requires deliberate reflection on possible loses that might have been caused in the absence of a budget.

The results of Chapter 3 indicate that despite its weaknesses, financial literacy does contribute to some economic engagements when certain conditions encountered, specifically to economic behavior that does not require much cognitive resources. The next two chapters tested the influence of financial education on the ability to adopt new financial habits. That study is based on administrative data that was collected by the NGO that delivers the intervention and on responses to surveys collected from participants and graduates of the program. By evaluating the participants' financial state and behavior before, during, and after the intervention, this study serves as a field test of the proposed explanation for the influence of financial knowledge. The results confirmed that participants were less likely to adopt principles from the program that are related to management and planning, compared to wise consuming practices.

Chapter 4 focuses on the short-term impact of the intervention and is more descriptive by nature. The analysis in this chapter stresses the differences between participants from different socioeconomic status and reveals different paths to recovery - increase in income for low-wage participants and decrease in expenses for high-income participants.

Chapter 5 focuses on the long-term outcome of the program and it too allows to test CMEB model proposed in this work. Results indicate that all participants adopted principles of the program that were related to consumption. On the other hand, the likelihood to conduct management practices several years after the intervention was related to the participants' financial situation. 
So too, a longitudinal analysis shows that participants' financial situation at the end of the intervention predicts their management scores several years later, but not their consumption. The results confirm that the influence of financial knowledge is mediated by their financial situation, and by the features of the financial task that is being performed. The link is explained if we accept that lack of financial resources leads to cognitive load (Mani et al., 2013; Mullainathan \& Shafir, 2013). Further analyses that tested the effect of self-control, neuroticism, and financial avoidance showed the same pattern. Emotion or personality traits that lead to the depletion of cognitive resources decreased the tendency to engage in complicated management activities but did not impact the simple consumption engagements.

Chapter 6 looks at the dependency between knowledge and behavior in the context of pension decisions. The first study confirms previous findings regarding savers' poor pension knowledge and limited engagement. However, while researchers emphasize the link between knowledge and pension planning (Lusardi \& Mitchell, 2007), the present study reveals that early withdrawals are better explained by the need for money rather than by knowledge. Two behavioral experiments indicate a way to reduce early withdrawal by associating money cash-out with retirement savings at the time of the decision. The first experiment shows that a high level of financial literacy does not reduce the willingness to conduct early withdrawals. The second experiment reveals a framing effect in which savers that were offered to take compensation out of their retirement savings account were less likely to withdraw than savers that were asked to decide if they want to take the money or add it to their account. In both cases, subjects were told that the money comes from severance payments that were accumulated as compensation funds, but their behavior was affected by the framing of compensation as windfall or as long-term savings. Chapter 6 confirms the influence of poor knowledge on pension behavior, yet its importance stems from the results of the two behavioral experiments. While general financial literacy has little influence on behavior, wise display of information that takes savers' perceptions and limitations into account can reduce their desire to conduct early withdraw and so help them increase their long-term savings. 


\section{Theoretical framework}

The motivation for this research came from advancements in the field of financial education. Studies that challenged the methodology of financial literacy research and the logic behind investment in financial education have shifted the discussion from financial literacy to financial capability, a concept that concentrates on behavior, rather than knowledge (Johnson \& Sherraden, 2007; Sherraden, 2013). But we cannot discount the importance of knowledge. A strong link between financial knowledge and behavior was demonstrated, and naturally, financial literacy is considered to be part of financial capability. A meta-analysis by Miller et al. (2015) concluded that financial education positively influences certain areas of behavior, under certain conditions. As a result, the authors urge researchers to distinguish between different financial engagements in order to have a better understanding of the contribution of financial literacy. In this work, I extended this idea and devised the CMEB model that enables us to predict the domains and conditions in which financial literacy is likely to influence behavior.

The main principle that stands at the basis of this work is the similarity between literacy and rationality. By adopting the concept of rationality, I was able to apply a model of limitedresources on financial literacy. This seemingly simple idea paves the way for a sophisticated investigation of the mechanism by which financial knowledge influences behavior. The reason for irrational behavior has been heavily investigated in the past, and many researchers offered explanations for human behavior (Chaiken \& Trope, 1999; Kahneman, 2011; Stanovich \& West, 2000). Some focus on limited cognitive ability, while others focus on time perspective and separate short- and long-term considerations (Shefrin \& Thaler, 2004; Thaler \& Shefrin, 1981). The results presented in this work integrate these ideas. While knowledge had an influence on simple behaviors, it did not impact individuals' ability to perform complex economic engagements. In addition, the proposed model highlights the time frame of the decision under consideration. Knowledge strongly affects economic engagements that provide immediate and noticeable revenue but weakly influence behaviors whose contribution could be only traced in the long-term. 


\section{Limitations and future research}

The study has some limitations that should be acknowledged. The survey used in Chapter 2 was not designed for the purposes of this particular study and therefore should be interpreted with caution. Respondents in Chapter 3 were recruited via Amazon Turk Tool and might have different features from the general population (Ross, Irani, Silberman, Zaldivar, \& Tomlinson, 2010). Chapters 4 and 5 are subjected to selection bias of participants in intervention programs, and also due to their agreement to fill in the surveys (Collins \& O'Rourke, 2010). Despite a sound theoretical background, some of the findings might indicate correlations rather than causation and should, therefore, be interpreted with caution. On Chapter 6, participants in the first experiment were all students, who have little interest in pension domains.

The main weakness of the study is that it relies mostly on surveys and data analysis and does not test stipulated process directly. Therefore, one cannot exclude alternative explanations and reverse causality. Nevertheless, the results of all studies are consistent and point to the interrelations between knowledge and the availability of cognitive resources. The work should be seen as a fresh attempt to develop a comprehensive theory covering the varied effects of financial literacy, which still needs to be further investigated in the lab. For example, one can test the assumption that wise consumption requires fewer resources than planning. By manipulating cognitive load in a lab setting, we could get a clearer picture of the way cognitive limitations affect the ability to use pre-existing knowledge. Another interesting avenue would be the link between financial difficulties and financial avoidance. As for now, evidence regarding the direction of influence between the two is inconclusive (Shapiro \& Burchell, 2012; Sochos \& Latchford, 2016).

\section{Implications}

During this study, I was troubled by the meaning of my findings. Should we accept the idea that a large majority of the population is limited only to acquiring simple financial principles? The answer to this question came from work about human rationality. In their book Nudge, Thaler and Sunstein state that: "The more choices you give people, the more help with decision making you need to provide." Understanding that we need to work around humans' weaknesses can 
change our perception of the contribution of financial literacy, as we take those limitations into account.

In an attempt to increase the effectiveness of the intervention that was described in Chapters 4 and $5 \mathrm{I}$ conducted several meetings with the management of the NGO that delivered the program. Our understanding that we "cannot choose our clients" has led us to think of the architecture of the program as a supportive way to preserve program achievements. In those meetings, I have asked the attendees to think of ways that would reduce participants' need for self-control. This yielded several creative ideas. For example, providing people with a list of rules of thumb, ask program participants to plan their response for different situations in advance, and using automatic periodic reminders to push program graduates to work on their budgets. Apparently, studies have already confirmed the effectiveness of such practices. For example, Drexler, Fischer, \& Schoar (2014) demonstrated the effectiveness of rules of thumb; Gollwitzer's interventions, also known as implantation intentions, are formed around the concept of preplanning (Gollwitzer, 1999); and automatic reminders were shown to be very effective in several studies (Ericson, 2017; Karlan, McConnell, Mullainathan, \& Zinman, 2016). However, the majority of participants in those meetings did not know those practices before our meeting. Instead, it was their fresh understanding of the role of self-regulation and deliberate thinking that has led them to propose such solutions. This story demonstrates the contribution of a supportive theory that provides guidance and direction for action, instead of a random process of trial and error.

The implications of constructing a theoretical model of financial literacy have considerable implications for this research area. It would enable assessing the contribution of different elements over one's behavior and could serve as a basis to develop specific intervention programs among different populations. For example, we could identify that people from low economic status struggle to manage their money but can easily adopt simple principles and rules of thumb. For the high-income population, on the other hand, we can offer more sophisticated training, because they have the mental capacity needed to acquire and adopt complicated financial engagements such as planning, budgeting, and money management. Most importantly, I consider that the main contribution of this work is that it set the ground for developing theoretical advances in the field of financial literacy. While financial literacy research usually 
focuses on "what" rather than "why", the CMEB model propose a mechanism to explain the wideranging influence of financial literacy on economic behavior. This simple mechanism provides us with better understanding of the way people use financial knowledge and paves the way for new insights and theoretical developments that are still much needed in this field. 


\section{References}

Ando, A., \& Modigliani, F. (1963). The" life cycle" hypothesis of saving: Aggregate implications and tests. The American Economic Review, 53(1), 55-84.

Atkinson, A., McKay, S., Collard, S., \& Kempson, E. (2007). Levels of financial capability in the UK. Public Money and Management, 27(1), 29-36.

Baumeister, R. F. (2002). Yielding to temptation: Self-control failure, impulsive purchasing, and consumer behavior. Journal of Consumer Research, 28(4), 670-676.

Braunstein, S., \& Welch, C. (2002). Financial literacy: An overview of practice, research, and policy. Fed.Res.Bull., 88, 445.

Carmel, E., Carmel, D., Leiser, D., \& Spivak, A. (2015). Facing a biased adviser while choosing a retirement plan: The impact of financial literacy and fair disclosure. Journal of Consumer Affairs, 49(3), 576-595.

Chaiken, S., \& Trope, Y. (1999). Dual-process theories in social psychology. New York: Guilford Press.

Chen, H., \& Volpe, R. P. (1998). An analysis of personal financial literacy among college students. Financial Services Review, 7(2), 107-128. 
Cheng, Y., Shein, P. P., \& Chiou, W. (2012). Escaping the impulse to immediate gratification: The prospect concept promotes a future-oriented mindset, prompting an inclination towards delayed gratification. British Journal of Psychology, 103(1), 129-141.

Clark, R. L., Morrill, M. S., \& Allen, S. G. (2012). The role of financial literacy in determining retirement plans. Economic Inquiry, 50(4), 851-866.

Central Bureau of Statistic [CBS]. (2012). Financial Literacy Survey: Knowledge, Opinions and Behavior in Financial Issues. Media release. retrieved from: http://cbs.gov.il/www/hodaot2012n/25_12_297e.pdf

Cochran, W. G., \& Rubin, D. B. (1973). Controlling bias in observational studies: A review. Sankhyā: The Indian Journal of Statistics, Series A, , 417-446.

Cole, S. A., \& Shastry, G. K. (2009). Smart money: The effect of education, cognitive ability, and financial literacy on financial market participation. Harvard Business School Boston, MA.

Collins, J. M., \& O'ROURKE, C. M. (2010). Financial education and counseling-Still holding promise. Journal of Consumer Affairs, 44(3), 483-498.

De Meza, D., Irlenbusch, B., \& Reyniers, D. (2008). Financial capability: A behavioural economics perspective, Financial Services Authority. London.

Drexler, A., Fischer, G., \& Schoar, A. (2014). Keeping it simple: Financial literacy and rules of thumb. American Economic Journal: Applied Economics, 6(2), 1-31. 
Duflo, E. (2006). Poor but rational? understanding poverty. Oxford, 367-378.

Ericson, K. M. (2017). On the interaction of memory and procrastination: Implications for reminders, deadlines, and empirical estimation. Journal of the European Economic Association, 15(3), 692-719.

Evans, J. S. B., Handley, S. J., \& Bacon, A. M. (2009). Reasoning under time pressure: A study of causal conditional inference. Experimental Psychology, 56(2), 77.

Fernandes, D., Lynch Jr, J. G., \& Netemeyer, R. G. (2014). Financial literacy, financial education, and downstream financial behaviors. Management Science, 60(8), 1861-1883.

Finucane, M. L., Alhakami, A., Slovic, P., \& Johnson, S. M. (2000). The affect heuristic in judgments of risks and benefits. Journal of Behavioral Decision Making, 13(1), 1.

Forster, M., Chen, W., \& Llenanozal, A. (2011). Divided we stand: Why inequality keeps rising OECD.

Galai, D., \& Sade, O. (2006). The "ostrich effect" and the relationship between the liquidity and the yields of financial assets. The Journal of Business, 79(5), 2741-2759.

Ghilarducci, T., Radpour, S., Fisher, B., \& Webb, A. (2016). Household economic shocks increase retirement wealth inequality. The New School, Schwartz Center for Economic Policy Analysis. 
Gick, M. L., \& Holyoak, K. J. (1983). Schema induction and analogical transfer. Cognitive Psychology, 15(1), 1-38.

Gollwitzer, P. M. (1999). Implementation intentions: Strong effects of simple plans. American Psychologist, 54(7), 493.

Hilgert, M. A., Hogarth, J. M., \& Beverly, S. G. (2003). Household financial management: The connection between knowledge and behavior. Fed.Res.Bull., 89, 309.

Huston, S. J. (2010). Measuring financial literacy. Journal of Consumer Affairs, 44(2), 296-316.

Jaffe, D. H., Eisenbach, Z., Neumark, Y. D., \& Manor, O. (2005). Individual, household and neighborhood socioeconomic status and mortality: A study of absolute and relative deprivation. Social Science \& Medicine, 60(5), 989-997.

James, S., Lahti, T., \& Thaler, R. H. (2006). Individual preferences, monetary gambles, and stock market participation: A case for narrow framing. The American Economic Review, 96(4), 1069-1090.

Johnson, E., \& Sherraden, M. S. (2007). From financial literacy to financial capability among the young. J.Soc.\& Soc. Welfare, 34, 119.

Kahneman, D. (2011). Thinking, fast and slow Macmillan.

Karlan, D., McConnell, M., Mullainathan, S., \& Zinman, J. (2016). Getting to the top of mind: How reminders increase saving. Management Science, 62(12), 3393-3411. 
Karlsson, N., Loewenstein, G., \& Seppi, D. (2009). The ostrich effect: Selective attention to information. Journal of Risk and Uncertainty, 38(2), 95-115.

Krill, Z. (2016). What is the expected standard of living for young savers? Discussion paper. (Hebrew), Ministry of Finance. Jerusalem, Israel:

http://mof.gov.il/ChiefEcon/EconomyAndResearch/ArticlesSet/Article_2016323.pdf

Laibson, D. (1997). Golden eggs and hyperbolic discounting. The Quarterly Journal of Economics, 112(2), 443-478.

Leiser, D., \& Shemesh, Y. (2018). How we misunderstand economics and why it matters: The psychology of bias, distortion and conspiracy. London: Routledge.

Lemelson, D. (2017). Saving the compensation funds (Unpublished master's thesis). Ben-Gurion university of the Negev, Beer Sheva, Israel.

Liberman, N., Sagristano, M. D., \& Trope, Y. (2002). The effect of temporal distance on level of mental construal. Journal of Experimental Social Psychology, 38(6), 523-534.

Loibl, C. (2017). Living in poverty: Understanding the financial behaviour of vulnerable groups. Economic Psychology, 421-434.

Lusardi, A., \& Mitchell, O. S. (2007). Baby boomer retirement security: The roles of planning, financial literacy, and housing wealth. Journal of Monetary Economics, 54(1), 205-224.

Lusardi, A., \& Mitchelli, O. (2007). Financial literacy and retirement preparedness: Evidence and implications for financial education. Business Economics, 42(1), 35-44. 
Mani, A., Mullainathan, S., Shafir, E., \& Zhao, J. (2013). Poverty impedes cognitive function. Science (New York, N.Y.), 341(6149), 976-980.

McClure, S. M., Laibson, D. I., Loewenstein, G., \& Cohen, J. D. (2004). Separate neural systems value immediate and delayed monetary rewards. Science, 306(5695), 503-507.

Miller, M., Reichelstein, J., Salas, C., \& Zia, B. (2015). Can you help someone become financially capable? A meta-analysis of the literature. The World Bank Research Observer, 30(2), 220246.

Mischel, W. (2014). The marshmallow test: Understanding self-control and how to master it Random House.

Modigliani, F., \& Brumberg, R. (1954). Utility analysis and the consumption function: An interpretation of cross-section data. Franco Modigliani, 1, 388-436.

Mullainathan, S., \& Shafir, E. (2013). Scarcity: Why having too little means so much Macmillan.

Pocheptsova, A., Amir, O., Dhar, R., \& Baumeister, R. F. (2009). Deciding without resources: Resource depletion and choice in context. Journal of Marketing Research, 46(3), 344-355.

Rabinovich, A., \& Webley, P. (2007). Filling the gap between planning and doing: Psychological factors involved in the successful implementation of saving intention. Journal of Economic Psychology, 28(4), 444-461. 
Rha, J., Montalto, C. P., \& Hanna, S. D. (2006). The effect of self-control mechanisms on household saving behavior. Financial Counseling and Planning, 17(2)

Rosen, M. H., \& Sade, O. (2017). Does financial regulation unintentionally ignore less privileged populations? Bank of israel research department. Jerusalem: Israel

Ross, J., Irani, L., Silberman, M., Zaldivar, A., \& Tomlinson, B. (2010). Who are the crowdworkers?: Shifting demographics in mechanical turk. Paper presented at the $\mathrm{CHI} 10$ Extended Abstracts on Human Factors in Computing Systems, 2863-2872.

Schmeichel, B. J., Vohs, K. D., \& Baumeister, R. F. (2003). Intellectual performance and ego depletion: Role of the self in logical reasoning and other information processing. Journal of Personality and Social Psychology, 85(1), 33.

Shah, A. K., Mullainathan, S., \& Shafir, E. (2012). Some consequences of having too little. Science, 338(6107), 682-685.

Shalvi, S., Eldar, O., \& Bereby-Meyer, Y. (2012). Honesty requires time (and lack of justifications). Psychological Science, 23(10), 1264-1270.

Shapiro, G. K., \& Burchell, B. J. (2012). Measuring financial anxiety. Journal of Neuroscience, Psychology, and Economics, 5(2), 92.

Shefrin, H. M., \& Thaler, R. H. (1988). The behavioral life-cycle hypothesis. Economic Inquiry, 26(4), 609-643. 
Shefrin, H. M., \& Thaler, R. H. (2004). Mental accounting, saving, and self-control. Advances in Behavioral Economics, , 395-428.

Sherraden, M. S. (2013). Building blocks of financial capability. Financial Education and Capability: Research, Education, Policy, and Practice, , 3-43.

Simon, H. A. (1972). Theories of bounded rationality. Decision and Organization, 1(1), 161-176.

Sirin, S. R. (2005). Socioeconomic status and academic achievement: A meta-analytic review of research. Review of Educational Research, 75(3), 417-453.

Sochos, A., \& Latchford, E. (2016). Financial aversion and its link to attachment anxiety. Current Psychology, 35(4), 606-614.

Stanovich, K. E., \& West, R. F. (2000). Individual differences in reasoning: Implications for the rationality debate? Behavioral and Brain Sciences, 23(5), 645-665.

Thaler, R., \& Sunstein, C. (2008). Nudge: Improving decisions about health, wealth, and happiness yale university press. New Haven, $C T$,

Thaler, R. (1985). Mental accounting and consumer choice. Marketing Science, 4(3), 199-214.

Thaler, R. H., \& Shefrin, H. M. (1981). An economic theory of self-control. Journal of Political Economy, 89(2), 392-406.

Trope, Y., \& Liberman, N. (2000). Temporal construal and time-dependent changes in preference. Journal of Personality and Social Psychology, 79(6), 876. 
Tversky, A., \& Kahneman, D. (1974). Judgment under uncertainty: Heuristics and biases. Science, 185(4157), 1124-1131.

Tversky, A., \& Kahneman, D. (1981). The framing of decisions and the psychology of choice. Science, 211(4481), 453-458.

Van Rooij, M., Lusardi, A., \& Alessie, R. (2011). Financial literacy and stock market participation. Journal of Financial Economics, 101(2), 449-472.

Vohs, K. D. (2013). Psychology. the poor's poor mental power. Science, 341(6149), 969-970.

Webb, T. L., Chang, B. P., \& Benn, Y. (2013). 'The ostrich problem': Motivated avoidance or rejection of information about goal progress. Social and Personality Psychology Compass, 7(11), 794-807.

Willis, L. E. (2008). Against financial literacy education. lowa Law Review, 94, 08-10.

Willis, L. E. (2011). The financial education fallacy. The American Economic Review, 101(3), 429434.

Zhan, M., Anderson, S. G., \& Scott, J. (2006). Financial knowledge of the low-income population: Effects of a financial education program. J.Soc.\& Soc. Welfare, 33, 53. 


\section{Appendix 2A - Financial Literacy Survey: Knowledge, Behavior and}

\section{Perceptions}

The survey was developed and delivered by the Israeli Central Bureau of Statistics. Fall 2012

\section{A. CURRENT ACCOUNT}

1. Do you have a current account at the bank? (your own, or joint with a member of your household)

1. Yes $\rightarrow$ continue to next question

2. No $\rightarrow$ Jump to question 6

2. Have you checked the status of your current account in the last 12 months, and if so, how often?

1. I haven't $\rightarrow$ jump to question 4

2. Yes, once a week or more

3. Yes, several times a month

4. Yes, once a month to once in three months

5. Yes, once in three months or less

3. In the last 12 months, have you used the following information sources to get updated about the state of your current account?

1. Messages received from the bank (by mail, email, or SMS)

2. The Bank's website

3. A phone call

4. An automatic banking services machine (ATM, Bankat)

5. A meeting at the bank which you've initiated

6. Other

Describe:

4. Is someone else in your household tracking the state of your current account? Yes/No/I don't know

5. Following is a list of various events related to the conduct of your current account, indicate how often they have occurred in the last 12 months (Never/Once/2-3 times/4 times or more/This is usually the case)

1. You had an overdraft in your current account

2. A bank clerk contacted you due to a deviation from your credit limit 


\section{Your current account was blocked}

6. Who is the household member mostly responsible for paying bills, such as electricity and municipal tax?

1. You

2. Your partner (who lives with you in the same household)

3. A parent (who lives with you in the same household)

4. Another member of the household

5. There isn't one member of the household who is primarily responsible

6. Someone outside the household

7. No one is responsible

8. I don't know

\section{B. CREDIT CARDS}

7. How many credit cards do you have, including non-bank cards such as those of supermarkets, gas stations, etc.

1. I don't have a credit card $\rightarrow$ jump to question 11

2. One credit card

3. Two cards

4. Three cards

5. Four cards or more

8. During the last 12 months, have you done any of the following with your credit card? (Yes/No/Don't know)

1. Postponement of payment

2. Purchasing in installments, without interest

3. Paying interest on a transaction

4. Taking a loan from the credit card company

9. Were these considerations important to you when selecting a credit card company?

1. This is the card issued by the bank

2. Discounts at businesses/accumulation of points or stars/consumers' club

3. Suitable credit

4. A possibility to receive loans and/or spread payments, or having a suitable interest rate for transactions made in payments 
5. Low card rates or an exemption from card rates

6. Other

10. In the last 12 months, has your credit card been blocked or has a transaction been blocked due to financial irregularities? (Yes/No/Don't know)

\section{MORTGAGE - A LOAN TAKEN TO BUY REAL ESTATE/A HOUSE}

The following questions relate to a mortgage you have separately or jointly with someone from your household

11. Do you have a mortgage?

1. Yes $\rightarrow$ continue to the next question

2. No $\rightarrow$ jump to question 13

12. What sources of information did you use when taking the mortgage?

1. A mortgage bank

2. A different professional advisor

3. Websites and/or commercials

4. Friends and relative

5. A different source of information

6. No sources of information

7. I don't know

\section{LOANS AND DEBTS}

13. Do you have a loan from one of the following bodies? Not including mortgage (Yes/No/Don't know)

1. A credit card company

2. An insurance company

3. A financial body that manages provident funds, pension funds etc.

4. An employer

5. A business/a different organization

6. A private individual

7. A different body:

14. In the last year, have you had debt or bills that weren't paid on time? 
1. No debt or bills that weren't paid on time $\rightarrow$ jump to question 16

[No/Don't know/Yes, up to 1000 ILS/Yes, 1000-5000 ILS/Yes, over 5000 ILS]

2. The tax authority

3. The Enforcement and Collection

4. A municipality

5. A service provider such as the electricity or water company

6. A different business or organization

7. A private individual

8. Other:

15. During the last 12 months, have you been subject to pressure to pay debt from private bodies to which you owe money? (Yes/No/Don't know)

\section{E. FINANCIAL INVESTMENTS - SAVINGS, FUNDS, SECURITIES, AND INSURANCE}

16. Do you own any of the following financial products: (Yes/No/Don't know)

1. A savings account and/or deposit at the bank

2. An advanced study fund

3. A provident fund

4. A pension fund

5. Managers' insurance

6. Life insurance with a savings component (excluding managers' insurance)

7. A mutual fund or an exchange-traded note

8. Bonds or stock

9. A different financial investment:

If you answered "yes" at least once $\rightarrow$ continue to the next question

If you answered "no" or "I don't know" on all sections $\rightarrow$ jump to question 18

17. Who is the main decider in the household in the choice between different investment options or financial companies?

1. You

2. Your partner (who lives with you in the same household)

3. A parent (who lives with you in the same household)

4. Another member of the household

5. There isn't one member of the household who is primarily responsible

6. Someone outside the household 
7. No one is responsible

8. I don't know

18. Are you insured with the following types of insurance: (Yes/ No/ DK/ I have nothing to Insure)

1. comprehensive car insurance

2. Apartment structure

3. Apartment contents

4. Health and/or nursing

5. Mortgage insurance

6. Life insurance (excluding managers' insurance)

19. In the past year, have you used paid services of a consultant (such as pension advisor, tax consultant, accountant, insurance agent etc.) for: [Yes/No/Don't know]

1. Managing the day-to-day household budget

2. Insurance

3. Mortgage loans

4. Savings and deposits

5. Provident fund or pension fund

6. Managing an investment portfolio

\section{F. KNOWLEDGE AND OPINIONS IN FINANCIAL MATTERS}

20. Following are several statements regarding financial matters. Please mark whether you think each statement is true or false:

1. "Prime interest" is higher than the interest rate set by the Bank of Israel

2. When inflation is high, the cost of living increases quickly

3. The risk level of an investment portfolio can be diminished by buying a large variety of financial instruments

4. An investment with a high yield (high profit) is mostly a risky investment

21. Say you've made a one-time investment of 1,000 NIS to a savings account that yields an interest of 2 percent a year. How much money would accumulate in the account at the end of the first year (the account isn't linked to the consumer price index; the total is before tax deduction)?

1. The amount is: NIS

2. I don't know

22. Say you've made a one-time investment of 1,000 NIS to a savings account that yields a compound interest of 5 percent a year. How much money would accumulate in the account 
at the end of two years (the account isn't linked to the consumer price index; the total is before tax deduction)?

1. Over $1,100 \mathrm{NIS}$

2. Exactly 1,100 NIS

3. Under $1,100 \mathrm{NIS}$

4. It's impossible to know provided the existing information

5. I don't know

23. Do you know the exact interest rates in your savings accounts?

1. I don't have savings accounts in the bank

2. I know the exact interest rates

3. I know the interest rates, but not precisely

4. I don't know

24. How frequently do you seek information on economic and financial subjects in the following data sources: [Never/Less than once a month/1-3 times a month/Once a week/ Several times a week]

1. Newspaper articles (printed or online)

2. Radio or TV shows

3. People who you think are familiar with the subject

4. Internet forums

5. Government bodies such as the Ministry of Finance or the Bank of Israel

6. Financial business companies

7. NGOs or nonprofits

8. Other information sources:

25. Following are several statements on financial issues. Please mark the degree to which you agree with each of them: [Agree Strongly-----Disagree]

1. I keep close track of my expenses

2. Most months I have a hard time making ends meet

3. I pay my bills on time

4. I buy things even if I have no money

5. I Compare prices before purchase

6. I'm more frugal than a lavish spender

7. My knowledge of financial issues is sufficient to choose between investments

8. I'm willing to take risks when investing

9. I'd rather spend money today than save for the long-term

10. I make comparisons between investment options and/or financial companies when choosing an investment

26. In which financial areas would you like to expand your knowledge?

1. Managing a family budget 


\section{Consumer awareness}

3. Loans

4. Savings and investment

5. Insurance

6. Mortgage

7. I don't feel a need to expand my knowledge

27. Would you be interested in reading and/or receiving information on financial and economic subjects from the following sources? [Interested/Not interested/Don't know]

1. Newspaper articles (printed or online)

2. Radio or TV shows

3. People who you think are familiar with the subject

4. Internet forums

5. Government bodies such as the Ministry of Finance or the Bank of Israel

6. Financial business companies

7. NGOs or nonprofits

8. Paid financial consultants

9. Other information sources:

If you answered "interested" to one of the sections $\rightarrow$ continue to next question

If you answered "not interested" or "I don't know" to all of them $\rightarrow$ jump to question 29

28. Out of the list of sources you've marked in the last question (27), which is your preferred channel to receive information on financial matters?

1. Write the answer number from the list:

2. No preferred information sources

3. I don't know

29. What, in your opinion, is your level of knowledge regarding mortgage tracks (different payment options)

1. Very good

2. Good

3. Mediocre

4. Weak

5. I have no knowledge on the subject 
Appendix 2B - Factor Loadings

\author{
Factor Loadings (Quartimax raw). \\ Extraction: Principal component. Eigenvalue $>1$. \\ Marked loadings are $>.50$
}

\begin{tabular}{lll}
\hline & Management & Investment \\
\hline Follow monetary expenses & 0.645 & 0.013 \\
Struggle to pay for basic expenses & 0.590 & 0.150 \\
Pay bills on time & 0.687 & 0.082 \\
I buy things even if I have no money & 0.547 & 0.326 \\
\hline I Compare prices before purchase & 0.768 & 0.149 \\
Thrifty & & 0.201 \\
\hline Improvident & 0.730 & 0.741 \\
\hline Sufficient knowledge to invest & 0.256 & 0.802 \\
\hline Take risks in investments & 0.210 & 0.751 \\
\hline Compare investment tracks & 0.246 \\
\hline
\end{tabular}

Money management: Q1-Q6

Choosing products: Q7-Q10 


\section{Appendix 3A - Financial Capability and Literacy Survey}

* The survey was delivered to an international group of respondents using Amazon MTurk platform.

In the following survey you will be asked about your habits, attitudes, and knowledge in diverse aspects of your daily life. We would like you to report as accurately as you can.

Keep in mind that most questions are about you personally and do not have a correct answer. Information will be used for academic purposes only.

What is your age?

What is your gender?

What is your country of origin? Write 'none' if you are uncomfortable answering.

What is your ethnicity?

o White

- Hispanic or Latino

- Black or African American

- Native American

- Asian or Pacific Islander

o Other

- I don't want to share.

Q1.6 What is your marital status?

Q1.7 What is the highest level of education you've achieved thus far?

Q1.8 What is your employment status?

Q1.9 What is your household income compared to the average household income in your region?

○ Much less

○ Less

- Somewhat Less

○ The Same

- Somewhat More

○ More

- Much More

- I don't want to share.

Q1.10 How would you define your current financial condition?

○ Very Bad

- Bad

- Neither Bad nor Good 
○ Good

- Very Good

o I don't want to share.

Financial capability

\section{Money management}

Please choose the answer you identify with the most [one to five Likert scale 1 - Strongly agree, 5 - Strongly disagree]:

- I keep close track of my income and expenses.

- I built a budget of my income and expenses according to my expected cash flows for the upcoming year.

- I am staying within the confines of my budget according to changes in my financial situation and do not exceed financial resources.

- At the end of the month, I have money left in my account.

- I have enough resources to pay my bills on time.

- My income is higher than my expenses.

- I know approximately how much money I owe on my bank credit card balance(s).

\section{Planning ahead:}

For each of the following statements, choose the best answer you most identify with [1-Strongly agree, 5 - Strongly disagree]:

- I identify large expenses that are to be paid in the near future and am preparing for them, for example, holidays, birthdays, car insurance.

- I identify large expenses that are to be paid in the far future and am preparing for them, for example, a new car, house upgrades, higher education.

- I set aside money for my pension every month.

- I have funds allocated for emergencies.

- I know how to prepare for unexpected expenses. 


\section{Choosing products}

For each of the following statements, choose the best answer you most identify with [one to five Likert scale 1- Not at all, 5 - Very much]:

- I compare prices prior to purchasing a new product.

- Before buying, I consult with others or search for peer reviews.

- When I buy something, I purchase unrelated items impulsively.

- I occasionally check my service provider's product offerings (television, telephone, pension services) and actively seek better options.

- I look for alternatives to making purchases if possible (e.g., renting a library book, using public transportation rather than buying a car).

- I plan my purchases prior to shopping, e.g., creating a grocery list before going to the supermarket.

\section{Staying informed}

You will now be given statements about different sources of financial information. Please choose the answer you identify with the most [1- Strongly agree, 5 - Strongly disagree]:

- I read my bank statements.

- I consult a professional before making important financial decisions.

- I consult a family member(s) before making important financial decisions.

- I read financial periodicals or otherwise follow financial news via other media, e.g. television, radio, podcasts.

- I believe it is important to have financial knowledge.

- I follow the changes in: real estate market; stock market; national inflation rate; national interest rates; taxation; job market.

\section{Financial literacy}

Please answer the following questions to the best of your ability by yourself. 
1. Imagine that five brothers are given a gift of $\$ 1,000$. If the brothers have to share the money equally, how much does each one get?

2. Now imagine that the brothers have to wait for one year to get their share of the $\$ 1,000$ and inflation stays at 2 percent. In one year's time will they be able to buy:

a. More with their share of the money than they could today

b. The same amount

c. Less than they could buy today

d. I don't know

3. You lend $\$ 25$ to a friend one evening and he gives you $\$ 25$ back the next day. How much interest has he paid on this loan?

4. Suppose you put $\$ 100$ into a "no fee" savings account with a guaranteed interest rate of $2 \%$ per year. You don't make any further payments into this account and you don't withdraw any money.

How much would be in the account at the end of the first year, once the interest payment is made?

5. Continued from previous question: How much would be in the account at the end of five years. Would it be:

a. More than $\$ 110$

b. Exactly $\$ 110$

c. Less than $\$ 110$

d. It is impossible to tell from the information given

e. I don't know

6. An investment with a high return is likely to be high risk.
a. True
b. False
c. I don't know

7. High inflation means that the cost of living is increasing rapidly.
a. True
b. False
c. I don't know

8. It is usually possible to reduce the risk of investing in the stock market by buying a wide range of stocks and shares.
a. True
b. False
c. I don't know 


\section{Appendix 3B - Cluster Analysis of Financial Capability Survey}

The analysis reveals two main clusters:

a. Upper cluster that contains "money management" and "planning ahead"

b. Lower cluster includes "choosing product" and "staying informed".

Statements in the upper cluster are formed around the two topics:

(i) having sufficient resources - pay bills on time, having enough money, having emergency savings, etc., (ii) practical administration of household income and expenditures - keep record, create budget, plan for the short and the long-term (see Figure).

Based on this segmentation the groups were labeled as "making ends meet", and "money management".
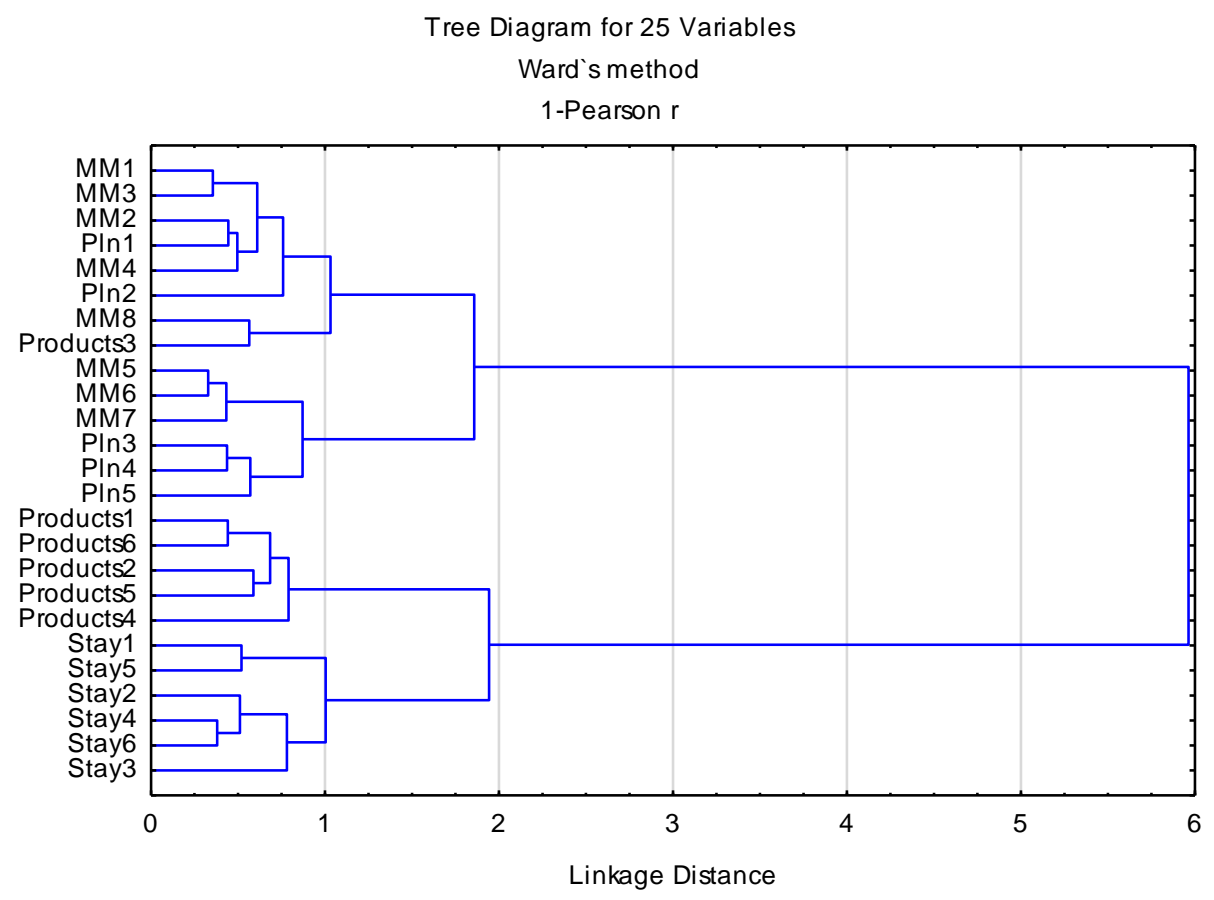

Cluster labels:

MM - Managing Money

Pln - Planning Ahead

Products - Choosing Products

Stay - Staying Informed 


\section{Appendix 4A - Paamonim Intervention. Program Description}

The intervention includes personal guidance and supervision by trained volunteers that serve as mentors. Each volunteer or pair of volunteers works with one or two households at a time. They help the households get a clear picture of their situation, take actions to improve it, and finally advise them on how to deal with outstanding debt and plan for the future.

Meetings are conducted at the participants' house every 2-4 weeks. When necessary, participants are offered free-of-charge professional support of insurance agents, mortgage consultant, and financiers. Mentors may also escort participants to the bank or be present while they negotiate with their lenders, but participants are required to be active and to take responsibility for their action. Proactivity is defined as a keystone of the program, and unmotivated members may be dismissed from the program. Typical treatment includes 7-10 meetings during a 6-12-month period.

The mentors operate according to a four-stage scheme. At each stage, the volunteers consult with senior volunteers and professional staff.

\section{$\underline{\text { Program structure }}$}

1. Intake - reflection of the household financial state

2. Striving to balance - create and implement initial budget

3. Recovery Plan - develop and implement permanent budget and taking care of debts

4. Ending Sessions - plans for the future and summary.

The program has two objectives: to attain financial recovery and to develop financial capabilities that would enable the participants to act responsibly after the completion of the program.

According to their website, during 2016 the organization had 2800 volunteers who worked with 7080 families and individuals. For more information about the program, see: http://www.paamonim.org/en/ 
Factor Loadings (Quartimax raw).

Extraction: Principal component. Eigenvalue $>1$.

Marked loadings are $>.60$

Management Consumption Competence

\begin{tabular}{llll}
\hline 1. Organize documents on regular basis & 0.52 & 0.29 & -0.02 \\
\hline 2. Keeping track of your expenses & 0.72 & 0.21 & 0.15 \\
\hline 3. Annual planning & 0.74 & 0.06 & 0.16 \\
\hline 4. Follow budget & 0.68 & 0.08 & 0.26 \\
\hline 5. Short-term preparation & 0.79 & 0.03 & 0.12 \\
\hline 6. Long-term preparation & 0.69 & 0.04 & 0.26 \\
\hline 7. Have regular savings & -0.12 & 0.13 & 0.37 \\
\hline 8. Compare prices & 0.21 & 0.76 & 0.06 \\
\hline $\begin{array}{l}\text { 9. Shopping list } \\
\text { 10. Looking for alternatives }\end{array}$ & 0.20 & 0.73 & 0.15 \\
\hline 11. Confidence on ability to manage financial \\
affairs
\end{tabular}

Management: Q1-Q6*

Consumption: Q8-Q10

Sense of financial competence: Q11-Q13

*The management category includes Q1 despite a relatively small loading based on the categorization offered by Atkinson et al. (2007). 


\section{Appendix 4C - Income and Demographic Distributions}

Income distribution of program participants comparing to the general population.

\begin{tabular}{ccccc|c}
\hline \multicolumn{5}{c}{ Paamonim } & ISRAEL \\
Decile & 2011 & 2013 & 2014 & 2015 & 2012 \\
\hline 1 & 4,921 & 5,847 & 6,486 & 5,810 & 4,000 \\
2 & 7,473 & 8,664 & 8,978 & 8,581 & 6,564 \\
3 & 8,977 & 10,291 & 10,718 & 10,437 & 8,459 \\
4 & 10,074 & 11,628 & 12,086 & 11,779 & 10,238 \\
5 & 11,107 & 12,805 & 13,148 & 13,223 & 12,110 \\
6 & 12,165 & 14,098 & 14,258 & 14,608 & 14,243 \\
7 & 13,325 & 15,566 & 15,559 & 16,123 & 16,686 \\
8 & 14,985 & 17,263 & 17,100 & 17,905 & 20,016 \\
9 & 16,791 & 19,802 & 18,905 & 20,108 & 24,595 \\
10 & 21,511 & 25,289 & 25,428 & 26,063 & 38,393 \\
Average & 12,133 & 14,125 & 14,266 & 14,464 & 15,530
\end{tabular}

\begin{tabular}{|l|c|c|}
\hline Area & $\begin{array}{c}\text { Paamonim } \\
\text { population }\end{array}$ & $\begin{array}{c}\text { General } \\
\text { population }\end{array}$ \\
\hline Jerusalem district & 9 & 4 \\
\hline North district & 16 & 12 \\
\hline Haifa district & 6 & 15 \\
\hline Center district & 38 & 24 \\
\hline Tel-Aviv district & 7 & 23 \\
\hline South district & 13 & 3 \\
\hline Judea and & & \\
district & &
\end{tabular}


Income distribution of sample comparing to the target population.

\begin{tabular}{|c|c|c|}
\hline Decile & $\begin{array}{c}\text { Target population } \\
\text { (ILS) } \\
2011-2013\end{array}$ & $\begin{array}{c}\text { Sample (ILS) } \\
2015\end{array}$ \\
\hline 1 & 5,475 & 6,146 \\
\hline 2 & 8,177 & 8,589 \\
\hline 3 & 9,739 & 10,403 \\
\hline 4 & 11,014 & 12,054 \\
\hline 5 & 12,174 & 13,737 \\
\hline 6 & 13,336 & 15,400 \\
\hline 7 & 14,840 & 17,573 \\
\hline 8 & 16,423 & 19,577 \\
\hline 9 & 18,768 & 21,925 \\
\hline 10 & 24,288 & 28,737 \\
\hline Total & 13,423 & 15,414 \\
\hline
\end{tabular}

Households' earnings were a bit higher among the sample group than expected, although this might be related to inaccurate self-reports. During the course of time since graduation, participants had an average increase of 12 percent in their income, comparing to an average 8.7 percent increase in the general population in Israel. 


\section{Appendix 5A - Sample Distributions}

Area of living comparing to the target population.

\begin{tabular}{|c|c|c|c|}
\hline Area & $\begin{array}{c}\text { Target } \\
\text { population }\end{array}$ & Study 1 & Study 2 \\
\hline Jerusalem district & 9 & 11 & 11 \\
\hline North district & 16 & 13 & 13 \\
\hline Haifa district & 6 & 5 & 10 \\
\hline Center district & 38 & 40 & 32 \\
\hline Tel-Aviv district & 7 & 7 & 16 \\
\hline South district & 12 & 12 & 9 \\
\hline $\begin{array}{l}\text { Judea and Samaria } \\
\text { district }\end{array}$ & 13 & 13 & 8 \\
\hline
\end{tabular}

Distribution of area of residence of the two samples comparing to the target population. Study 3 oversampled program graduates from Haifa and Tel-Aviv districts. 
Income distributions:

Study 1

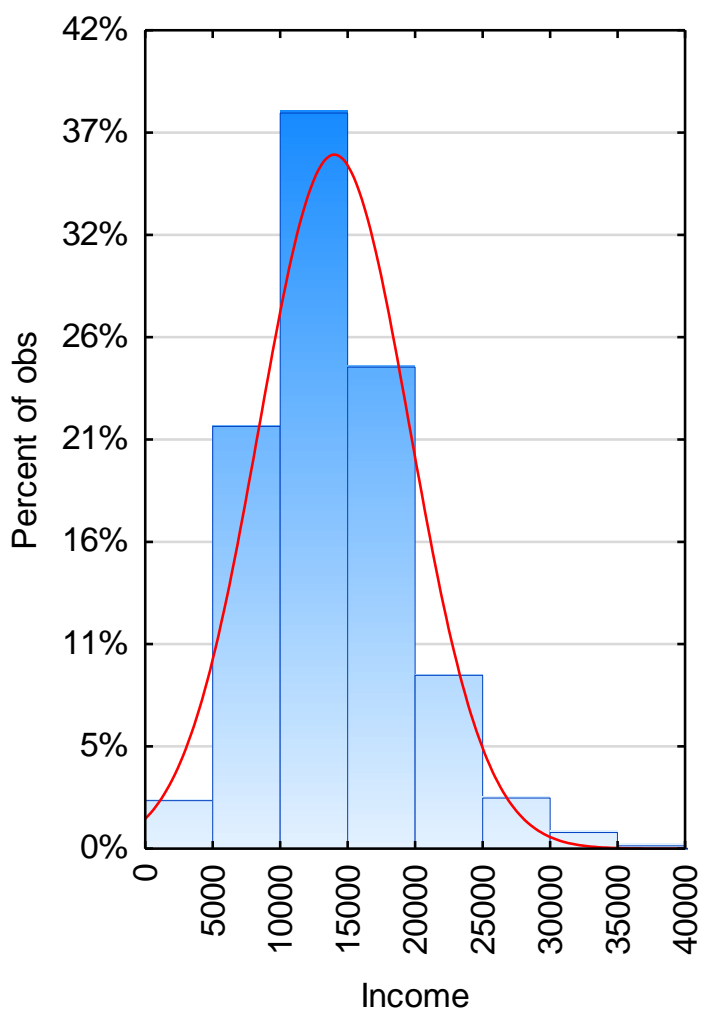

Study 2

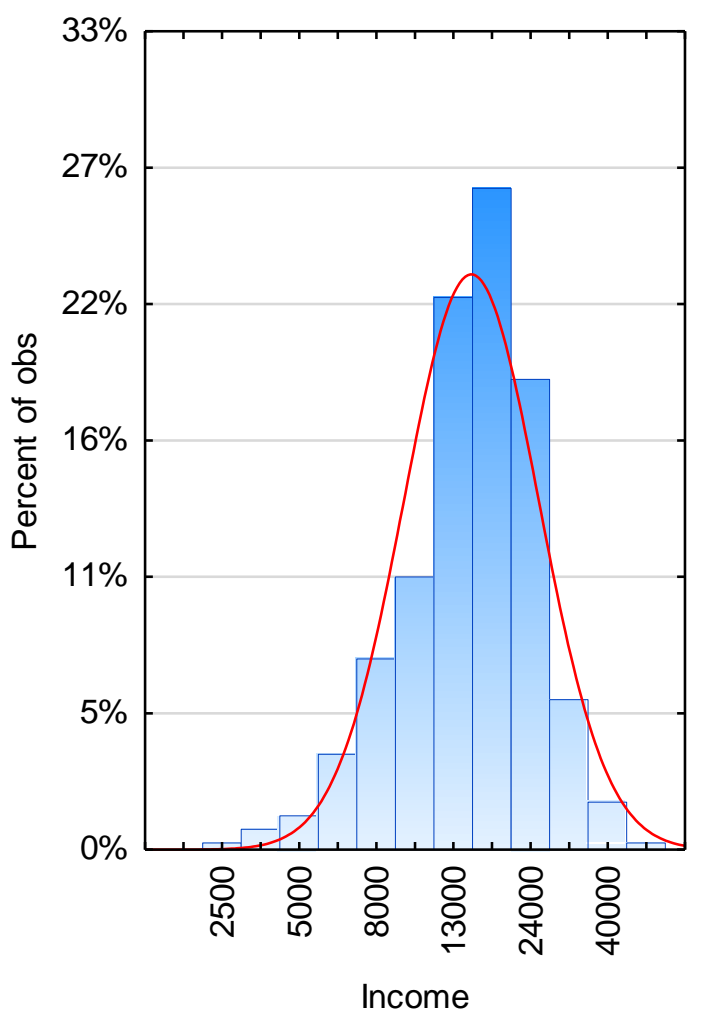

Each study had a different measurement for household income. Study 1 was based on direct report of monthly income, while Study 2 used a categorical question. This difference prevents a direct comparison between the two studies yet comparing income distributions reveals that Study 2 contained a smaller proportion of low-income participants comparing to the Study 1 sample. 


\section{Appendix 6A - Financial literacy survey}

\author{
COMPOUND INTEREST 1 If you invest $\$ 1,000$ today at $4 \%$ a year, your balance in a \\ year will be higher if the interest is compounded: \\ daily rather than monthly/quarterly rather than weekly/ \\ yearly rather than quarterly/\$1040/\$1000 \\ MORTGAGE \\ DIVERSIFICATION \\ A fifteen-year mortgage requires higher payments than a \\ 30-year mortgage, but the overall interest over 15 years \\ would be lower: \\ true/false/Don't know \\ Buying a single company stock usually provides a safer \\ return than a stock mutual fund. \\ true/false/Don't know
}

COMPOUND INTEREST 2

INSURANCE 1

PENSION

INSURANCE 2

INFLATION

INFLATION 2
Suppose you have taken a $\$ 1000$ loan with a yearly interest of $20 \%$. How long would it take the loan to accumulate to $\$ 2000$ if you will not return it:

less than 5 years $/ 5$ years/more than 5 years The main reason to purchase insurance is to: protect you from a loss recently incurred/ provide you with excellent investment returns/ protect you from sustaining a catastrophic loss/ protect you from small incidental losses/ improve your standard of living by filing fraudulent claims. How would a year without payment affect your pension: increase future annuity/reduce future annuity/would not impact future annuity

During the insurance qualification period, you are: entitled to make claims/do not need to pay monthly payments/ cannot make claims/don't know

Imagine that the interest rate on your savings account was $1 \%$ per year, and inflation was $2 \%$ per year. After 1 year, would you be able to buy

more than/exactly the same as/or less than today with the money in this account?

Suppose over the next 10 years the prices of the things you buy double. If your income also doubles, will you be able to buy:

less than you can buy today/the same as you can buy today/or more than you can buy today? 
